\title{
WestVirginiaUniversity
}

THE RESEARCH REPOSITORY @ WVU

Graduate Theses, Dissertations, and Problem Reports

2003

\section{Rx plays multiple roles in eye development}

Vera A. Voronina

West Virginia University

Follow this and additional works at: https://researchrepository.wvu.edu/etd

\section{Recommended Citation}

Voronina, Vera A., "Rx plays multiple roles in eye development" (2003). Graduate Theses, Dissertations, and Problem Reports. 1902.

https://researchrepository.wvu.edu/etd/1902

This Dissertation is protected by copyright and/or related rights. It has been brought to you by the The Research Repository @ WVU with permission from the rights-holder(s). You are free to use this Dissertation in any way that is permitted by the copyright and related rights legislation that applies to your use. For other uses you must obtain permission from the rights-holder(s) directly, unless additional rights are indicated by a Creative Commons license in the record and/ or on the work itself. This Dissertation has been accepted for inclusion in WVU Graduate Theses, Dissertations, and Problem Reports collection by an authorized administrator of The Research Repository @ WVU.

For more information, please contact researchrepository@mail.wvu.edu. 


\title{
Rx Plays Multiple Roles in Eye Development
}

\author{
Vera A. Voronina \\ Dissertation submitted to the School of Medicine \\ at West Virginia University \\ in partial fulfillment of the requirements \\ for the degree of \\ Doctor of Philosophy in Biochemistry
}

\author{
Peter H. Mathers, Ph.D., Chair \\ Mark B. Lewandoski, Ph.D. \\ Daniel Flynn, Ph.D. \\ Michael Miller, Ph.D. \\ Lisa Salati, Ph.D.
}

\author{
Department of Biochemistry and Molecular Pharmacology \\ Morgantown, West Virginia \\ 2003
}

Keywords: Rx, anophthalmia, microphthalmia, animal models, conditional knock out, transgenics 


\title{
Abstract \\ Rx Plays Multiple Roles in Eye Development
}

\begin{abstract}
Vera A. Voronina
The homeobox was first identified as a common feature of Drosophila genes that control pattern formation during embryogenesis. These genes have been implicated in the regional specialization of the developing brain, spinal cord and other body structures. Homeobox gene families are highly conserved and encode DNA-binding regulatory proteins. Certain members of the homeobox gene family, including Pax6, Chx10, Lhx2, Otx2, Six3 and Six6, are crucial for development of the eye. A new family of retinal homeobox genes, $\mathrm{Rx}$, is expressed early in embryogenesis in retinal stem cells. This expression pattern, along with results of overexpression and gene deletion studies, is consistent with a role for $\mathrm{Rx}$ in retinal stem cell specification and proliferation. In this dissertation, studies of Rx expression in adult organisms reveal that $\mathrm{Rx}$ is abundantly expressed in human and mouse adult neural retina. A number of patients with anophthalmia and microphthalmia were screened and it was found that these conditions are associated with mutations in the Rx gene. The data generated in the first two projects raise a question about the role of $\mathrm{Rx}$ at different stages of eye development. To address this problem, a conditional allele of the Rx gene was generated. This allele retains normal $\mathrm{Rx}$ activity but is subject to inactivation by Cre recombinase. Using Cre recombinase under the control of a forebrain-specific promoter (Foxg1 promoter), Rx conditional inactivation is achieved. Conditional animals (Rx-Foxg1-Cre) lack eyes and optic nerves but otherwise appear to be perfectly normal, making them an ideal model for nonsyndromic anophthalmia as seen in the patient population. Analysis of Rx-Foxg1-Cre mice indicates that $\mathrm{Rx}$ is critical not only for the initial steps of eye development but also for axial patterning, since both, dorso-ventral and proximo-distal markers are affected.
\end{abstract}




\section{Acknowledgements}

I would like to thank my advisors, Dr. Peter Mathers and Dr. Mark Lewandoski for sharing their knowledge and skills with me. I would also like to express my appreciation to my graduate committee members, Dr. Daniel Flynn, D. Michael Miller, and Dr. Lisa Salati for their critical suggestions and encouragement during the course of my research. I am grateful to West Virginia University Biochemistry Department faculty, staff and graduate students and to the members of Cancer and Developmental Biology Laboratory at the National Cancer Institute for their help

I am especially thankful to Catherine Wilson and Dr. Serguei Kozlov whose help in the conditional knock out project is hard to overestimate. I would like to thank Rhonda Anderson for teaching me the valuable skill of managing a mouse colony and Cindy Elder for helping me to take care of my mice.

Finally, I would like to acknowledge children of all graduate students who wake up every Sunday with certain understanding that both of his/her parents will work today. The only question is who goes to work first. 


\section{Table of Contents}

Abstract $\quad$ ii

Acknowledgements

Table of Contents

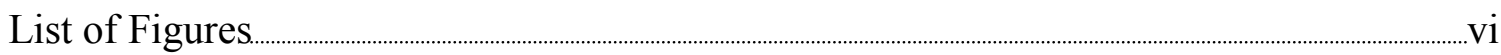

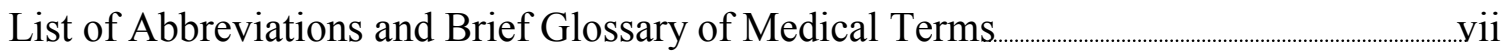

Latin Species Names

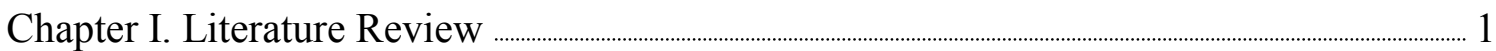

A. Introduction

1. Early Eye Development $\quad \ldots$

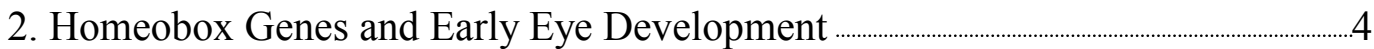

B. Transcription Factors Required for the Early Eye Development $\ldots \ldots \ldots \ldots \ldots \ldots \ldots \ldots \ldots \ldots \ldots \ldots \ldots \ldots \ldots \ldots \ldots$

1. Retinal Determination and the Development of the Optic Vesicle

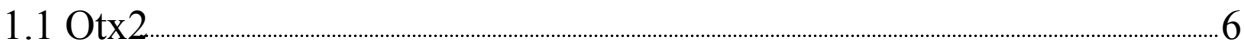

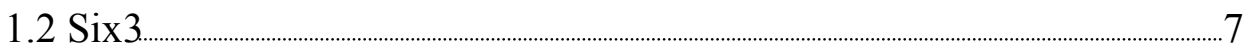

1.3 Pax6

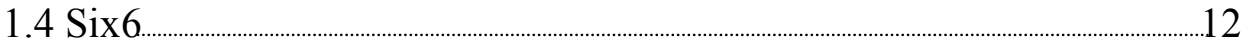

$1.5 \operatorname{Lhx} 2 \ldots \ldots \ldots$

2. Formation of the Optic Cup and Axial Patterning of the Eye $\ldots \ldots \ldots \ldots \ldots \ldots \ldots \ldots \ldots \ldots \ldots \ldots \ldots \ldots \ldots \ldots . .13$

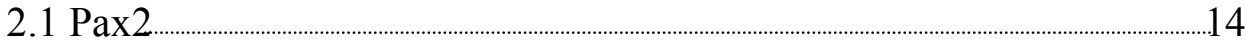

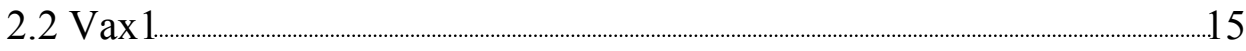

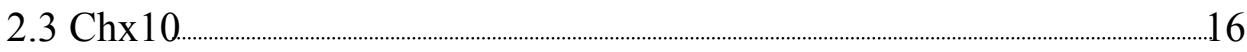

2.4 Genes Important for Dorso-Ventral and Naso-Temporal Patterning....17

C. The Retinal Homeobox gene $(\mathrm{Rx}) \ldots \ldots$

1. Isolation of the Rx Gene and Structure of the Rx Protein $\ldots \ldots \ldots \ldots \ldots \ldots \ldots \ldots \ldots \ldots \ldots \ldots \ldots \ldots \ldots \ldots \ldots . . .19$

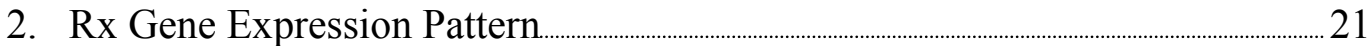

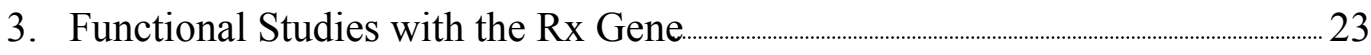

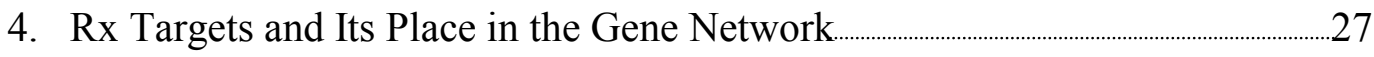

5. Mutations in the Rx Lead to Anophthalmia in Mouse and Fish ……….................28

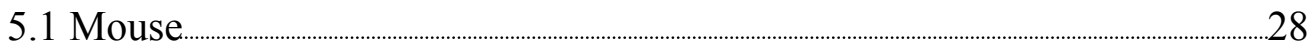


5.2 Medaka Fish 30

6. Human Conditions that May Result from Mutations in the Rx Gene___ 31

Chapter II. Rx Expression throughout Mammalian Retinal Development and in Adults 33

A. Introduction

B. Materials and Methods

C. Results

D. Discussion__ 44

Chapter III. Mutations in the Human RX Homeobox Gene in a Patient with Anophthalmia and Sclerocornea___ 47

A. Introduction $\longrightarrow 48$

B. Materials and Methods $\longrightarrow 50$

C. Results

D. Discussion— 60

Chapter IV. Conditional Inactivation of Rx Leads to Anophthalmia 62

A. Introduction -63

B. Materials and Methods__ 68

C. Results 71

D. Discussion_ 86

Chapter V. Summary and Future Directions___ 91

Chapter VI. References _ 94 


\section{List of Figures}

Figure 1. Eye and retina composition___ 3

Figure 2. Structure of Rx protein and conservation of Rx-family homeodomain among species_ 20

Figure 3. Rx expression in mouse embryo_ 22

Figure 4. Overexpression of $\mathrm{Rx} \quad 24$

Figure 5. Knock out of mouse Rx results in anophthalmic embryos__ 26

Figure 6. Rx gene expression in the adult mammalian tissues $\_40$

Figure 7. Localization of Rx expression in the adult mouse eye __ 41

Figure 8. Dynamics of mouse Rx expression __ 43

Figure 9. Position of RX locus mutations and ocular phenotype of proband___ 54

Figure 10. Sequencing analysis of proband and immediate family_ 56

Figure 11. Pedigree and mutation detection in proband's family $ـ 57$

Figure 12. Electrophoretic mobility shift assay with normal and mutant Rx proteins_59

Figure 13. Generation of the allelic series at the $\mathrm{Rx}$ locus and recombination analysis 72

Figure 14. Phenotype of mice carrying modified Rx alleles ㄴ 74

Figure 15. Eye development and dynamics of Cre-mediated excision in $\mathrm{Rx} \stackrel{\text { Foxg1-Cre }}{76}$

Figure 16. Phenotype of the adult $\mathrm{Rx}^{\text {Foxg1-Cre }}$ mice___ 78

Figure 17. Expression of genes implicated in proliferation $\quad 80$

Figure 18. Marker analysis for dorso-ventral and naso-temporal patterning of the eye in $\mathrm{Rx}^{\text {Foxg1-Cre }} 82$

Figure 19. Markers of proximo-distal patterning in $\mathrm{Rx}^{\text {Foxg1-Cre }}$ embryos ___ 85 


\section{List of Abbreviations}

bp - base pair

CORD - cone-rod dystrophy

GAG - glucoseaminoglycans

D-V - dorso-ventral

$\mathrm{kb}$ - kilobase pair

neo ${ }^{\mathrm{R}}$ - neomycin resistance cassette

$\mathrm{NR}$ - neural retina

$\mathrm{N}-\mathrm{T}$ - naso-temporal

OC - optic cup

$\mathrm{ON}$ - optic nerve

OS - optic stalk

OV - optic vesicle

PBS - phosphate-buffered saline

PCR - polymerase chain reaction

P-D - proximo-distal

$\mathrm{RGC}$ - retinal ganglion cells

RPE - retinal pigmented epithelium

RT-PCR - reverse transcriptase polymerase chain reaction

\section{Brief Glossary of Medical Terms}

aniridia - iris hypoplasia

anophthalmia - lack of the orbit structures

coloboma - failure of the retinal and optic nerve folds to fuse

holoprosencephaly - failure of forebrain and facial structures to separate into left and right hemispheres/sides

microphthalmia - reduced orbit structures 


\section{Latin Species Names}

Cave fish - Astyanax mexicanus

Chicken - Gallus gallus

Frog - Xenopus laevis

Fruit fly - Drosophila melanogaster

Human - Homo sapiens

Medaka fish - Oryzias latipes

Mouse - Mus musculus

Rat - Rattus norvegicus

Zebrafish - Danio rerio 


\section{Chapter I.}

\section{Literature Review}




\section{A. Introduction}

\section{Early Eye Development}

Determination of the mechanisms controlling organogenesis is the central problem in developmental biology. The formation of the developing eye has been the subject of study since the beginning of the last century when Spemann performed his classical experiments in 1901 (Spemann, 1988, reprint of 1938).

The eye develops from two major components, the neural ectoderm and the surface ectoderm. The initial events of eye formation occur within the early anterior neural plate, where a uniform field of stem cells is specified toward development of the future retina (Fig.1A, EF; Li et al., 1997). As development proceeds, the retinal field is divided along the midline of the embryo by the action of the secreted signaling protein, Sonic hedgehog (shh; Ekker et al., 1995; Macdonald et al, 1995; Li et al., 1997), creating two independent retinal domains.

The first morphologically visible stage of the retina development is a lateral protrusion of the telencephalon called the optic pit (Fig.1A, OP). The optic pits grow and become optic vesicles that contact the lens placodal ectoderm (Fig.1A, OV). This contact is critical for induction of lens differentiation and correct positioning of the eye (Grainger, 1992). Surface ectoderm thickens and forms a lens placode (Fig.1A, OC1). Evagination of the lens placode results in formation of the lens vesicle via closure of the external opening. This event is coupled with invagination of the optic vesicle that leads to formation of the optic cup around mouse embryonic day 10.5 (Fig.1A, OC2). Presence of the growing lens is indispensable for normal eye development (Ashery-Padan et al., 2000).

The inner layer of the optic cup develops into the neural retina (NR), while the outer layer gives rise to the retinal pigmented epithelium (RPE). The "stem" connecting the optic cup to the brain narrows, elongates and becomes the optic stalk (OS) that provides the route for the optic nerve. Invagination of the optic vesicle around the lens begins in the ventral part of the developing eye. At the end of invagination a narrow opening, known as an optic fissure, remains in the ventral-most part of the optic cup and the optic stalk. The optic fissure allows retinal axons to enter the optic stalk and is also critical for 
A
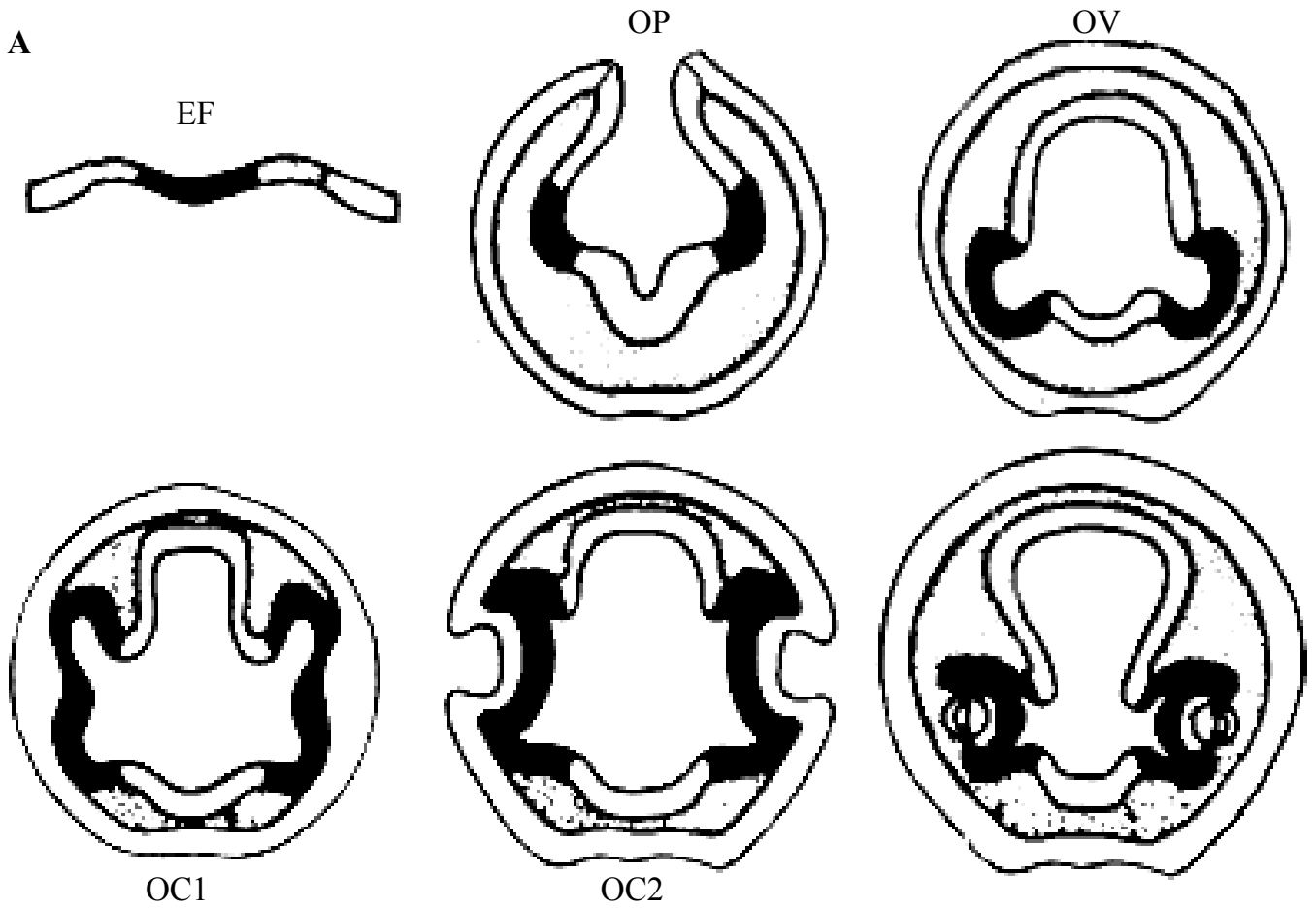

B

$$
\text { C }
$$

RPE
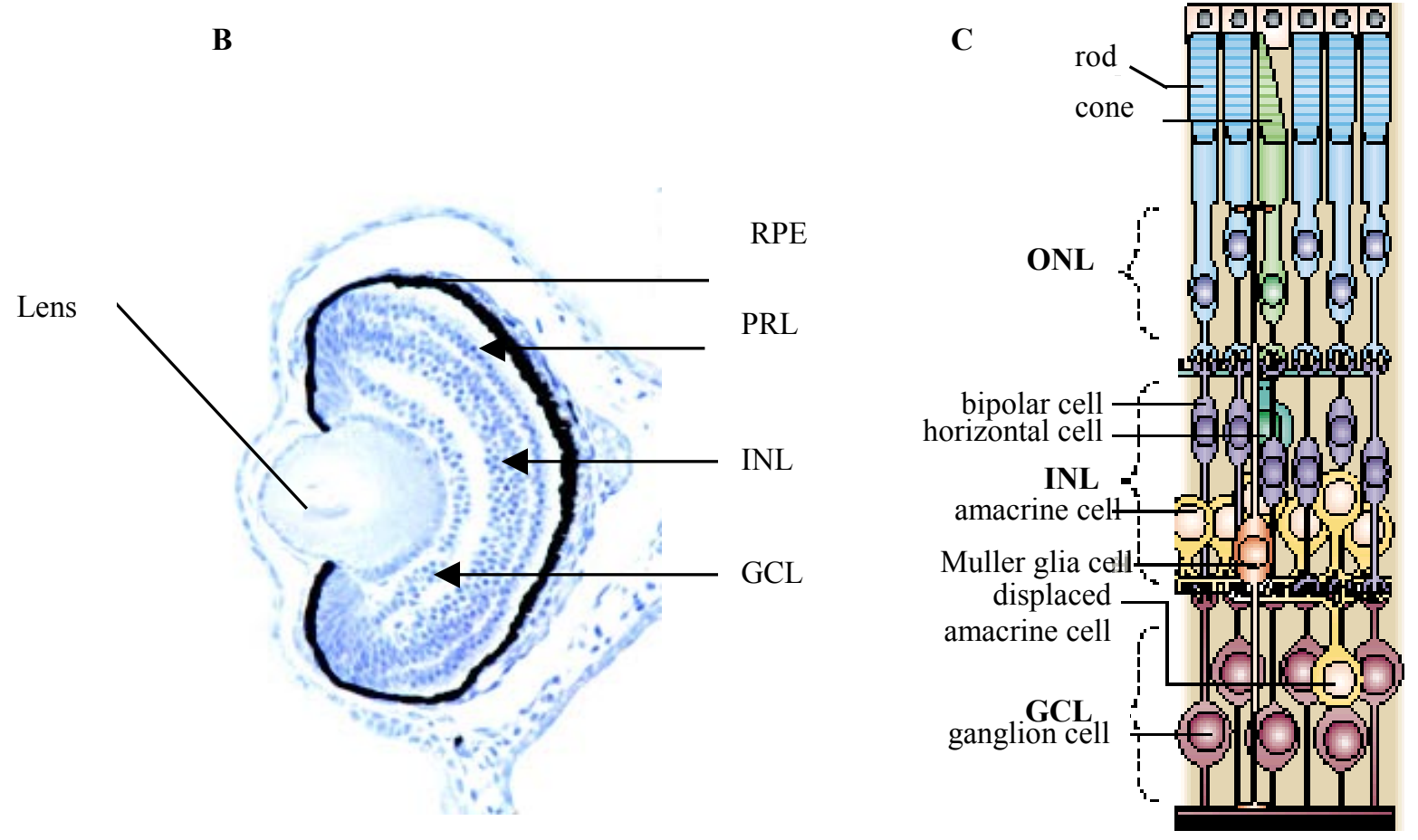

Fig.1 Eye and retina composition

A. Development of the eye in vertebrates. Stages are designated as follows: EF - eye field, OP - optic pit, OV - optic vesicle, OC - optic cup.

B. Major components of the eye are lens, retinal pigmented epithelium (RPE) and neural retina (NR). Neural retina is composed of three cellular layers: ganglion cell layer (GCL), inner nuclear layer (INL) and photoreceptor layer (PRL).

C. Cell types of the mature neural retina (adapted from Dyer \& Cepko, 2001). 
the blood vessels to reach the retina. Both the optic stalk and the optic fissure are transient structures. The optic fissure is closed by fusion of retinal folds soon after retinal ganglion cells project through the optic stalk. Later, optic stalk cells differentiate into astrocytes that will populate the body of the mature optic nerve (Lupo et al., 2000). Finally, differentiation of the retinal stem cells creates the individual cell types that comprise the pigment epithelium and the neural layers of the retina (Fig. 1B; Sidman, 1961; Adler and Hatlee, 1989; Adler, 1993). Neural retina is composed from seven main types of cells - rod and cone photoreceptors, bipolar cells, ganglion cells, amacrine cells, horizontal cells and Müller glia - that are organized into three distinct cellular layers (Fig. $1 \mathrm{C})$.

Adult mammalian retina loses its ability to regenerate thus posing a serious problem in case of eye injury. Recently it has been demonstrated that lack of regenerative capacity of the optic nerves comes from the signals sent by the amacrine cells. Once differentiated, amacrine cells signal retinal ganglion cells to decrease their axon growth. This irreversible process prevents the ability of adult optic nerves to regenerate (Goldberg et al., 2002).

\section{Homeobox Genes and Early Eye Development}

The molecular events responsible for eye development have been extensively studied in the last decade. Many genes have been isolated that show expression in the developing eye and a role in its formation (reviewed in Oliver \& Gruss, 1997; Chow \& Lang, 2001). These genes are candidates for regulating specification, determination, proliferation and differentiation of retinal cells. Among these candidates are the genes coding for transcription and growth factors. Certain members of a highly conserved family of DNAbinding factors, called homeobox genes, are crucial for development of the eye. This family includes Pax6, Lhx2, Chx10, Six3, Six6, Rx and others.

Homeobox genes were named for the highly conserved region of 180 nucleotides that distinguishes this family of genes. Homeoboxes were initially characterized to be preferentially associated with homeotic and segmentation genes of Drosophila (Duboule, 1994; McGinnis, 1994). The protein sequence encoded by a homeobox, the homeodomain, contains three regions composed of amino acids that are prone to 
formation of an alpha helix. The second and third helical regions are arranged in the helix-turn-helix motif, which is found in DNA-binding proteins throughout the various kingdoms.

The DNA sequences recognized by homeodomains are 7-8 nucleotides in length and contain the core sequence (TAAT) flanked by three to four additional bases. Different techniques indicate that the most highly conserved amino acids in the homeodomain interact directly with the TAAT core sequence (Catron et al., 1993). Sequences less conserved across different types of homeodomains interact with nucleotides immediately flanking the core and determine specificity of binding.

Homeobox sequences have been sufficiently conserved during evolution to allow vertebrate homologues of many Drosophila homeobox genes to be recognized. However, except for motifs such as the paired box (PAX), the SIX and the LIM domains, sequences found outside the homeobox often vary among species (Beebe, 1994). This suggests that specific DNA-binding properties of the homeodomain have been preserved during evolution, but other regions of homeodomain-containing proteins may have acquired new functions, or they are less tightly constrained in terms of primary sequence.

Vertebrate homeobox genes can be placed in two broad categories based on their pattern of expression and their functions. The first group includes genes controlling the position-specific development of groups of embryonic cells. Homeodomain proteins of the second group function as tissue-specific transcription factors in adult tissues. Some homeodomain proteins may serve both functions.

In the last several years, significant progress has been achieved in the identification of co-factors and homeoprotein response elements (Biggin \& McGinnis, 1997). It has been shown that homeoprotein response elements are localized to certain promoter regions, sometimes far upstream of the transcription start or in introns. These response elements, which frequently consist of multiple homeoprotein recognition sites, can be activated or repressed by multiple homeoproteins in a complex combinatorial regulatory network (Manak et al., 1994; Gould et al., 1997). The specificity of DNA-homeoprotein interaction also depends on binding sites for tissue-specific cofactors, which typically exhibit no obvious spacing pattern to nearby homeoprotein binding sites (Biggin \& McGinnis, 1997). 


\section{B. Transcription Factors Required for the Early Eye Development}

Early eye development can be schematically divided into three major steps: retina determination, development of the optic vesicle and formation of the optic cup. All steps of ocular development are regulated by sets of growth and transcription factors. The roles of these factors are assessed by their expression pattern, by the mutant phenotype or by the effect of overexpression.

\section{Retinal determination and the development of the optic vesicle}

Initially, a uniform field of stem cells in the anterior neural plate commits toward development of the future retina (this field is called "the eye field", Fig.1A, EF). Later the eye field splits creating two retinal primordia within the presumptive forebrain region that begin to evaginate forming optic pits (Fig.1A, OP). Growth of the optic pits toward the surface ectoderm converts them to the optic vesicles (Fig.1A, OV). The following genes are known to be critical in these events:

\section{$1.10 t x 2$}

Otx2 is a bicoid-type homeodomain protein with numerous functions (reviewed in Boncinelli \& Morgan, 2001). Otx2 is first expressed in mouse at embryonic day 5.5 (E5.5) in the epiblast. Three days later, it is broadly expressed in the developing forebrain and midbrain (Simeone et al., 1992) and its expression continues in the optic vesicle (Simeone et al., 1993). As retinal development proceeds, Otx2 becomes specifically restricted to the presumptive retinal pigmented epithelium (Bovolenta et al., 1997). At E17, when neural retina differentiation occurs, a second wave of Otx2 expression is found in the neural retina and retinal pigmented epithelium (Simeone et al., 1993).

Otx2-null mice lack the rostral portion of the brain from rhombomere 3 of the hindbrain (Acampora et al., 1995; Matsuo et al., 1995; Ang et al., 1996). Deletion of brain structures is visible by E9.5 and homozygous mutants reabsorb by E10.5 (Acampora et al., 1995; Ang et al., 1996). Otx2-null heterozygotes as well as double mutants for Otx1 and Otx2 (Otx2-null heterozygous; Otx1-null homozygous) display 
microphthalmia and anophthalmia, demonstrating requirement of Otx2 in retina development (Matsuo et al., 1995; Martinez-Morales et al., 2001).

Otx2 may provide the anterior neuroectoderm with the necessary competence for ocular specification, since ectopic retina formation occurs almost exclusively in the Otx2expressing domain of the neuroectoderm (Chow et al., 1999; Loosli et al., 1999; Bernier et al., 2000).

About two days later in development, other homeobox genes - Rx, Six3, Lxh2, and Pax6 - are expressed in the medial portion of the developing forebrain, which represents the retinal field. Involvement of these homeoproteins in retinal formation is demonstrated by loss-of-function models, where Rx and Six3 appear to define retinal primordia. The expression pattern and potential role(s) of the Rx gene will be discussed in details later.

\section{$\underline{1.2 \text { Six3 }}$}

Six 3 is a homeobox gene that also has a conserved SIX domain. The Six 3 homeodomain shares about 90\% amino acid identity with Drosophila Optix (Toy et al., 1998; Seimiya et al., 2000). Six 3 is first expressed in the late gastrula, which corresponds to E7.5 of mouse development, and later in the eye field (Oliver et al., 1995; Bovolenta et al., 1998; Loosli et al., 1998; Granadino et al., 1999; Lagutin et al., 2001). Expression continues in the optic stalk and neural retina (Oliver et al., 1995; Bovolenta et al., 1998; Loosli et al., 1998; Granadino et al., 1999; Ghanbari et al., 2001). When the retinal cell layers are formed Six 3 is expressed in the inner nuclear layer in the amacrine and the horizontal cells and in the ganglion cells (Granadino et al., 1999; Zhu et al., 2002). In the same study it was shown that Six3 misexpression interferes with normal photoreceptor differentiation (Zhu et al., 2002).

Six 3 is expressed in the lens placode prior to lens differentiation suggesting a role for this gene in lens formation. Detailed analysis of Pax6 mutant mouse embryos (Sey/Sey) revealed that Six 3 expression is abolished in the lens ectoderm, implicating Six 3 in regulation of lens placode formation (Lagutin et al., 2001). In chicks the invagination of the lens placode is inhibited by Six3 overexpression (Zhu et al., 2002). Overexpression of 
murine Six3 in the medaka fish results in formation of an ectopic lens in the otic placode (Oliver et al., 1996). These data demonstrate a role for Six3 in lens morphogenesis.

Gain-of-function experiments were done in multiple species. In medaka and Xenopus the effect ranges from retinal enlargement to the formation of ectopic lens or retina (Oliver et al., 1996; Loosli et al., 1999). Six3 misexpression in zebrafish results in an enlargement of the rostral forebrain (Kobayashi et al., 1998). Pax2 upregulation in the optic stalk upon Six 3 overexpression suggests that Six 3 is important for determination of cell fate within the optic stalk (Kobayashi et al., 1998). Overexpression of Six 3 in mouse leads to formation of ectopic optic vesicle-like structures in the mid- and hindbrain that are positive for the eye-specific marker Pax6 (Lagutin et al., 2001). Six3 misexpression in the chick optic primordium affects development of the mesenchymal derivatives of the anterior segment, resulting in corneal protrusion, eyelid hypoplasia, retarded sclera and at low frequency leads to anophthalmia (Hsieh et al., 2002).

The Six3 knockout mouse has not been reported yet though unpublished reports suggest a severe phenotype, including ablation of anterior neural structures. Loss of function experiments in medaka show that elimination of Six 3 increases apoptosis in the presumptive forebrain, later preventing formation of the forebrain and eyes (Carl et al., 2002). These experiments also revealed that Six 3 affects proximo-distal patterning of the eye, since mildly affected morphants do not express Vax1 in the optic stalk. The absence of Vax1 in turn abolishes optic stalk formation (Carl et al., 2002). Thus, Six3 regulates both, Vax1 and Pax2, and through this regulation controls proper optic stalk development.

Heterozygous mutations in SIX3 are associated with holoprosencephaly (Wallis et al., 1999). This condition is characterized by failure of forebrain separation into left and right hemispheres. Microphthalmia and coloboma observed in mild cases of holoprocencephaly further support the role for the SIX3 gene in the developing eye (Wallis et al., 1999).

Six3 appears to function as a repressor that positively regulates eye and forebrain formation (Kobayashi et al., 2001). Fusion of zebrafish Six3.2 with a repressor domain of Drosophila Engrailed mimics Six3.2 overexpression results, which manifest themselves in an increase of eye and forebrain territories. In contrast, Six3.2 fusion with the 
activation domain of herpes simplex virus VP16 decreases the eye and forebrain size (Kobayashi et al., 2001). Six 3 repressor function is explained by interaction with the corepressor Groucho. Vertebrate homologues of Drosophila Groucho, known as TLE, are co-repressor proteins that are recruited to the DNA through protein-protein interactions with DNA-binding transcription factors (reviewed in Chen and Courey, 2000). Zhu and colleagues recently found that murine Six 3 interacts with mouse counterparts of Groucho, Grg5 and Grg4 (Zhu et al., 2002). Medaka-Six3 interacts with Xenopus homologue of Groucho and other basic helix-loop-helix factors (Tessmar et al., 2002), while the same is true for human SIX3 (Lopez-Rios et al., 2003).

Pax6 and Lhx2 seem to participate in the eye formation at slightly later stages than $\mathrm{Rx}$ and Six3. Both Pax6 (Hogan et al., 1986; Grindley et al., 1995) and Lhx2 (Porter et al., 1997) deficient embryos develop optic vesicles but are defective at subsequent stages. Lhx 2 and Pax6 appear to function in parallel pathways, since Pax6 is expressed in the Lhx2-nulls mice and, vice versa, Lhx2 is detected in Pax6-deficient mice (Porter et al., 1997).

\section{$\underline{1.3 \operatorname{Pax} 6}$}

Pax6 is a paired box homeobox gene that has maintained an extremely high level of conservation throughout evolution (reviewed in Callaerts et al., 1997; Van Heyningen \& Williamson, 2002). In vertebrates Pax6 is first expressed toward the end of gastrulation in the anterior neural plate, which corresponds to E8.0 in mouse (Grindley et al., 1995). In the developing optic structures Pax6 is initially expressed in all cell types of the dorsal optic vesicle and presumptive lens ectoderm (Grindley et al., 1995). In the differentiated retina its expression is limited to ganglion and amacrine cells (Hitchcock et al., 1996; Belecky-Adams et al., 1997; Koroma et al., 1997). Drosophila has two Pax6 orthologs, eyeless (ey) and twin of eyeless (toy; Czerny et al., 1999). The eyeless name originated from a Drosophila phenotype that is caused by mutations in this gene. A number of different ey mutations have been isolated, some of which are lethal. The viable hypomorphic homozygous flies show a reduction or lack of eyes. Strong mutants of ey 
and toy are headless indicating that these factors are required for the development of all structures derived from eye-antennal discs (Kronhamn et al., 2002).

Overexpression of Pax6 leads to formation of ectopic eyes in Drosophila (Halder et al., 1995a) and Xenopus (Chow et al., 1999). This shows that Pax6 plays a critical role in early eye development. The induction of ectopic eyes in Drosophila by the mouse or squid Pax6 gene demonstrates that Pax6 genes not only maintain extremely high sequence homology across the species but also that their biochemical activities and targets are conserved as well (Hirsch and Harris, 1997; Pichaud et al., 2001).

Loss-of-function mutations in Pax6 are semi-dominant. In the heterozygous state they lead to small eye (Sey) phenotype in mouse (Hogan et al., 1986; Hill et al., 1991) and rat (Matsuo et al., 1993). At first, these mutants form enlarged optic vesicles that make contact with surface ectoderm but lens placode thickening does not occur (Hogan et al., 1986; Matsuo et al., 1993; Grindley et al., 1995). Later, it results in microphthalmia and iris hypoplasia. Homozygous Sey mutants are anophthalmic and die soon after birth probably due to an absence of nasal structures that are required for newborn pups to nurse (Hogan et al., 1986; Hill et al., 1991; Matsuo et al., 1993; Grindley et al., 1995). Heterozygous mutations in the human PAX6 gene are associated with aniridia (iris hypoplasia) and cataract (Ton et al., 1991; Glaser et al., 1992; Jordan et al., 1992), whereas rare homozygous mutations are associated with anophthalmia (Glaser et al., 1994).

Recently roles for Pax6 in mouse development were studied by conditional inactivation of this gene. When Pax6 is removed from the surface ectoderm at E9.5 it disrupts lens formation and leads to serious abnormalities in retina invagination (AsheryPadan et al., 2000). These experiments proved that Pax6 is indispensable for lens formation and demonstrated again that the lens is essential for precise positioning and proper invagination of the neural retina. Conditional knock out of Pax6 in the neural retina prevents formation of all but one retinal cell type - amacrine cells alone compose distal retinas in these animals (Marquardt et al., 2001). This shows that Pax6 is required for the initiation of a differentiation program that leads to formation of distinct retinal cells from uncommitted retinal progenitor cells (Marquardt et al., 2001). Recent 
experiments indicate that Pax6 may play a role in the establishment of the naso-temporal axis of the eye (Baumer et al., 2002).

Multiple experiments in Drosophila and vertebrates indicate that Pax6 is capable of positive autoregulation (Schwarz et al., 2000; Baumer et al., 2002). Overexpression of ey induces ectopic expression of dachsund (Shen and Mardon, 1997), teashirt (Pan and Rubin, 1998), sine oculus (Halder et al., 1998), eyes absent (Halder et al., 1998) and the Ca-binding protein Necab, that can upregulate expression of Chx10 (Bernier et al., 2001). The original work in Drosophila led to the proposal that Pax6 (ey) is a "master regulatory gene for eye development" (Quiring et al., 1994; Halder et al., 1995b; Gehring \& Ikeo, 1999; Veraksa et al., 2000). This concept implies a linear hierarchy of genes that specify development of an organ and later research is not consistent with the role of Pax6 at the top of the eye-specifying cascade. First of all, mutations in several other genes lead to a more severe loss of the eye structures. These genes include Rx and Lhx2 in vertebrates (Mathers et al., 1997; Porter et al., 1997) and so, eya and dac in Drosophila (Bonini et al., 1993; Cheyette et al., 1994; Mardon et al., 1994; Bonini et al., 1997). Second, overexpression of Rx, Six 3 and Six6 lead to formation of ectopic retinas in vertebrates (Mathers et al., 1997; Loosli et al., 1999; Zuber et al., 1999; Bernier et al., 2000), suggesting that these genes function in Pax6-independent manner. Third, broad expression of the Pax6 genes in multiple locations even in organisms lacking eyes (Fernald, 2000), development of optic vesicles in Sey/Sey embryos, and analysis of the early retinal markers in these mutants (Grindley et al., 1995) suggest that Pax6 is not required for the inductive activity of the optic vesicle but rather maintains lens-bias in the surface ectoderm (Ashery-Padan \& Gruss, 2001). The role of the vertebrate Pax6 gene primarily in lens development is quite consistent with the indispensable function of ey in Drosophila, since both the vertebrate lens and the entire fly eye derive from the ectodermal placode. Thus, lens may be the only vertebrate eye region sharing a common origin with the Drosophila eye (Treisman, 1999). New data suggest that there is no single “master control gene" for eye development (Desplan et al, 1997; Pignoni et al., 1997; Fernald, 2000; Mathers and Jamrich, 2000) and an interactive gene network regulates this process. These interactions involve reciprocal feedback loops and formation of molecular 
complexes between protein products of eye specification genes (Chen et al., 1997a; Pignoni et al, 1997).

\section{$\underline{1.4 \operatorname{Six} 6}$}

Six6 is a homeobox gene belonging to the sine oculus gene family and is closely related to the Six3 gene (Toy et al., 1998). The insect ortholog of Six6 is optix (Seimiya et al., 2000). The Six6 expression pattern is quite conserved among vertebrates (LopezRios et al., 1999). Mouse Six6 is expressed starting around E8.0 which is later than Rx, Pax6 and Six3 (Jean et al., 1999; Toy et al., 1999). During eye development Six6 transcripts are abundant throughout the neural retina and optic stalk. Six6 expression peaks in the eye about E13.5 and later diminishes (Li et al., 2002). In adult mouse eyes the Six6 transcript is localized to the inner nuclear and ganglion cell layers of the neural retina with no expression in the photoreceptors (Toy et al., 1999). This expression pattern is consistent with that seen for human SIX6 (Gallardo et al., 1999). Human and mouse Six6 are also expressed in many areas of the developing brain (Gallardo et al., 1999; Toy et al., 1999).

Overexpression of Six6 in Xenopus leads to retinal enlargement and ectopic retinal formation through activation of Rx, Six3 and Pax6 (Zuber et al., 1999; Bernier et al., 2000). The increase in retina size is due to increased mitotic activity since neither a change in ratio of retinal cell types nor increase in apoptosis was observed (Zuber et al., 1999). Missexpression of Six6 in chicken retinal pigmented epithelium induces expression of the Chx10 gene, which is a neural retina marker (Toy et al., 1998). It suggests that Six6 normally functions as a neural retina fate determinant.

Transcriptional repression appears to be a primary role of Six6. It was demonstrated that fusion of Six6 with the Engrailed repression domain mimics Six6 overexpression results, while Six6-VP16 activation domain fusion results in reduction in size or complete elimination of eyes (Zuber et al, 1999). These results show striking similarity to Six3 “fusion" experiments (Kobayashi et al., 2001). Six6 null mice are viable, however, they have hypoplastic retina and pituitary, and frequently lack optic nerves and the optic chiasm (Li et al, 2002). Presence of all retinal cell types and a decreased number of cells for each cell type, together with reduced level of proliferation, implies that Six6 regulates 
the proliferation potential of retinal progenitor cells. A search for molecules that are regulated by Six 6 and may cause the decreased proliferation showed that several cyclindependent kinase inhibitors are upregulated in Six6 -/- embryos (Li et al., 2002). Yeast two-hybrid and overexpression studies showed that SIX6 recruits TLE1 and AES proteins, that are members of the Groucho family of co-repressors (Lopez-Rios et al., 2003). These data indicate that Six6 acts as a transcriptional repressor and its main function is to regulate proliferation and maintain retinal specification.

\section{$\underline{1.5 \operatorname{Lh} x 2}$}

One of the most critical steps in eye formation is the establishment of proper contact between the surface ectoderm and the optic vesicle. This contact induces thickening of the lens placode, and lens vesicle growth that leads to transformation of the optic vesicle to the optic cup. Lhx2 plays a critical role during this transition.

Lhx2 is a LIM homeobox gene. It contains LIM domains that are involved in proteinprotein interactions and may modulate the function of the homeodomain. Lhx 2 is expressed in developing B-cells, forebrain and neural retina (Xu et al., 1993). In the murine optic vesicle, Lhx2 expression is initially detected around E8.5, and later it is localized to the inner nuclear layer of the retina (Xu et al., 1993; Porter et al., 1997). Deletion of Lhx2 results in anophthalmia, among other defects (Porter et al., 1997). Optic vesicles are formed in these animals but their development stalls prior to contact with the surface ectoderm and lens placode formation does not occur (Porter et al., 1997). The molecular targets of Lxh2 are currently unknown. It is known, however, that Pax6 and Lhx2 seem to function independently (Porter et al., 1997).

\section{Formation of the optic cup and axial patterning of the eye.}

When the optic vesicle contacts the surface ectoderm the ectoderm thickens and forms a lens placode (Fig.1A, OC1). The contact of the optic vesicle with the surface ectoderm is critical for further eye development (Grainger et al., 1992). Invagination of the lens placode leads to the formation of the lens vesicle that is coupled with invagination of the optic vesicle. Together it results in the formation of the optic cup (Fig.1A, OC2). The optic cup consists of neural retina (inner layer of the cup), retinal pigmented epithelium 
(outer layer of the cup) and the optic stalk (Fig.1B). Later the optic stalk will serve as a route for the optic nerve.

All the genes that were described above are expressed and seem to play specific roles throughout the development of the eye and in the adult organism. However, these late roles are largely unknown due to limitations of conventional knock out techniques that reveals only the earliest gene function.

Other genes are expressed later and their primary role has been established in the formation of the neural retina or the optic stalk. Pax2 and Vax1 are two genes that mark the developing optic stalk and inhibit retinal characteristics. Chx10 is important for early patterning of the neural retina. The boundary between the neural retina and the optic stalk is determined by counter balance of stalk-promoting (Vax 1, Pax2) and retina-promoting (Rx, Pax6) factors.

\section{$\underline{2.1 \operatorname{Pax} 2}$}

Pax2 is first expressed in the mouse optic vesicle at E9.5, one day later its expression is localized to the ventral half of the optic cup and optic stalk, and at E11.5 Pax2 is expressed in the optic stalk and in the proximal neural retina (Nornes et al., 1990; Dressler et al., 1990). Expression pattern, PAX2 mutations in patients with optic nerve colobomas (Sanyanusin et al., 1995) and functional studies implicate Pax2 in the establishment of proximo-ventral identity of the developing eye. This identity requires midline signaling (Macdonald et al., 1995). Overexpression of the midline-expressed molecules sonic hedgehog (Shh) and tiggiwinkle hedgehog (Twhh) leads to expansion of the Pax 2 domain and almost complete loss of Pax6 expression. In contrast, absence of Shh results in lack of Pax2, expansion of the Pax6 domain, and later leads to cyclopia (Ekker et al., 1995; Macdonald et al., 1995).

Pax2 null mice (Torres et al., 1996) and KRD (kidney and retinal defects) mice carrying a naturally occurring Pax2 mutation (Keller et al., 1994; Favor et al., 1996) have optic nerve colobomas, extension of the retinal pigmented epithelium in the developing optic stalk region, and abnormalities of optic projections (Torres et al., 1996).

Normally, there is a sharp border between the retinal pigmented epithelium and the optic stalk, where Pax2 positive cells do not show pigmentation (Torres et al., 1996). This 
border appears to be established in mice by E9.5 before the development of retinal pigmented epithelium (Schwarz et al., 2000). This conclusion is based on exclusive expression patterns of Pax 2 and Pax6 genes. It is believed that reciprocal transcriptional repression between Pax 2 and Pax6 defines the optic vesicle/ optic stalk boundary (Schwarz et al., 2000).

\subsection{Vax1}

Vax1 is first expressed in mice at E8.0 in the anterior neural ridge and adjacent ectoderm (Hallonet et al., 1998). Later the expression continues in the ventral forebrain and its overgrowth - the optic structures. At E9.5 Vax 1 expression is found in the optic stalk ending in the proximal optic vesicle with no transcription found in the distal optic vesicle (Ohsaki et al., 1999). At later stages of development Vax 1 continues to be expressed in the optic stalk and ventral forebrain.

Abrogation of zebrafish Vax 1 with antisense Morpholinos results in coloboma, while depletion of both, Vax1 and Vax2, results in expansion of retina to the brain indicating that zebrafish Vax1 and Vax2 are critical to limit retinal development to the optic cup (Take-uchi et al., 2003). Knock out of Vax1 in mice is characterized by coloboma, telencephalic defects, holoprocencephaly and lack of the optic chiasm (Hallonet et al., 1999). Optic stalks of Vax1-null mice have the normal number of axons, but they are not myelinated. This mispatterning results in coloboma of the optic nerve, despite the normal optic stalk patterning along both the dorso-ventral and nasal-temporal axis (Bertuzzi et al., 1999). Marker analysis demonstrated that Vax 1 and Pax2 function independently, while both genes are required for the optic fissure closure and formation of the optic nerve (Hallonet et al., 1999). It may indicate that Vax 1 and Pax 2 function in parallel developmental pathways or they may regulate a common downstream target. Shh directly or indirectly activates Vax 1 that, in turn, inhibits Rx in the optic stalk suggesting another mechanism for optic stalk vs. optic cup separation in addition to Pax2/Pax6 counterbalance (Hallonet et al., 1999). In addition to Shh , Nodal and fibroblast growth factor (Fgf) signaling appear to regulate Vax1 expression (Take-uchi et al., 2003). Another role of $\operatorname{Vax} 1$ is regulation of the axonal chemoattractant Netrin1. Axons that 
form the optic nerve fail to penetrate the hypothalamus in Vax1-null mice, probably due to the absence of Netrin1 (Bertuzzi et al., 1999).

\section{$2.3 \operatorname{Ch} x 10$}

Chx10 is first expressed in the optic vesicle upon contact with the surface ectoderm at a stage that corresponds to embryonic day 9.5 of mouse development (Liu et al., 1994). Inductive signals from the presumptive lens tissue seem to be required for initiation of Chx10 expression (Nguyen \& Arnheiter, 2000). Later Chx10 becomes restricted to the presumptive neural retina and finally, to the mature bipolar cells located in the inner nuclear layer of the retina (Liu et al., 1994). Expression of Chx 10 is neural retina specific, as no expression can be detected in the retinal pigmented epithelium, optic nerves or in the lens (Liu et al., 1994; Chen \& Cepko, 2000).

Chx10 mutations in mice and human lead to microphthalmia, cataracts and iris abnormalities (Burmeister et al., 1996; Ferda Percin et al., 2000). In mouse a premature stop codon in Chx 10 leads to the ocular retardation (or ${ }^{J}$ ) phenotype. Retinas of or ${ }^{J}$ mice have all neural retina cell types except bipolar cells, but all these cells show abnormal morphology and are not organized into layers. The net number of cells is decreased 19fold compared to wild type mice (Green et al., 2003). The developmental defects of or ${ }^{\mathrm{J}}$ mice indicate that $\mathrm{Chx} 10$ is essential for retinal cell proliferation and for bipolar cell development (Burmeister et al., 1996). This phenotype can be significantly modified by the genetic background (Bone-Larson et al., 2000). The partial rescue of the or ${ }^{\mathrm{J}}$ phenotype on certain genetic backgrounds indicates that overall retinal growth depends on other factors in addition to Chx10. The or ${ }^{\mathrm{J}}$ phenotype can also be rescued by inactivation of the cyclin-dependent kinase inhibitor, Kip1 (p27). Chx10/Kip1 double knock out retinas have about five times more cells than or ${ }^{\mathrm{J}}$ retinas (Green et al., 2003). Chx10 does not repress Kip1 transcription directly, rather cyclin D1 appears to mediate the inhibitory effect of Chx10 on Kip1 (Green et al., 2003). Antisense inhibition of the Alx gene, the zebrafish homologue of Chx10, results in microphthalmia and abnormal retinal organization (Barabino et al., 1997). This phenotype is reminiscent of that observed in or ${ }^{\mathrm{J}}$ mice. 
In humans, mutations in Chx10 were found in two families with microphthalmia, cataracts and iris colobomas (Ferda Percin et al., 2000). In these individuals both alleles of Chx10 carry a substitution of a conserved arginine to either glutamine or proline. The mutated arginine resides in helix 3 of the homeodomain and is known to be important for DNA-binding. In fact, both identified mutations abolish DNA binding ability in vitro (Ferda Percin et al., 2000).

Misexpression of Chx 10 in retinal explants shows that this gene alone can increase the population of inner nuclear layer cells, but is not sufficient for their maturation (Hatakeyama et al., 2001). Bipolar cell fate specification can be induced by co-expression of Chx10 with basic helix-loop-helix factors, such as Mash1 or Math3 (Hatakeyama et al., 2001).

\subsection{Genes important for dorso-ventral and naso-temporal patterning.}

Once the neural retina is formed, dorso-ventral and naso-temporal polarities develop. The most well studied effect of retinal patterning is the projection of retinal axons to the brain, specifically to the superior colliculus in mammals and optic tectum in other vertebrates (Crosland et al., 1974).

Genes important for dorso-ventral patterning include: BMP4, Tbx5, EphrinB1 and EphrineB2, that determine dorsal fate; and Vax2, Pax2, EphB2 and EphB3 that are critical for the proper development of the ventral retina.

Overexpression of Vax2 in Xenopus and chicken results in coloboma, where the optic fissure remains widely open both in the optic vesicle and optic stalk. In addition, the optic stalk is greatly enlarged (Barbieri et al., 1999; Schulte et al., 1999). Marker analysis revealed expansion of the ventral marker Xpax2 and suppression of the dorsal marker Xvent2. In another study overexpression of Vax 2 results in Pax 2 expansion to the optic cup (Lupo et al., 2000). This indicates that Vax2 may affect proper specification of the optic stalk and optic cup territories. Knock out of Vax2 leads to partially penetrant coloboma in one study (Barbiery et al., 2002), or has no effect on retina composition and closure of the optic fissure in the other study (Mui et al., 2002). Tbx5 (early dorsal marker) and Pax2 (early ventral marker) expression patterns are unaffected in Vax2-/mice, while mid-late stage retinal markers EphrinB1 and EphrinB2 show dorsalisation of 
the expression. Abrogation of Vax2 expression in zebrafish also leads to coloboma; no changes in the early dorso-ventral patterning markers were found (Take-Uchi et al., 2003). Similar to overexpression results, Vax 2 knock out affects retinal ganglion cell projections (Barbieri et al., 2002; Mui et al., 2002). Thus, Vax2 misexpression causes the adaptation of the ventral retinal characteristics and abolishes the normal pattern of dorsal (in case of overexpression) or ventral (in loss-of-function experiments) axon projection to the brain.

Tbx5 is a T-box protein expressed in the dorsal part of the optic vesicle starting at about E9.5 of mouse development (Chapman et al., 1996; Sowden et al., 2001). When Tbx5 is overexpressed by electroporation in ovo, the ventral neural retina assumes the dorsal fate as concluded from cell morphology, suppression of ventral markers (chicken Vax and Pax2) and expansion of dorsal marker (Ephrin B1 and Ephrin B2) expression domains (Koshiba-Takeuchi et al., 2000). Projection of ventral axons was affected in Tbx 5 misexpression experiments. Tbx 5 appears to be a target of BMP4, which can dorsalize the eye through expansion of the Tbx 5 domain and repression of $\mathrm{cVax}$ and Pax2 in the ventral retina (Koshiba-Takeuchi et al., 2000).

Specification of naso-temporal polarity in the developing eye is a less well-understood process compared to dorso-ventral patterning. Two winged-helix transcriptional factors Foxg1 and Foxg2 are restricted to the nasal and temporal retina and optic stalk respectively (Hatini et al., 1994). Foxg1 knock out mice die within minutes of birth. They have irregularly shaped eyes with large colobomas (Huh et al., 1999). Optic cups and pigmented epithelium of these animals expand medially to the brain abolishing formation of the optic stalk. However, differentiation of cell types in the neural retina is initiated normally and retinal ganglion cell axons somehow project from the retina toward the brain. In Foxg1 knock out mice Foxg2 expression is found in the nasal retina suggesting that these two genes downregulate each other (Huh et al., 1999). Misexpression of Foxg1 results in abnormal projection of temporal axons, while in Foxg2 misexpression experiments nasal, but not temporal, axons make abnormal connections (Yuasa et al., 1996). These data indicate that Foxg1 and Foxg2 may determine naso-temporal specificity of the retina and consequently specify the topographic projections of retinal ganglion cell axons. 


\section{The Retinal Homeobox $(\mathbf{R x})$ Gene}

1.Isolation of the $\mathrm{Rx}$ gene and structure of the $\mathrm{Rx}$ protein.

The first Rx gene was isolated by screening a Xenopus cDNA library using as probes two fragments of the mouse homeobox gene Orthopedia. This novel paired-like class homeobox gene showed prominent expression in the developing retina and other head structures (Casarosa et al., 1997). Subsequently, Rx genes were isolated from multiple species. There is only one Rx gene in mouse (Furukawa et al., 1997; Mathers et al., 1997), human (Mathers et al., 1997; Kimura et al., 2000), and fruit fly (Mathers et al., 1997; Eggert et al., 1998); two homologous Rx genes in chicken (Ohuchi et al., 1999; Chen and Cepko, 2002), Xenopus (Casarosa et al., 1997; Mathers et al., 1997), and medaka fish (Deschet et al., 1999) and three in zebrafish (Mathers et al., 1997; Chuang et al., 1999). Rx belongs to the $\mathrm{Q}_{50}$ paired-like (prd-like) sub-class of homeobox genes. Genes of this sub-class have a homeodomain sequence that is similar (50-60\% identity) to the homeodomain found in the Drosophila paired protein (Burglin, 1994). Paired subclass genes, also known as Pax genes, contain homeo- and paired domains. The major discrepancy between these two classes of genes is that $p r d$-like genes do not encode a paired domain that is a second DNA-binding domain in prd class (Treisman et al., 1991). They also differ at the characteristic residue 50 of the homeodomain, which plays a key role in determining DNA-binding specificity. $\mathrm{Rx}$ belongs to $\mathrm{Q}_{50}$ sub-class and has a glutamine residue at position 50, while Pax genes have serine and belong to $\mathrm{S}_{50}$ subclass (Galliot et al., 1999).

The Rx protein (Fig. 2A) contains several conserved domains. An octapeptide domain is commonly found in the paired-class homeobox genes (Noll, 1993) and is related to the Drosophila Engrailed gene repressor sequence eh-1. Both Engrailed eh-1 and its homologue from Goosecoid, GEH, are required for transcriptional repression (Smith \& Jaynes, 1996; Mailhos et al., 1998). A homeodomain that is a 60 amino acid DNA binding domain, a nuclear localization signal and the paired-tail domain are other conserved structural elements found in Rx proteins. The paired-tail domain, also known as the OAR domain or C-peptide, functions as a transactivator domain in Orthopedia (Simeone et al., 1994), although deletion of its homologue in Alx-4 protein had little 


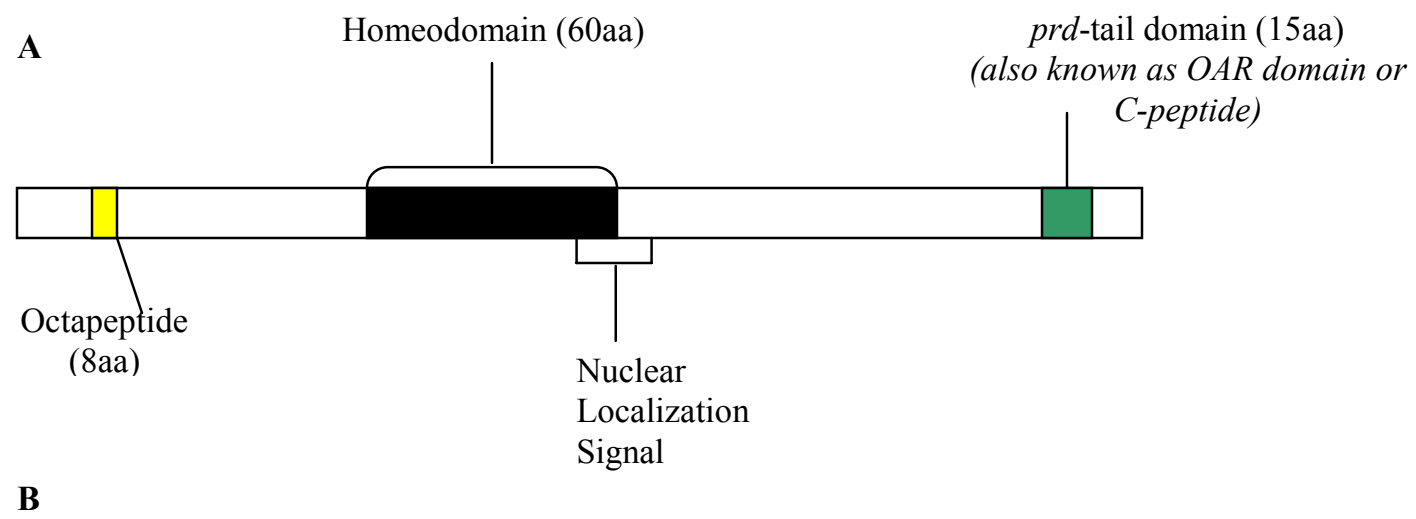

Mouse Rx HRRNRTTFTT YQLHELERAF EKSHYPDVYS REELAGKVNL PEVRVQVWFQ NRRAKWRRQE

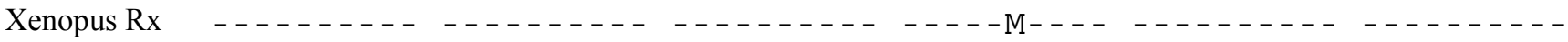

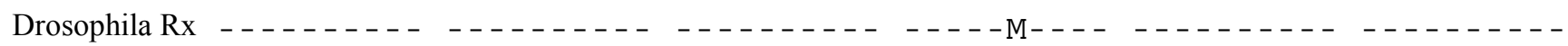

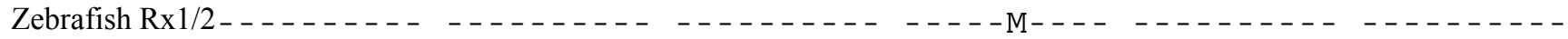
Zebrafish Rx3

C Exon 1 Exon 2 Exon 3

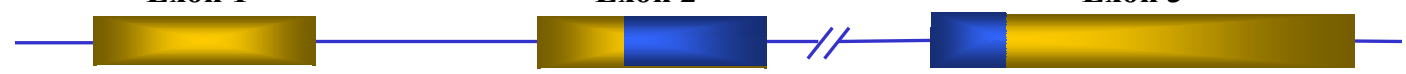

Fig.2 Structure of Rx protein and conservation of Rx-family homeodomain among species

A. Schematic representation of $\mathrm{Rx}$ protein.

B. Comparison of homeodomain sequence from $\mathrm{Rx}$ family of transcription factors

C. Organization of human and mouse Rx locus, homeobox is shown in blue 
effect on reporter activity (Hudson et al., 1998). OAR domain might be a transactivation domain in the Rx protein, since overexpression of truncated $\triangle \mathrm{OAR} R \mathrm{R}$ mRNA produces in about one third of the injected embryos anterior deletions and reduction of the eye size similar to the Rx depletion experiments (Andreazzoli et al., 1999). Proteins encoded by the Rx gene family show strong conservation across species (Fig. 2B). Human and mouse Rx genes that will be the subjects of the experimental part of this dissertation share similar organization. The coding region is composed by three exons with the homeobox split between exons 2 and 3 (Fig. 2C).

\section{Rx gene expression pattern.}

The Rx gene is expressed in vertebrates at the beginning of neurulation in the anterior neural plate. This region of early activity corresponds to the entire presumptive forebrain and possibly the midbrain. The field of Rx early expression overlaps with the expression of other homeobox genes expressed in the anterior neural plate, including Pax6, Otx 2 and Six3 (Furukawa et al, 1997). As development proceeds, the ocular expression of Rx becomes localized to the optic vesicles (Fig. 3A). At this stage Rx is also expressed in the hypothalamus (Fig. 3B) and posterior pituitary (Fig. 3C). Mouse and human Rx genes (Furukawa et al., 1997; Mathers et al., 1997; Kimura et al., 2000) and their orthologs from zebrafish (Zrx1 \& Zrx2)(Chuang et al., 1999), medaka (O1-Rx3)(Deschet et al., 1999), cave fish (CFRx1)(Stricklet et al., 2002), chicken (cRax)(Ohuchi et al., 1999) and Xenopus (Xrx1)(Casarosa et al., 1997) are expressed in the optic structures. Drosophila $\mathrm{Rx}$, however, is not expressed in the eye disk primordia or later in the imaginal disks of third instar larva (Eggert et al., 1998; Treisman \& Lang, 2002), while the forebrain expression pattern is very similar to Rx expression in the other species.

It was originally reported that Rx activity is lost in the mouse retina between the first and second week after birth, when cell proliferation in the retina ceases (Furukawa et al., 1997; Mathers et al., 1997). This pattern of Rx expression is consistent with the position and timing of retinal stem cell proliferation in the mouse (Sidman, 1961). It was 


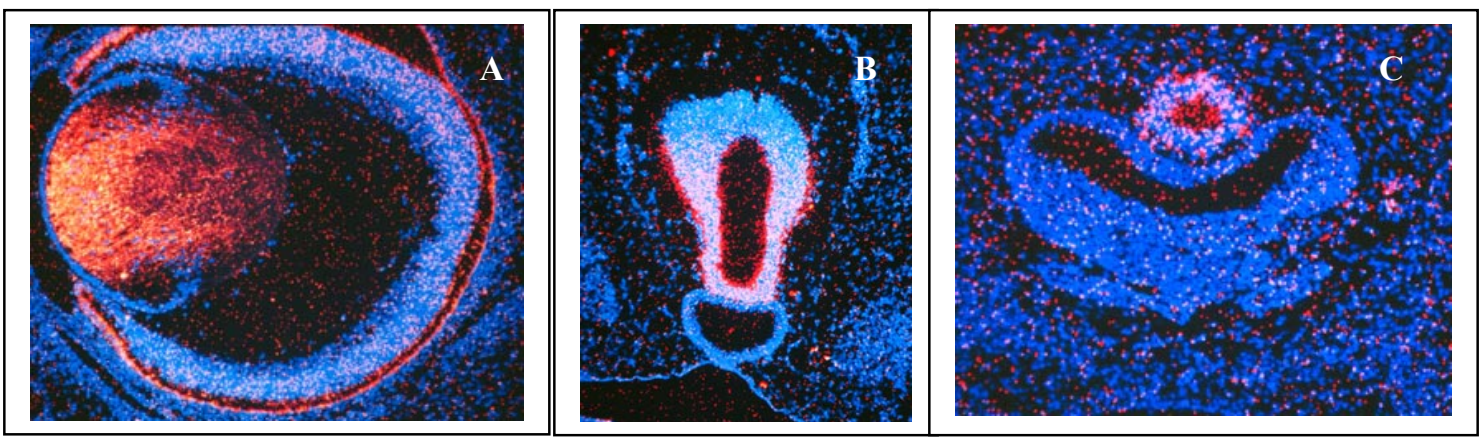

Fig.3 Rx expression in mouse embryo (adapted from Mathers et al., 1997)

A. Section of E15.5 mouse eye hybridized with ${ }^{35} \mathrm{~S}$-labelled Mrx riboprobe showing uniformal Rx expression within the neural retina

B. Expression in the ventral hypothalamus at E10.5.

C. Expression in the posterior pituitary at E10.5 
hypothesized that Rx plays an important role in retinal cell specification and stem cell proliferation (Furukawa et al., 1997; Mathers et al., 1997). More recent papers present three different points of view: a) $\mathrm{Rx}$ is expressed in all cell types of the adult rat retina (Kimura et al., 2000); b) Rx is expressed exclusively in Müller glia cells that are located in the inner nuclear layer of the adult rat retina (Furukawa et al., 2000; Marquardt et al., 2001); c) Zrx1/2 is expressed in the adult zebrafish cone but not rod photoreceptors, while $\mathrm{zRx} 3$ is expressed in the INL of the adult retina (Chuang et al., 1999). In addition to controversial adult eye expression, $\mathrm{Rx}$ is expressed in the ventral forebrain of adult rats and medaka fish, particularly in the pineal gland, the floor of the $3^{\text {rd }}$ ventricle, and in the posterior pituitary (Deschet et al., 1999; Asbreuk et al., 2002). A detailed analysis of the ocular Rx expression pattern of the adult mouse is presented in Chapter 2 of this dissertation.

\section{Functional studies with Rx genes}

In an effort to determine the function of the Rx genes during eye development two types of studies have been performed. Overexpression of the Rx gene was done by injection of synthetic Rx RNA into cleavage-stage Xenopus embryos. Upon histological analysis, hyperproliferation and in severe cases duplication of neural and pigmented retinas (Fig. 4B), as well as the anterior neural tube (Fig. 4C), was observed. As a result of this Rx-induced hyperproliferation, the neural retina extrudes beyond the limits of the pigment layer and lens development is severely disrupted (Fig. 4B \& 4C). These defects are specific to Rx-injected embryos, as injection of Pax6 or Otx2 synthetic RNAs has no effect on eye formation (Mathers et al., 1997; Andreazzoli et al., 1999). Marker analysis revealed that Xpax6, Xotx2 and Xsix3 are activated in the overproliferating tissue, while Xpax2 and En2 are repressed in the mid-hindbrain junction (Andreazzoli et al., 1999; Lupo et al., 2000). Overexpresion experiments in zebrafish led to replacement of forebrain structures by retinal tissue (Fig. 4D \& E; Chuang and Raymond, 2001). This probably represents a conversion of forebrain precursors to retinal precursors. These results suggest a role for $\mathrm{Rx}$ in the specification or proliferation of retinal stem cells. 

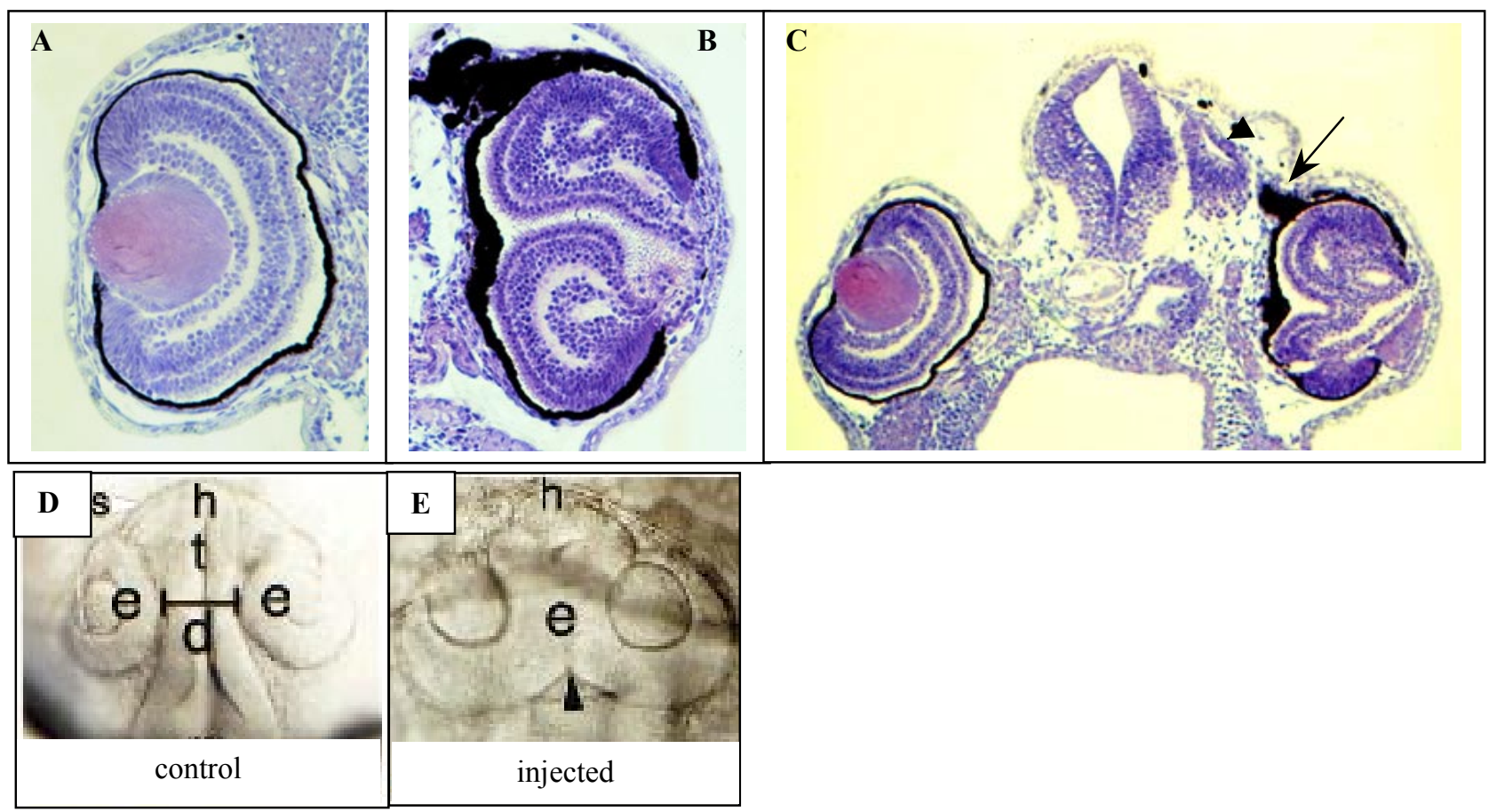

Fig.4 Overexpression of Rx (adapted from Mathers et al., 1997; Chuang and Raymond, 2001)

A. Normal tadpole eye.

B. Eye of Rx injected tadpole showing duplication of the neural retina due to hyperproliferation.

C. Secondary neural tube (arrowhead) and hyperprolyferation of RPE (arrow) and neural retina on the injected side.

D. Uninjected zebrafish embryos (e - eyes, $\mathrm{h}$ - hypothalamus, $\mathrm{t}$ - telencephalon, $\mathrm{d}$ diencephalon; adapted from Chuang and Raymond, 2001).

E. Embryos injected with zebrafish $\mathrm{rx} 2$ show expansion of eyes into the forebrain region that results in complete dorsal forebrain deletion. 
To investigate the effect of Rx gene deletion, a knock out mouse strain was generated (Mathers et al., 1997). A targeting vector was constructed to delete exons 1 and 2 of the mouse Rx gene, including the protein start site and the majority of the homeodomain (Fig. 5A). Deletion of the Rx gene from the mouse genome results in the birth of anophthalmic pups, which die within the first day after birth. The loss of ocular tissue in Rx-deleted embryos is apparent at E13.5 when the retinal pigmented epithelium layer of normal embryos is pigmented (Fig. 5B). Defects are also detectable at earlier stages starting from E8.5 when the anterior neural tube evaginates to form the optic pits. The Rx-null embryos show a complete failure in the formation of the optic vesicle (Fig. 5C \& D). That suggests that $\mathrm{Rx}$ is involved in the specification of the lateral wall of the forebrain that forms the optic pit and later the optic vesicle (Jean et al., 1998).

In addition to the defects during organogenesis of the eye, targeted deletion of the Rx gene product causes other malformations in the newborn pups. Defects in the neural tube can range from deletion of the pituitary and hypothalamus to nearly complete absence of the forebrain and midbrain (Fig. 5E \& G). Other associated abnormalities, when present, can include a cleft lip covering $\sim 20 \%$ of the head length of the pup, and the absence of the palate that leaves an opening between the mouth and neural tube. The defects in palate formation are observed starting at E12. At this stage there is little or no intervening mesoderm between the oral and neural ectoderm in Rx-null embryos (Zhang et al., 2000). The lack of eyes and defects in the brain, pituitary, lip and palate are all conditions that are present in human anophthalmic patients (Ashley, 1947; Leichtman et al., 1994; Brodsky and Frindik, 1996).

Studies described above demonstrated that a functional Rx gene is critical for formation of the neural retina and retinal pigmented epithelium. The Rx mouse knock out phenotype is the earliest known defect in retinal development, preceding effects from disruption of Pax6, Lhx2, and Chx10 genes. In the latter cases optic vesicles are formed but fail to develop into normal eyes. 
A

Endogenous Rx locus

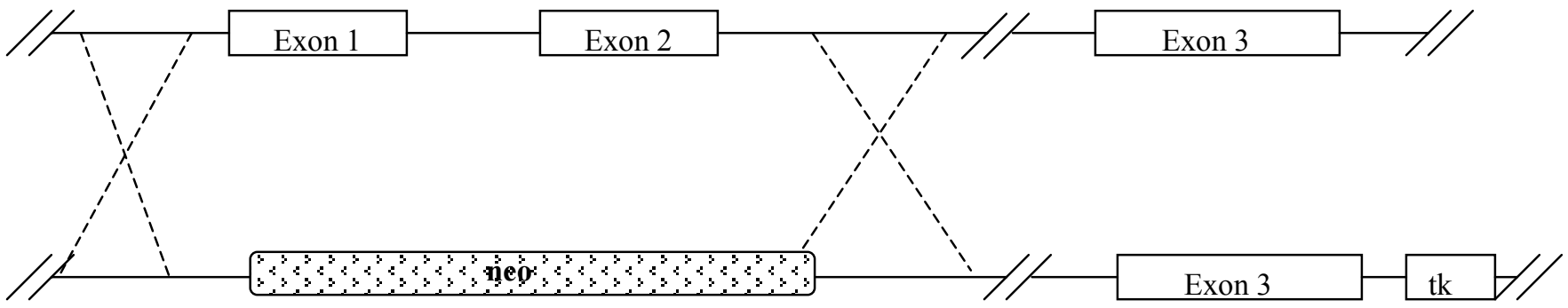

Targeting vector

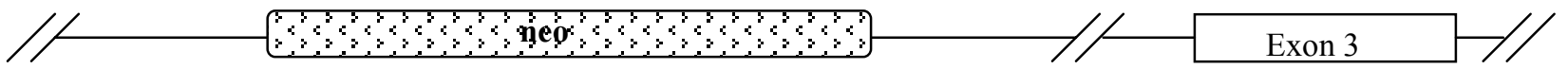

Targeted locus
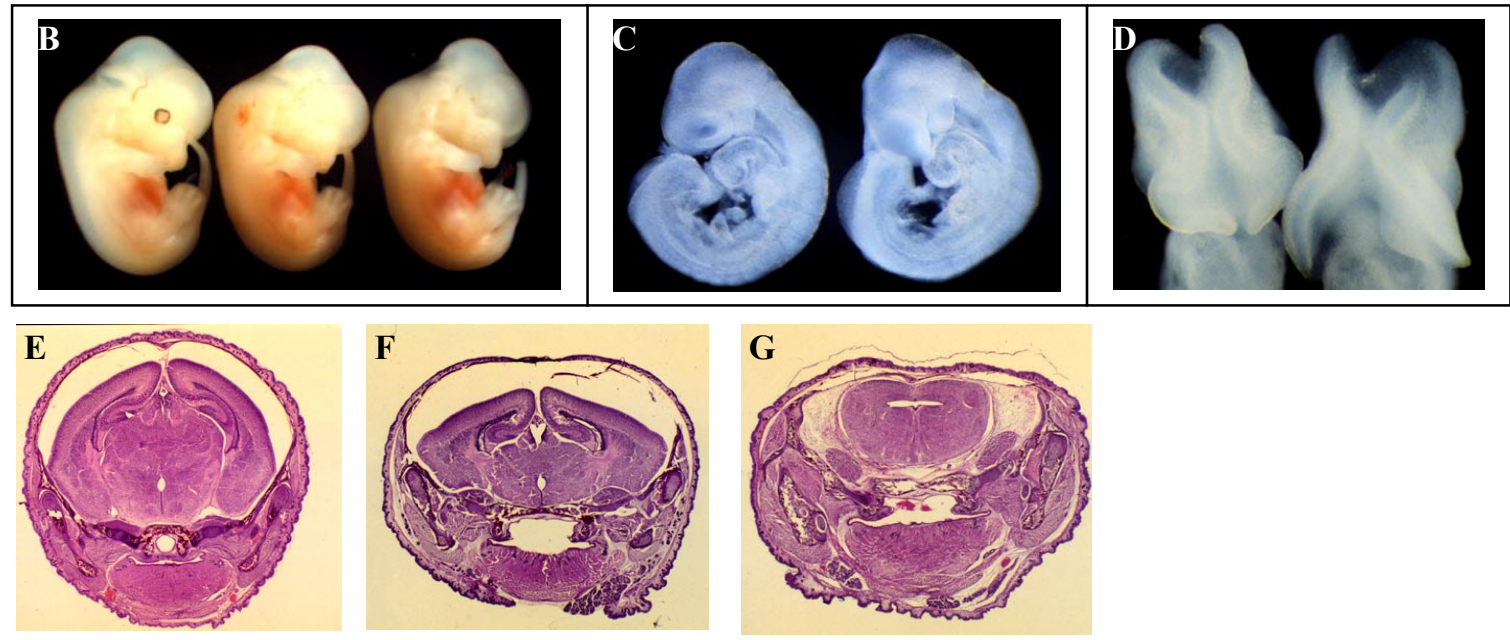

Fig.5 Knock out of mouse Rx results in anophthalmic embryos

(adapted from Mathers t al., 1997)

A. A strategy used to inactivate Rx gene in germline

B. Embryos at E13.5 where the wild-type (left) shows eye formation and Rx-null mutants (middle and right) have no eyes.

C. Embryos at E9.0 where optic vesicle formation has occurred in the wild-type (left), but not in Rx-null mutant (right).

D. Failure to close neural tube at E9.0 in Rx-knockout homozygous (right) in comparison to normal neural tube formation of wild-type embryo (left).

E. Cross-section through the midbrain of $\mathrm{Rx}+/-$ newborn.

F. Smaller than normal midbrain in the Rx-/- newborn.

G. Severely affected midbrain in the Rx-/- newborn. 


\section{$\underline{4 . ~ R x ~ t a r g e t s ~ a n d ~ p l a c e ~ i n ~ t h e ~ g e n e ~ n e t w o r k ~}$}

The homology to other homeodomain-containing proteins is consistent with $\mathrm{Rx}$ function as a transcription factor. Overexpression studies in Xenopus demonstrated that excessive doses of Xrx1 repress Xotx2 and the cement-gland-specific marker XAG-1 at early neurula stage, while overexpression of Xrx1 at later stages results in ectopic activation of the same genes (Andreazzoli et al., 1999). Xrx 1 microinjections lead to repression of Pax2, En-2, and Krox20 expression in the brain and ectopic activation of Foxg1. Targets and effects of Rx were studied by Kimura and co-workers in vitro, they found that human RX binds to PCE-1 elements in mouse arrestin and interphotoreceptor retinoid-binding protein (IRBP) promoters and upregulates their transcription (Kimura et al., 2000). In human 293 embryonic kidney cells, RX upregulated transcription from the arrestin promoter 6.4 -fold and from the IRBP promoter 14.8-fold. It was shown that the PCE-1 core consensus sequence CAATTA(G/A) is essential for Rx binding. PCE-1 sites are found in other photoreceptor-specific promoters, such as red-cone opsin for instance (Moritz et al., 2002).

Other potential targets of Rx activation are the Notch1 and Hes1 promoters. In transient transfection experiments Rx upregulates these genes and promotes formation of Müller glia (Furukawa et al., 2000). Notch1 and Hes1 are normally expressed in the germinative layer of the neural retina. These factors repress differentiation of mitotic cells that result in preservation of a pool of mitotic progenitor cells (Jean et al., 1998).

Since inactivation of mouse $\mathrm{Rx}$ in the germline results in complete ablation of eye development, it raises a question of how Rx affects the network of genes critical for eye development. At least three critical genes Otx2, Six 3 and Pax6 are normally expressed in the presumptive forebrain of the Rx-null embryos at early stages (Zhang et al., 2000). In wild type embryos these genes are upregulated on embryonic day 9.0 in the presumptive retinal field. However, this upregulation is not observed in Rx-null embryos (Zhang et al., 2000). This indicates that $\mathrm{Rx}$ is not necessary for primary activation of Otx $2, \operatorname{Six} 3$ and Pax6 but it is critical for upregulation and stabilization of these transcripts in the developing eye field. Expression patterns of Rx, Otx2, Six 3 and Pax6 in Rx-null embryos suggest that they are activated by other unidentified factors (Zhang et al., 2000). Antagonists of the bone morphogenetic (BMP) signaling pathway are among candidate 
activators (reviewed in Chow \& Lang, 2001). Although, not much is known about this upstream signaling, recent studies in zebrafish raise the possibility that Zrx1 may function as a mediator of Shh signaling at least at the stage of photoreceptor differentiation (Stenkamp et al., 2002). This observation is consistent with inhibition of Rx by Vax 1 during formation of the optic stalk, since Vax1 is activated by Shh (Hallonet et al., 1999). Chapter 4 of this dissertation will present new data regarding potential targets of Rx in eye development.

\section{Mutations in the Rx gene lead to anophthalmia in mouse and fish}

\section{$\underline{5.1 \text { Mouse }}$}

In 1938 Dr. C.C. Little of the Jackson Laboratory observed smaller than normal eyes in some laboratory mice. Subsequent inbreeding yielded a stable strain designated ZRDCT-An, where "An” stands for anophthalmia (Chase \& Chase, 1941). The phenotype observed in this strain is very similar to human anophthalmia, giving this strain the name eyeless. Approximately $90 \%$ of ZRDCT mice do not have eyes and lack optic nerves (Chase \& Chase, 1941), and the entire orbit is filled with a much larger than normal Harderian gland. Despite the absence of optic tracts, visual brain centers (the lateral geniculate nuclei and visual cortex) form attenuated projections (Chase, 1945; Olavarria \& Van Sluyters,1984). The remaining 10\% of the eyeless mice are microphthalmic. The eye size varies from specks of pigment to an almost normally organized eye on one side. In the latter case, optic nerves can be formed (Chase \& Chase, 1941). All microphthalmic animals have similar pathological characteristics that include thinner retinal layers, especially loss of ganglion cells and their axons, displastic rosette pattern in the photoreceptor layer, and late onset of lens differentiation (Silver et al., 1984).

The initial stages of eye development proceed normally in ZRDCT mice. The critical period is about E10, after which organogenesis of the eye fails to proceed. It was originally proposed that around E10 optic vesicles from ZRDCT embryos become retarded and only poorly contact the surface ectoderm, which interferes with normal eye morphogenesis (Chase \& Chase, 1941). Lens development is not completely abolished in 
these mice. When present, the lens has the ability to differentiate, albeit later than in control animals (Zwaan and Silver, 1983). Variability of phenotype from bilateral anophthalmia to relatively mild unilateral microphthalmia can depend on positioning of the lens relative to the center of optic cup. If the lens invaginates into the center of the cup, a microphthalmic eye will be formed. Invagination close to the rim will lead to the loss of the lens and subsequently to collapse of optic vesicle and anophthalmia (Harch et al., 1978). The eyeless phenotype has also been attributed to the lack of contact between optic vesicle and surface ectoderm due to absence of mesenchymal cell death (Silver \& Hughes, 1974). Mesenchymal cells that are located between the developing retina and the lens normally die when lens development begins. This cell death never occurs in ZRDCT mice. Proliferating mesenchymal cells displace the abnormal lens from the eye cavity. More recent studies of the extracellular matrix and the optic vesicle basal lamina demonstrated lower than normal concentration of glucosaminoglycans (GAG) at the initial stages of lens development (Webster et al., 1984). GAGs are believed to function as a cementing medium between the developing optic and lens vesicles. It was proposed that GAG deficiency within the basal lamina affects adhesion between the optic vesicle and lens and thus leads to anophthalmia.

Circadian rhythms are abnormal in ZRDCT mice, ranging from completely arrhythmic in the anophthalmic group to almost normal rhythms in some microphthalmic animals (Faradji-Prevautel et al., 1990; Laemle et al., 1995; Laemle and Ottenweller, 1998). The degree of synchronization to light/dark conditions seems to be dependent on the density of retinal ganglion cells in the retina of microphthalmic mice (Faradji-Prevautel et al., 1990). Suprachiasmatic nuclei that are the primary oscillators of the mammalian circadian rhythm have abnormal nuclear distribution that indicates that retinal projections may play a role in establishing the adult pattern (Laemle \& Rusa, 1992). The geniculohypohthalamic tract is present and expanded to compensate for the missing retinal projections (Laemle et al., 1993).

Based on results of crosses of ZRDCT-An mice with other mouse strains it was proposed that there is one major recessive factor and at least one very strong modifier that lead to eyelessness in this mouse strain (Chase, 1942). This hypothesis was confirmed by a reverse mutation toward normal eyes that occurred in ZRDCT-An strain 
(Chase, 1944). Recently, the major recessive determinant of the eyeless phenotype was linked to chromosome 18 where the mouse Rx gene is located (Tucker et al., 2001). Mutational screening revealed a single amino acid substitution M10L in the Rx gene of eyeless mice. This mutation is not present in other mouse strains tested in this study (Tucker et al., 2001). Methionine codon \#10 is highly conserved among species and together with methionine \#1 serves as a translation initiation codon for Rx protein synthesis. The M10L mutation lowers the level of Rx protein leading to the anophthalmic phenotype (Tucker et al., 2001).

\subsection{Medaka fish}

The medaka eyeless (el) mutant was identified as a spontaneous recessive mutation that affects eye development. The el phenotype is temperature sensitive. When $\mathrm{el}^{-}$ medaka embryos are grown at the permissive temperature of $28^{\circ} \mathrm{C}$, all embryos demonstrate eye abnormalities ranging from the complete absence of optic cups to the slight asymmetric decrease of orbital structures (unilateral microphthalmia). When raised at the restrictive temperature of $18^{\circ} \mathrm{C}, 100 \%$ of el embryos do not have visible optic cups (Winkler et al., 2000). This indicates that temperature affects the transcription at the $\mathrm{el}^{-}$ locus, the $\mathrm{el}^{-}$allele is hypomorphic at the permissive temperature and amorphic at the restrictive temperature. A search for candidate genes showed that expression of medaka gene Rx3 is completely absent in el mutants. Subsequent experiments revealed the presence of at least $13 \mathrm{~kb}$ insertion in intron 2 of the Rx3 in el mutants, but not in their wild type littermates (Loosli et al., 2001). It was also shown that delivery of Rx3 expression plasmid rescues the phenotype of $\sim 37 \%$ of el mutants (Loosli et al., 2001), proving the causative nature of the $\mathrm{Rx} 3$ mutation.

While the optic anlage is formed and later split into two retinal primordia, optic vesicles do not evaginate in $\mathrm{el}^{-}$mutants. This suggests that $\mathrm{Rx} 3$ is not required for the formation of retinal anlage and puts medaka Rx3 downstream of Six3 and Pax6 genes, the expression of which determines the retinal anlage. Complete absence of optic vesicles in $\mathrm{el}^{-}$embryos demonstrates that $\mathrm{Rx} 3$ is indispensable for the initiation of evagination and the maintenance of the proliferation of the optic vesicle (Loosli et al., 2001). Detailed studies of $\mathrm{el}^{-}$brain revealed optic cup-like structures that are formed in the telencephalon 
(Ishikawa et al., 2001). These structures have opsin-positive cells, indicating their retinal origin, and persist in the brain of the adult fish. Despite the presence of optic cup-like structures $\mathrm{el}^{-}$fish are functionally blind (Ishikawa et al., 2001). An abnormally small hypothalamus and hypophysis in these fish is also consistent with phenotype of Rx-null mice.

\section{Human conditions that may result from mutations in the $\mathrm{Rx}$ gene}

Homeobox genes regulate development of many tissues, accounting for the fact that mutations in these genes frequently cause serious developmental defects. Such correlations have been shown for the ocular homeobox genes Crx, Pax6, Chx10 and Six3. Mutations in the CRX gene lead to Cone Rod Dystrophy 2 (CORD2) (Chen et al., 1997b; Freund et al., 1997), while heterozygous defects in PAX6 are associated with aniridia, a congenital disorder characterized by the complete or partial absence of the iris (Ton et al., 1991; Glaser et al., 1992; Jordan et al., 1992; Koroma et al., 1997). Mutations in CHX10 lead to microphthalmia (Ferda Percin et al., 2000). SIX3 mutations are associated with cases of holoprosencephaly in human, where mildly affected patients also had anophthalmia (Wallis et al., 1999). Recently, SOX2 mutations were found in patients with anophthalmia (Fantes et al., 2003).

The finding that $\mathrm{Rx}$ null mice are anophthalmic prompted us to investigate a potential effect of mutations at the RX locus in humans. In addition to anophthalmia and microphthalmia, the human RX gene maps to the region critical for formation of CORD1. These facts make the RX gene a potential candidate for causing these disorders.

Anophthalmia is a failure of the optic vesicle to evaginate from the developing forebrain. It leads to the absence of the globe and ocular tissue (Ashley, 1947). Anophthalmia was known for centuries but the first report of congenital anophthalmia was published in 1934 (Sorsby, 1934). This paper presents an unpublished manuscript by Briggs from 1813-1826 and illustrates the range of defects that can occur in anophthalmia. One end of the range is marked by people with complete absence of eyes that is, anophthalmia - whereas at the other end are cases that are rather arbitrarily diagnosed because no clear-cut border exists between mild microphthalmia and small normal eyes (Mariman, 1998). Congenital anophthalmia normally displays recessive 
transmission, although both autosomal (Ashley, 1947; Kohn et al., 1988) and sex-linked (Joseph, 1957) inheritance patterns have been observed.

The overall prevalence of anophthalmia and microphthalmia is 1.0 per 10,000 live births (Dolk et al., 1998). According to another study, the prevalence rate for congenital anophthalmia is between 0.3 and 0.6 per 10,000 birth and the prevalence rate for microphthalmia is between 1.4 and 3.5 per 10,000 birth (Tucker et al., 1996). Anophthalmia and microphthalmia can be bilateral or unilateral and may be accompanied by mental deficiencies (Ashley, 1947), cleft lip and palate (Leichtman et al., 1994; Fryns et al., 1995), hypothalamic-hypophyseal disorders (Brodsky \& Frindik, 1996) and other defects. The complex nature of these syndromes suggests overlapping phenotypes caused by mutations in a number of different genes.

CORD represents a clinically heterogeneous group of retinal degeneration with different modes of inheritance. Autosomal dominant, recessive and X-linked inheritance patterns have been described (Evans et al., 1995). CORD affects both cone and rod functions throughout the retina (Freund et al., 1997). This condition is characterized by the patchy loss of photoreceptor function. In mildly affected areas, loss of cone function may be quantitatively greater than functional loss in rods (Evans et al., 1995). Based on electroretinographic recordings (which can reflect functional impairments) and the pattern of visual loss, four functionally distinct subtypes of CORD were identified (Szlyk et al., 1993). These different CORD phenotypes are likely to correspond to different genotypes. To date, four trait loci have been assigned for this disorder (Kylstra \& Aylsworth, 1993), including one at 18q21 (Warburg et al., 1991) where the human RX gene maps.

The molecular events that result in the progression of retinal dystrophies are not presently understood, but there has been increasing evidence that metabolic defects caused by mutation do not directly cause cell death (Bird, 1995). It has been shown that apoptosis causes the cell death in animals with genetically determined retinal degeneration (Lolley et al., 1994; Tso et al., 1994). 


\section{Chapter II.}

\section{Rx Expression throughout Mammalian Retinal Development}

and in Adults

Vera A. Voronina, Supriya Shah, and Peter H. Mathers 


\section{A. Introduction}

The retinal homeobox gene, $\mathrm{Rx}$, encodes a transcription factor with four evolutionary conserved motifs, including the octapeptide, the homeodomain, the Rx-domain, and the OAR or paired-like domain. Proteins of the $\mathrm{Rx}$ family show strong homeodomain conservation across species, as well as small islands of conserved sequences throughout the protein. Rx genes have been isolated from mouse (Furukawa et al., 1997; Mathers et al., 1997), human (Mathers et al., 1997; Kimura et al., 2000), fruit fly (Mathers et al., 1997; Eggert et al., 1998), chicken (Ohuchi et al., 1999; Chen \& Cepko, 2002), frog (Casarosa et al., 1997; Mathers et al., 1997), zebrafish (Mathers et al., 1997; Chuang et al., 1999), medaka fish (Deschet et al., 1999) cavefish (Strickler et al., 2002), and blind mole rat (Tucker et al., 2001).

Multiple lines of evidence link $\mathrm{Rx}$ genes with early eye development. Overexpression of Rx in Xenopus embryos leads to hyperproliferation and in severe cases duplication of neural and pigmented retinas, as well as anterior neural tube (Mathers et al., 1997; Andreazolli et al., 1999). As a result of this Rx-induced hyperproliferation, the neural retina extrudes beyond the limits of the pigment layer and lens development is severely disrupted. Overexpression experiments in zebrafish lead to replacement of forebrain structures by retinal tissue (Chuang and Raymond, 2001). These results suggest a role for $\mathrm{Rx}$ in the specification and/or proliferation of retinal stem cells.

Deletion of the Rx gene from the mouse genome results in the birth of anophthalmic pups (Mathers et al., 1997). These pups die within the first day after birth due to defects in the ventral forebrain. Rx null embryos show a complete failure in the formation of optic vesicle since evagination of the optic pit from the presumptive forebrain never occurs.

$\mathrm{Rx}$ is a good candidate gene for viable cases of anophthalmia, because the eyeless mouse mutation (eyl)(Chase and Chase, 1941) is due in part to the removal of an alternative start codon at position 10 of the Rx protein (Tucker et al, 2001). Another Rx gene mutation result in the eyeless (el) phenotype in medaka fish (Winkler et al., 2000). $\mathrm{Rx} 3$ expression is completely absent in el mutants due to a large insertion in intron 2 of the Rx3 gene (Loosli et al., 2001). Delivery of Rx3 expression plasmid partially rescues 
the phenotype. Eyeless fish have an abnormally small hypothalamus and hypophysis (Ishikawa et al., 2001), consistent with the brain defects observed in Rx null mice.

Embryonic expression of $\mathrm{Rx}$ genes has been characterized thoroughly. $\mathrm{Rx}$ is expressed in vertebrates at the beginning of neurulation in the anterior neural plate. This domain of early $\mathrm{Rx}$ expression corresponds to the entire presumptive forebrain and possibly the midbrain. This field of Rx expression overlaps with that of other homeobox genes expressed in the anterior neural plate, including Pax6, Otx2 and Six3 (Furukawa et al., 1997; Zhang et al., 2000). As development proceeds, the expression of Rx localizes to the forming optic vesicles, hypothalamus, and the posterior pituitary in the mouse (Mathers et al., 1997).

Contrary to the embryonic expression pattern, current data on adult mammalian $\mathrm{Rx}$ expression are largely controversial. In the initial reports on mouse expression patterns, it was postulated that mouse Rx expression stops between the first and the second week after birth, coinciding with the time when mitotic activity in the retina ceases (Furukawa et al., 1997; Mathers et al., 1997). This expression pattern, as well as overexpression experiments in Xenopus, suggests an early role for $\mathrm{Rx}$ in retinal cell specification and stem cell proliferation. More recent papers, however, present at least three alternative points of view: a) Rx is expressed in all layers of the adult rat retina (Kimura et al., $2000)$; b) Rx is expressed exclusively in the cell bodies of Müller glia located in the inner nuclear layer of the rat retina (Furukawa et al., 2000; Marquardt et al., 2001), c) zebrafish $\mathrm{Rx} 1 / 2$ are expressed only in the cone photoreceptors in the adult fish retina while Zrx3 is expressed in the inner nuclear layer of the adult fish (Chuang et al., 1999). Although these data suggest a role of the Rx gene at the late stages of eye development and/or in maintenance of the adult retina functionality, these inconsistencies in the literature limit further speculation about putative roles of the Rx gene in the adult eye. If the Rx gene is expressed solely in the photoreceptors, it would suggest a potential involvement in rhodopsin turnover that is critical for proper vision. On the other hand, expression in the Müller glia points to a potential role of $\mathrm{Rx}$ in the retinal progenitor cells and regeneration (Fischer and Reh, 2001). Alternatively, uniform Rx expression throughout the neural retina is suggestive of a general role for Rx in maintaining retinal cell fate. Recently, Rx expression has been detected in the forebrain of adult rats, particularly in the pineal 
gland, the ventral lining of the third ventricle, and the posterior pituitary (Asbreuk et al., 2002). This is consistent with the fact that Rx is expressed in the brain of the adult medaka fish, where it is detected in the pituitary, rostral hypothalamus, and cells bordering the third ventricle (Deschet et al., 1999).

To address discrepancies in the adult ocular expression pattern of Rx in a systematic way, we have studied Rx expression in panels of adult tissues, including retina and brain samples. We found that $\mathrm{Rx}$ is expressed in both the mouse and human adult retina, with the strongest expression observed in the photoreceptor and inner nuclear layers of the mouse neural retina. We also discovered abundant expression in the ciliary bodies located at the periphery of the retina in adult mice. We traced the dynamics of expression of the mouse $\mathrm{Rx}$ gene after birth to determine if $\mathrm{Rx}$ activity is modulated during retinal maturation. Our data argue that, contrary to previous reports, $\mathrm{Rx}$ is expressed in a restricted fashion within the mammalian retina throughout the postnatal period and into adulthood. 


\section{B. Materials and Methods}

The animal work was done in accordance with and approval by the IACUC at West Virginia University and followed the ARVO policy on research with animals.

\section{$\underline{1 .}$ Tissue collection for adult cDNA samples \& isolation of total RNA}

RNA was collected from two adult mice liver, brain, kidney, heart, lung, spleen and skeletal muscles. Eyes of these two mice and three of their littermates were pooled for RNA preparation. All samples were homogenized in $2 \mathrm{ml}$ of TRIzol reagent (Invitrogen, LifeTechnology, Ca, USA) at $+4^{\circ} \mathrm{C}$ followed by freezing on dry ice. Total RNA was isolated from a panel of tissues homogenized in TRIzol according to the manufacturer's protocol. RNA samples were treated with DNaseI for 15 minutes to decrease genomic DNA contamination. To track the dynamics of postnatal Rx expression, eyes were collected from wild type $129 \mathrm{SvJ} / \mathrm{C} 57 \mathrm{BL} / 6$ hybrid mice beginning the day of birth at seven-day intervals with the last collection taken from seven-week old mice.

\section{2. cDNA synthesis and RT-PCR}

Total RNA $(2 \mu \mathrm{g})$ collected from the tissues indicated above was used for cDNA synthesis using random hexamer primers and Superscript II reverse transcriptase according to the manufacturer's protocol (Invitrogen, Ca, USA). A PCR purification kit (Qiagen, Ca, USA) was used to eliminate random primers. Prepared mouse cDNA samples, human multiple tissue cDNA panel (Clontech, $\mathrm{Ca}, \mathrm{USA}$ ) and human retina cDNA obtained from 16 to 75 years old individuals (Clontech, $\mathrm{Ca}, \mathrm{USA}$ ) were amplified using sets of primers spanning intron 1 of the Rx gene. Primer sequences are shown in Table 1, where mouse Rx primers are MRx8 (forward) and MRx6 (reverse) and human Rx primers are HRxL (forward) and HRxR (reverse). 5' and 3' G3PDH primers were used to amplify ubiquitously expressed G3PDH gene. All PCRs were done in triplicate to confirm the observed expression pattern. 


\begin{tabular}{|l|l|}
\hline Primer name & Sequence \\
\hline MRx8 & 5'-GCACGGGAGCTTCTCGCT-3' \\
\hline MRx6 & 5'-GGTAGCAGGGCCTAGTAGC-3' \\
\hline HRxL & 5'-TCCTGGGGTTTACCAAGGAC-3' \\
\hline HRxR & 5'-TGCTTTTTCTTGGGCTGTTC-3' \\
\hline 5'G3PDH & 5'-TGAAGGTCGGWGTSAACGGATTTGG-3' \\
\hline 3'G3PDH & 5'-CATGTRGGCCATGAGGTCCACCAC-3' \\
\hline
\end{tabular}

Table.1 Primers for analysis of Rx expression.

\section{Whole-mount in situ hybridization}

Eyes were collected from adult CD-1 and FVB mice, washed once in PBS, and the lens dissected away. Retinas and the surrounding sclera and cornea were dissected from each other and fixed in $4 \%$ paraformaldehyde in PBS overnight at $+4^{\circ} \mathrm{C}$, dehydrated in $100 \%$ ethanol, and stored at $-20^{\circ} \mathrm{C}$ until processing.

In situ hybridization on whole retina and/or scleral/corneal fragments was done according to a previously published protocol (Cygan et al., 1997). After hybridization, retinal tissue was embedded in methacrylate resin (JB-4; Polysciences, PA, USA) or cryopreserved in 30\% sucrose in PBS and embedded in Tissue-Tek (Fisher Scientific, PA, USA). Sections of $14 \mu \mathrm{m}$ thickness were cut on either a Leica microtome or cryostat (Leica, Germany) and mounted on slides for analysis.

\section{$\underline{4 .}$ In situ hybridization on tissue sections}

Eyes were collected from adult 129SvJ/C57BL/6 hybrids, CD-1 and FVB stains and fixed overnight at $4^{\circ} \mathrm{C}$ in $4 \%$ paraformaldehyde in PBS. Eyes were cryoprotected as above and sectioned at $14 \mu \mathrm{m}$ on a Leica cryostat (Leica, Germany). In situ hybridizations on sections were performed according to a previously published protocol (Conlon and Rossant, 1992), with minor modifications. 


\section{Results}

\section{Rx gene expression in adult eyes}

To examine murine and human Rx expression in a panel of adult tissues, we used a reverse transcriptase-polymerase chain reaction (RT-PCR) approach. Primers for RTPCR span intron 1 of the Rx gene, allowing distinction between genomic and cDNA bands. To avoid potential amplification of other homeobox genes, primers were designed to anneal to non-conserved regions of the Rx gene (Fig. 6A). Rx transcripts were detected in the mouse eye (Fig.6B top panel) and human retina (Fig. 6C top panel) samples. Rxspecific signal was not observed in the other tissues tested, including the whole brain samples. Control amplifications using G3PDH primers on these the same tissue panels shows uniform expression in all examined samples. (Fig. 6B and $\mathrm{C}$, bottom panels). These data indicate that the differential expression observed in the retina/eye samples results from the selective accumulation of $\mathrm{Rx} / \mathrm{RX} \mathrm{RNA}$ in these samples.

\section{Localization of $\mathrm{Rx}$ transcript in the retina}

In situ hybridization was performed on mouse retinas to identify the localization of $\mathrm{Rx}$ transcript. Antisense and sense RNA probes were synthesized from a 3'-RACE cDNA clone (Mathers et al, 1997) encompassing exon 3 and the 3'untranslated region of the mouse Rx gene and used for expression profile studies. Strong Rx expression was detected exclusively in the adult photoreceptor and inner nuclear layers (Fig. 7A). Abundant expression was also observed in the ciliary body of the adult mouse eye (Fig. 7D).

These results were consistent for all three mouse strains tested, with the exception of the photoreceptor layer staining in the FVB strain. This strain is known to carry the $\mathrm{rd}^{1}$ mutation, and as expected, the photoreceptor layer in adults has degenerated. However, Rx gene expression in the inner nuclear layer and the ciliary body remains at roughly normal levels in this strain (Fig. 7B and E). 
A

Exon I $\quad$ Exon II

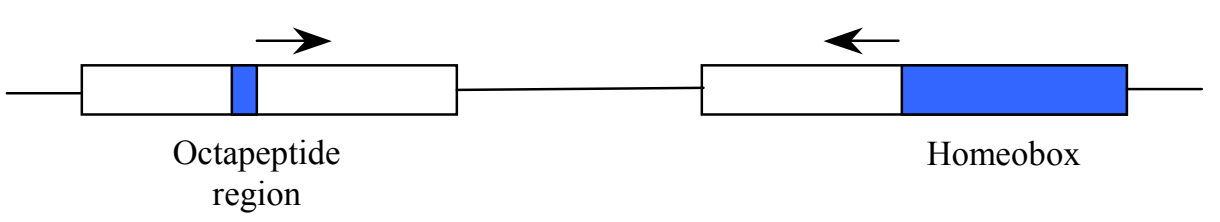

B

C
$\begin{array}{llllllllllll}1 & 2 & 3 & 4 & 5 & 6 & 7 & 8 & 9 & 10 & 11 & 12\end{array}$
$\begin{array}{llllllllllll}1 & 2 & 3 & 4 & 5 & 6 & 7 & 8 & 9 & 10 & 11\end{array}$
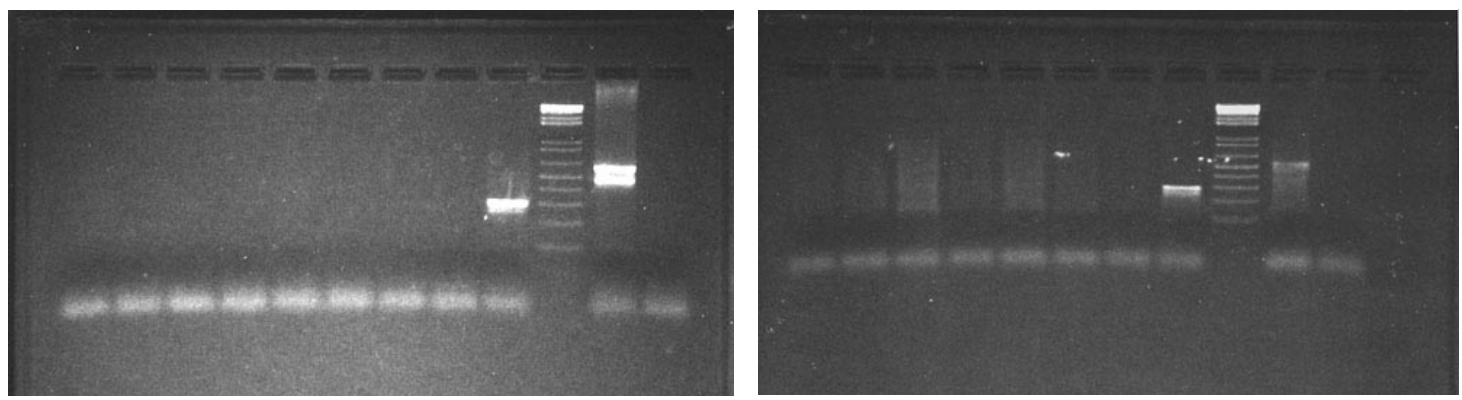

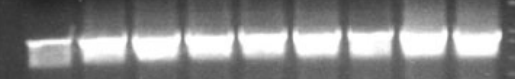

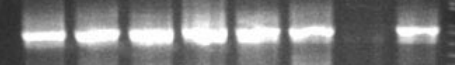

Fig.6 Rx gene expression in the adult mammalian tissues.

A. Primer pair used for the RT-PCR experiments

B. Upper panel: Rx expression in human tissues - brain (1), heart (2), kidney (3), liver (4), lung (5), pancreas (6), placenta (7), skeletal muscle (8), retina (9), $1 \mathrm{~kb}+$ ladder (10), genomic DNA (11), "no DNA" control (12).

Lower panel: G3PDH control expression in the same human tissues.

C. Upper panel: Rx expression in mouse tissues - brain (1), heart (2), kidney (3), liver (4), lung (5), skeletal muscle (6), spleen (7), eye (8), 1kb+ ladder (9), genomic DNA (10), "no DNA" control (11).

Lower panel: G3PDH control expression in the same mouse tissues. 

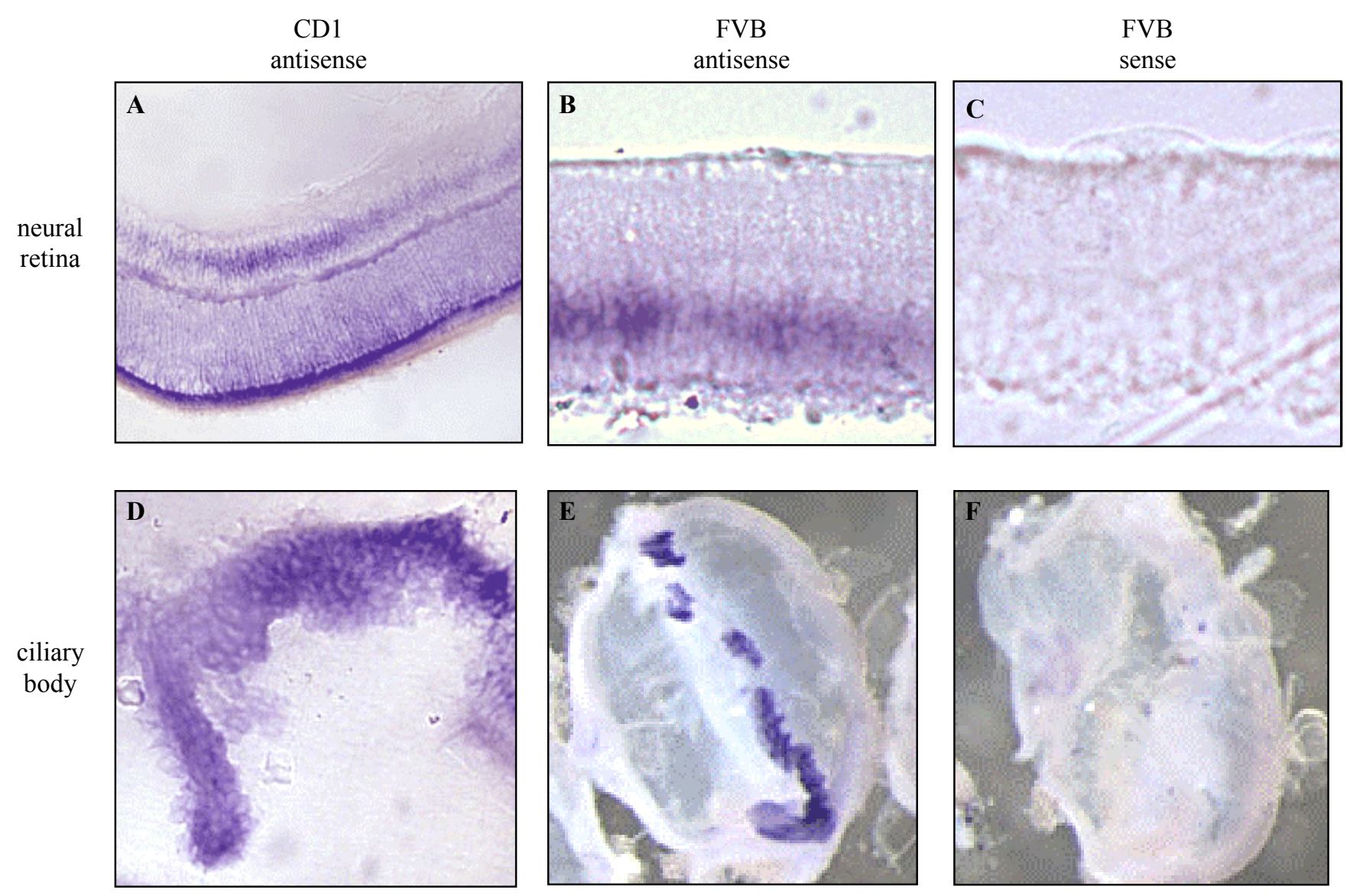

Fig.7 Localization of Rx expression in the adult mouse eye In situ hybridizations were performed on whole retinas and ciliary bodies of CD1 and FVB mouse strains. Tissues were later sectioned (A-D) or photographed as is (E-F). Sources of tissues and probes were used as indicated, ciliary body is attached to sclera on panels E-F. 


\section{Developmental dynamics of mouse Rx expression}

The zebrafish members of the $\operatorname{Rx}$ gene family (Zrx 1, 2, and 3) are activated during early embryogenesis in the presumptive retinal cells, but are subsequently downregulated in the neural retina at the onset of differentiation. The only remaining area of Zrx expression during this interim phase is in the germinal zone at the ciliary margin, where proliferating retinal stem cells are located. Once photoreceptors start to differentiate, $\mathrm{Zrx} 1$ and 2 expression is reactivated in the outer nuclear layer in cones, while $\mathrm{Zrx} 3$ is activated again in the inner nuclear layer (Chuang et al., 1999). Given the conflicting data on mammalian Rx expression in the maturing and adult retina, we set up to determine if the mouse Rx gene may undergo a similar deactivation/reactivation process to that seen in zebrafish.

We used the RT-PCR approach described above to trace the dynamics of Rx expression in the maturing mouse eye. Eyes were collected weekly starting at birth and ending at postnatal week seven, and cDNA was prepared from these eyes for RT-PCR amplification of Rx sequence. Gel electrophoresis of these samples showed that the mouse Rx gene is continuously expressed in the eye throughout the postnatal period (Fig. $8 \mathrm{~A})$. These results could be explained by continual expression of the Rx gene in the neural retina throughout postnatal mouse development. Alternatively, if the mouse $\mathrm{Rx}$ expression pattern resembles that seen in zebrafish, the expression seen by RT-PCR could represent the onset of ciliary body expression. To test between these two possibilities, the contralateral eye to those used in the RT-PCR developmental dynamics experiments were sectioned and probed with $\mathrm{Rx}$ antisense probe, $\mathrm{Rx}$ sense probe was used as a negative control. Similar to the adult transcript, $\mathrm{Rx}$ is detected in the photoreceptor and inner nuclear layers of the maturing retina at all stages analyzed (Fig. 8B-E, and data not shown) as well as in the ciliary body (Fig.8 F-I, and data not shown). Therefore, we conclude that Rx is expressed continuously starting at E7.5 of mouse development and proceeding into the adult neural retina and ciliary body. 

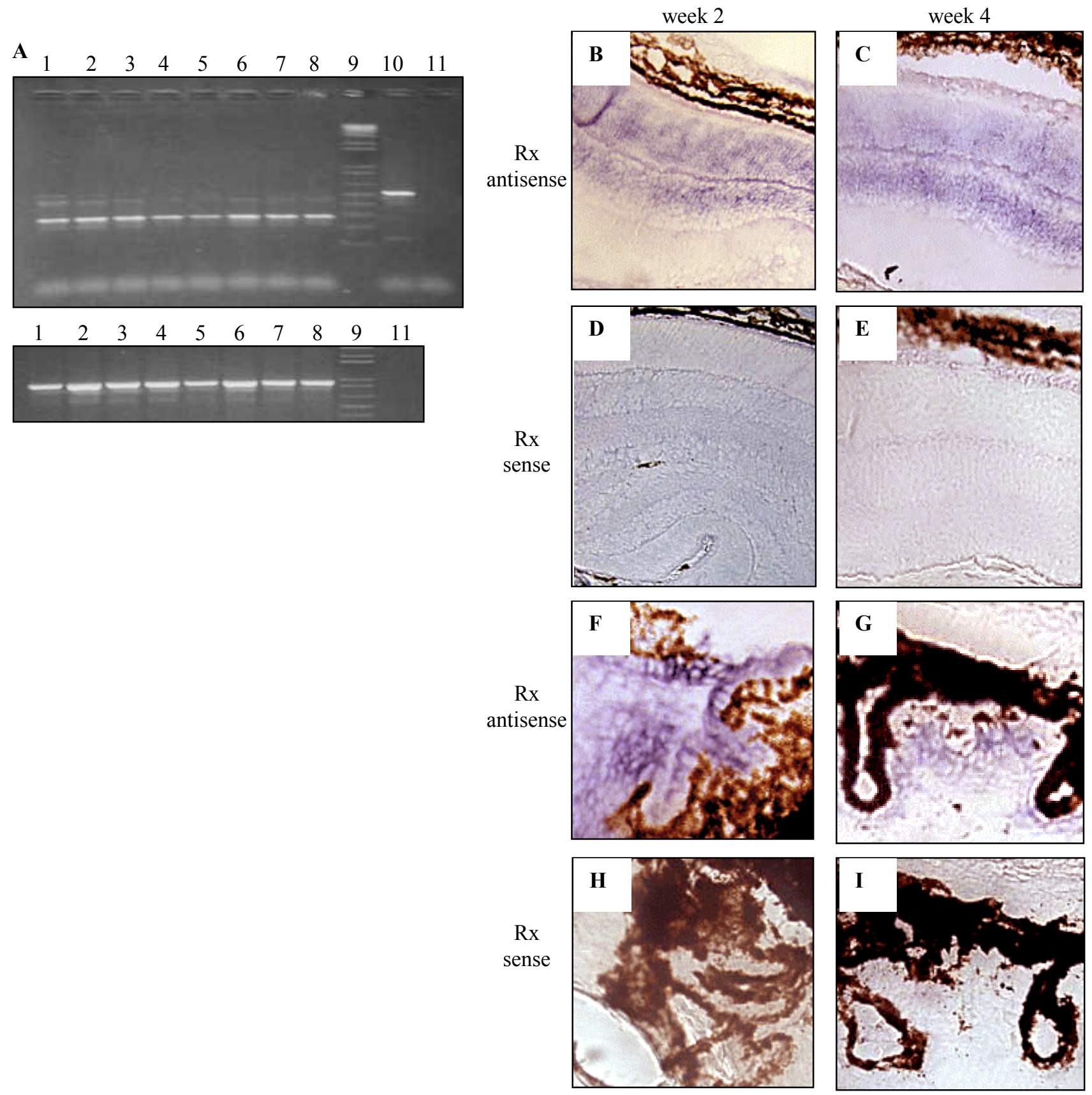

Fig.8 Dynamics of mouse Rx expression

A. Upper panel: mouse Rx gene expression during postnatal development: day of birth P0 (1), P7 (2), P14 (3), P21 (4), P28 (5), P35 (6), P42 (7), P49 (8), 1 kb+ ladder (9), genomic DNA (10), "no DNA" control (11).

Lower panel: G3PDH expression at the corresponding stages (genomic DNA control was not used).

B-I. In situ hybridization on sections. Panels B-E show mouse retinas, panels F-I show mouse ciliary bodies. Stages and probes were used as indicated. 


\section{Discussion}

In the present study we analyzed expression of the Rx gene in the mammalian eye at various postnatal stages and demonstrated that $\mathrm{Rx}$ is expressed in the neural retina, particularly in the photoreceptor and inner nuclear layers. We also observed high level expression of the Rx gene in the ciliary body from P14 through adulthood. Contrary to previous reports, no fluctuations of Rx gene expression were found in mouse eyes. $\mathrm{Rx}$ expression in the adult retina of mouse and human suggests dual roles for the Rx genes in both the development and maintenance of the visual system.

In early development, the Rx gene is critical for the initial steps of eye formation as demonstrated by the Rx expression pattern and phenotype of Rx null embryos, which fail to form optic pits. Initially, reduction of $\mathrm{Rx}$ expression in the eye was believed to coincide with the loss of mitotic activity of retinal progenitor cells. Our expression studies as well as in vitro experiments published by others (Kimura et al., 2000) show that $\mathrm{Rx}$ might play a distinct role in adult vision. The in vitro studies showed that $\mathrm{Rx}$ regulates expression of arrestin and IRBP (Kimura et al., 2000). These genes are expressed in photoreceptors, and their products are important for normal adult vision. Arrestin downregulates the phototransduction cascade through its interaction with photoactivated rhodopsin or cGMP-dependent phosphodiesterase, whereas IRBP shuttles retinoid between retinal pigment epithelium and the outer segment of photoreceptors. Upregulation of Hes1 and Notch1 promoters by Rx overexpression in newborn rat eyes also indicates a role for Rx distinct from retinal cell specification (Furukawa et al., 2000).

The finding of Rx expression in photoreceptors and inner nuclear layer cells is reminiscent of the combined expression pattern for the three zebrafish Rx genes, although the dynamics of mouse Rx expression is different. Zebrafish $\mathrm{Rx} 1 / 2$ are first expressed in the optic primordia where they become downregulated at the onset of retinal differentiation, although their expression persists in the ciliary marginal zone. As photoreceptors begin to differentiate, Zrx1/2 expression is upregulated in the photoreceptor layer and it is found only in the cone photoreceptors of the adult fish retina (Chuang et al., 1999). Zrx3 expression also starts in the lateral optic primordia, however, it quickly gets downregulated in the developing eye (Mathers et al., 1997). At the onset of 
neural retina differentiation, Zrx3 is upregulated in the inner nuclear layer of the adult fish (Chuang et al., 1999), presumably in differentiating Müller glial cells. We analyzed the dynamics of mouse Rx expression and found that Rx RNA accumulation persists in the photoreceptor and inner nuclear layer cells from birth to adulthood. Together with the identification of Rx-binding sites in a large number of retina-specific genes (Kikuchi et al., 1993; Kimura et al., 2000; Moritz et al., 2002) this might suggest that Rx is critical for driving restricted retina-specific gene expression. These data are also consistent with the recent findings of an Rx-related gene in chick, RaxL, that is capable of initiating photoreceptor differentiation (Chen and Cepko, 2002). Indeed, Rx may help to regulate multiple steps in retinal development ranging from the early requirements in initiation and proliferation of retinal stem cells to establishment of photoreceptor and Müller glial cell fate during retinal differentiation and the maintenance and biosynthetic function of these cells in adults.

In addition to its expression in the neural retina, mouse $\mathrm{Rx}$ transcripts are also found in the ciliary body of the mature eye, which is an analogue of the ciliary marginal zone in amphibians and fish. The level of Rx expression in the mouse ciliary body is qualitatively equal to or greater than that seen in the neural retina, making this a significant site of $\mathrm{Rx}$ expression in the adult. The ciliary marginal zone of amphibians and fish contains stem cells and serves as a source of retinal cell renewal in adults. Zebrafish and Xenopus $\mathrm{Rx} 1 / 2$ genes are also known to be expressed in the ciliary marginal zone (Casarosa et al., 1997; Mathers et al., 1997; Chuang et al., 1999).

It was recently demonstrated that, like those found in other vertebrates, mammalian ciliary bodies contain neural progenitor cells (Ahmad et al., 2000; Tropepe et al., 2000). These cells show a number of stem cell characteristics, such as self-renewal ability, expression of markers of uncommitted retinal progenitor cells, and the capability to differentiate into neuronal and glial cells and into retinal neurons (Ahmad et al., 2000). Thus expression of $\mathrm{Rx}$ in the mouse ciliary body points to a potential role of $\mathrm{Rx}$ in regeneration. To test this possibility, the mouse $\mathrm{Rx}$ gene could be inactivated in the ciliary body, then tissue explants from control and mutant mice would be compared by proliferation and marker analysis to test pluripotency of proliferating cells. Identification of progenitor cells in the mammalian ciliary body opens a possibility for stem cell 
therapy and Rx may be one of the factors necessary for maintenance of the pluripotent state of these stem cells, as appears to be its role during early development (Casarosa et al., 2003).

Although we did not observe strong Rx expression when analyzing whole brain samples by RT-PCR, we detected Rx transcripts during analysis of cDNA samples collected from various parts of the mouse brain (data not shown; OriGene Technologies, MD, USA). Our RT-PCR analysis on subsets of adult brain is consistent with results of Asbreuk and colleagues (Asbreuk et al., 2002). They recently showed that Rx is expressed in the adult forebrain, particularly in the posterior pituitary, the pineal gland and the lining of the third ventricle, which is very similar to the medaka $\mathrm{Rx} 3$ expression pattern (Deschet et al., 1999). Given the restricted expression domains of the Rx gene in the adult brain, it is not surprising that our whole brain cDNA samples were not sensitive enough to detect Rx gene expression there.

In this study we have demonstrated that human and mouse $\mathrm{Rx}$ genes are expressed in the adult retina. Transcripts of the mouse $\mathrm{Rx}$ gene are abundant in the neural retina and ciliary body from birth and continuing into adults. Expression of the Rx gene in retinal neurons suggests that this transcription factor might be responsible for the restricted expression pattern of many retina-specific genes, while expression of Rx in the ciliary body might indicate its role in maintenance of proliferative potential of progenitor cells identified in this region. The expression patterns of the human and mouse Rx genes in the eye demonstrate striking similarity thus supporting the use of mouse models for functional studies of Rx in the adult eye and brain. A role for the Rx gene in the adult photoreceptors and ciliary body might be tested by utilizing a conditional gene inactivation approach that allows for deletion of functional gene product at a chosen stage and in a tissue of interest. 


\section{Chapter III.}

Mutations in the Human RX Homeobox Gene in a Patient with Anophthalmia and Sclerocornea

Vera A. Voronina, Elena A. Kozhemyakina, Christina M. O'Kernick, Natan

D. Kahn, Sharon L. Wenger, John V. Linberg, Adele S. Schneider, and Peter H. Mathers 


\section{A. Introduction}

Microphthalmia, anophthalmia, and coloboma (MAC) represent a spectrum of structural eye malformations that result from developmental defects during ocular organogenesis at a rate of 1.9-3.5/10,000 live births (Campbell et al., 2002; Morrison et al., 2002). The combined occurrence rate for anophthalmia and microphthalmia alone is 1/10,000 births (Dolk et al., 1998). These conditions are genetically heterogeneous, with potentially overlapping phenotypes resulting from mutations in any of a number of genes and varying phenotypes resulting from mutations in a single gene. Several loci have been associated with syndromic and non-syndromic anophthalmia. Mutations in at least three genes, SOX2, PAX6, and SIX6, have been associated with anophthalmia (Hodgson and Saunders, 1980; Glaser et al., 1994; Gallardo et al., 1999; Fantes et al., 2003), though in the case of SIX6, deletion of 14q22.3-23 results in the loss of multiple genes. In addition, mutations in the $\mathrm{CHX} 10$ and $\mathrm{SHH}$ genes correlate with cases of microphthalmia (Ferda Percin et al., 2000; Schimmenti et al., 2003). Another related defect is septo-optic dysplasia, where mutations in the HESX1 gene have been implicated in its cause (Dattani et al., 1998; Thomas et al., 2001). Finally, mutations in the PAX2 and SHH genes have been found in patients with coloboma (Sanyanusin et al., 1995; Schimmenti et al., 1995). In each syndrome, mutations in any one gene represent fewer than $10 \%$ of the samples analyzed, suggesting that mutations in multiple genes are potentially responsible for the overlapping phenotypic effects seen in the MAC spectrum.

The Rx homeobox gene is one of the earliest factors expressed during retinal development and appears to direct the initial specification of retinal cell fate and/or the subsequent proliferation of retinal stem cells (Casarosa et al., 1997; Furukawa et al., 1997; Mathers et al., 1997; Andreazzoli et al., 1999; Chuang et al., 1999; Deschet et al., 1999; Furukawa et al., 2000; Zhang et al., 2000; Chuang and Raymond, 2001; Loosli et al., 2001; Tucker et al., 2001). We have previously demonstrated that the Rx homeobox gene (also known as Rax) is crucial for the proper formation of the optic vesicle during early mouse development and that deletion of $\mathrm{Rx}$ gene function in the mouse leads to nonviable anophthalmia (Mathers et al., 1997; Zhang et al., 2000). In addition, a mutation in the zebrafish Rx3 gene has been identified in the medaka fish eyeless mutant 
(Loosli et al., 2001) and a mutation in the Rx gene found in the mouse eyeless mutation associated with the ZRDCT strain (Chase and Chase, 1941; Tucker et al., 2001). The mouse mutant phenotype present in the Rx knockout and eyeless mutant strains correlates well with defects seen in some patients with anophthalmia (Bierich et al., 1991; Leichtman et al., 1994; Tucker et al., 1996). To examine whether mutations in the human RX gene are responsible for cases of anophthalmia, and/or microphthalmia, we performed a molecular characterization of the human RX locus and developed a screen for mutations in the RX protein-coding region. Using this screen, we identified a bilaterally affected proband with right anophthalmia and left sclerocornea associated with mutations in the RX gene. This individual carries a truncated RX allele (Q147X) that lacks the DNA-binding portion of the homeodomain, and a missense mutation (R192Q) in a highly conserved arginine within the DNA-recognition helix of the homeodomain. Both mutant alleles are inherited. Together with the mutation data in animal models of anophthalmia, these findings demonstrate a crucial role for the RX homeobox gene in human eye development. 


\section{B. Materials and Methods}

\section{Clinical Samples}

All work performed with human subjects received prior informed consent and/or assent, in compliance with the Institutional Review Boards of West Virginia University and Albert Einstein Medical Center. Buccal mucosa or saliva samples of individuals with anophthalmia and/or microphthalmia were obtained through the West Virginia University Department of Ophthalmology and the International Children's Anophthalmia Network (ican). Affected individuals were evaluated by their local ophthalmologist. Samples from 75 patients were screened for mutations in the human RX gene. Of these patients, 26 of them were bilaterally affected with anophthalmia, 11 had microphthalmia in both eyes, 7 were anophthalmic on one side and had an affected orbit on the other, 8 were anophthalmic on one side, and 23 were microphthalmic in only one eye. Saliva was collected from a group of 55 normal, ethnically matched, individuals as controls.

The proband is a 12-year old male born to non-consanguinous parents. Shortly after birth the patient's eyes were noted to be abnormal. Otherwise, the head was of normal shape and circumference was $38 \mathrm{~cm}\left(25^{\text {th }}\right.$ percentile $)$. On the right side, the eyelids were small and fused at the medial aspect (ankyloblepharon). There was no visible or palpable globe on the right side, although a conjunctival sac could be visualized. Ultrasound of the right orbit showed a very small, cystic remnant of a globe. The bony orbit was small on the right side. On the left side the eyelids were small, but normal in shape and contour. The globe was reported as small with sclerocornea, though axial length at two years measured $22 \mathrm{~mm}$ on CT scan. Ocular ultrasound showed persistent fetal vasculature (PHPV)(Goldberg, 1997) with a total retinal detachment. In addition to these ocular findings, EEG at seven years of age showed abnormal slowing of background activity consistent with underlying cortical abnormality, and the patient was diagnosed as autistic. However, a MRI of the brain was completely within normal limits.

\section{Isolation of human RX genomic clones}

Three independent human RX clones were isolated from a $\lambda$ phage genomic DNA library (Stratagene), using a human RX 5'-RACE cDNA clone as probe (Mathers et al., 
1997). Fragments containing these coding regions were subcloned and sequenced.

Alignment to the mouse Rx gene sequence was used to determine intron-exon junctions.

During this research project, a draft of the human genome sequence became available, confirming our sequencing results.

\section{Mutation screening}

DNA from buccal mucosa samples was purified using the MasterAmp ${ }^{\mathrm{TM}}$ Buccal Swab DNA Extraction kit (Epicentre Technologies, Madison, WI) according to the manufacturer's protocol. DNA from saliva samples was purified using a Blood Amp kit (Qiagen Inc., Valencia, CA). The RX coding region and flanking intronic sequences were PCR-amplified from genomic DNA in separate reactions for each of the three exons. The primers for exon 1 are 5'-GGGCGCCCGAACGGCCTC and 5'GCCTCTCCTCTCCGTCTCC. Primers for amplifying exon 2 are 5'GGAGTGCATCTGACCCTCC and 5'-TGGCTGCAATTTGGGCCTCG. Primers for amplifying exon 3 are 5'-GAGCTGAACCGGCTCAGG and 5'-

GGATCCCAAGACGTTCCCC. These same primers were also used for sequencing reactions, with the added internal primers 5'-AGCTGGCAGGCAGGCTCT and 5'GCTGGAGTCCTGGCTCG used for exon 3 because of its length. Each fragment was gel-purified and used for direct sequencing using the SequiTherm EXCEL II DNA sequencing kit (Epicentre Technologies, Madison, WI). Samples were analyzed by manual DNA sequencing. Anomalous bands were confirmed by resequencing both strands of the region in question. Mutations were also verified by restriction enzyme digestion. The Q147X mutation causes the loss of a Pvu II/MspA1 I site, while the R192Q mutation leads to the introduction of a novel MspA1 I site. For the Q147X mutation, RX exon 2 was amplified using 5'-TTTTGGGGAGTGCATCTGAC and 5'CTGTGCCTCTCCCTTGAGAC followed by purification and subsequent Pvu IIdigestion. For the R192Q mutation, RX exon 3 was amplified using 5'CCTCCGCTGCTGCCCGA and 5'-AGCTGGCAGGCAGGCTCT followed by purification and subsequent MspA1 I-digestion. In addition to these mutations, prevalent polymorphisms were identified in exon 1 at position 44 (D44E) and in exon 3 at position 294 (Q294Q). 


\section{Electrophoretic mobility shift assays}

Site-directed mutagenesis was used to create the Q147X and R192Q mutations in a RX cDNA clone (provided by Dr. T. Shinohara). These modified and the wild-type RX genes were subcloned into the pCMV-Tag2B plasmid vector (Stratagene, La Jolla, CA), which introduces a FLAG epitope tag at the amino-terminal end of the protein. Mutant and wild-type RX proteins were synthesized in a combined transcription-translation rabbit reticulocyte lysate (Promega Inc., Madison, WI). Unpurified lysates were used in electrophoretic mobility shift assays with the PCE I homeodomain recognition site, which has been shown to be a target for RX binding (Kimura et al., 2000). Equal loading of RXprogrammed lysate for DNA-binding assays was confirmed by Western blotting of lysates probed with anti-FLAG antibody (Stratagene, La Jolla, CA). Oligonucleotides of the PCE I binding site (5'-CAGAAGCTTTCAATTAGCTATT) and (5'CTGAATAGCTAATTGAAAGCTT) and the COUP-TF binding site (5'CAGCTTCTATGGTGTCAAAGGTCAAACTTCTG) and (5'CTGCAGAAGTTTGACCTTTGACACCATAGAAG) were used as specific and nonspecific RX binding site probes, respectively. Specificity of the mobility shift observed with RX binding to the PCE I site was confirmed by competing the shifted band away with increasing concentrations of unlabeled (cold) oligonucleotide in the binding assay. Cold oligonucleotides were added at 4-, 100-, and 1000-fold higher concentrations above the radioactive probe. The procedure for electrophoretic mobility shift assays followed that of Kimura et al. (Kimura et al., 2000), with minor modifications. 


\section{Results}

To test whether the RX gene has an important role in human ocular development and the conditions of anophthalmia and/or microphthalmia, we first isolated human genomic sequences encoding the RX gene. Three overlapping genomic clones were isolated, representing $\sim 22$ kilobases $(\mathrm{kb})$ from the RX locus. Three regions within the human $\mathrm{RX}$ locus cross-hybridized with mouse Rx cDNA clones. The sequence of these homologous regions revealed a protein-coding domain that is $86 \%$ identical to the predicted mouse $\mathrm{Rx}$ protein. The genomic structure of the human RX locus (Fig. 9A) is nearly identical to that found in mouse, including three coding exons and the position and relative size of the two introns. The putative functional domains, such as the octapeptide, homeodomain, nuclear localization signal, and the C-terminal (also called the OAR or paired-tail) domain, are $100 \%$ identical to the mouse protein sequence (Fig. 9B). The predicted protein sequence from the genomic clones is $99 \%$ identical to the previously characterized human RX cDNA sequence (Kimura et al., 2000), with a difference at amino acid 107 where glycine is found instead of tryptophan.

To determine whether mutations in the human RX gene are correlated with defects found within the MAC spectrum of disease, we screened 75 patients either unilaterally or bilaterally affected with anophthalmia and/or microphthalmia using PCR-based genomic sequencing of the three RX gene exons, along with the intron-exon borders. Two independent mutations were identified in a single proband within this patient population. The mutations were not observed in the control population of 55 individuals with normal eye development, whereas two prevalent polymorphisms (D44E and Q294Q) were detected in both patients and controls.

The single proband with RX gene mutations has clinical anophthalmia in the right orbit, with a retinal remnant observed at birth. The left eye has sclerocornea with persistent fetal vasculature and retinal detachment (Fig. 9C). A CT scan shows the extent of orbital defects (Fig. 9D). Sequence analysis from the DNA of the proband revealed a premature termination codon within exon 2 in one allele of the RX gene (Fig. 10A). The

patient carries a $\mathrm{C}>\mathrm{T}$ nonsense mutation, changing a conserved glutamine at position 147 to a stop codon $(\mathrm{Q} 147 \mathrm{X})$ and truncating the protein within helix 1 of the homeodomain. 


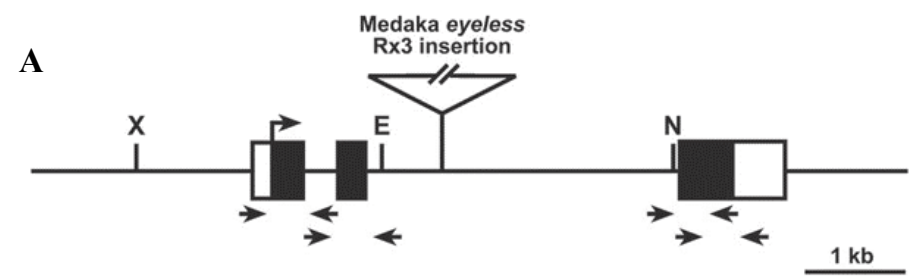

B
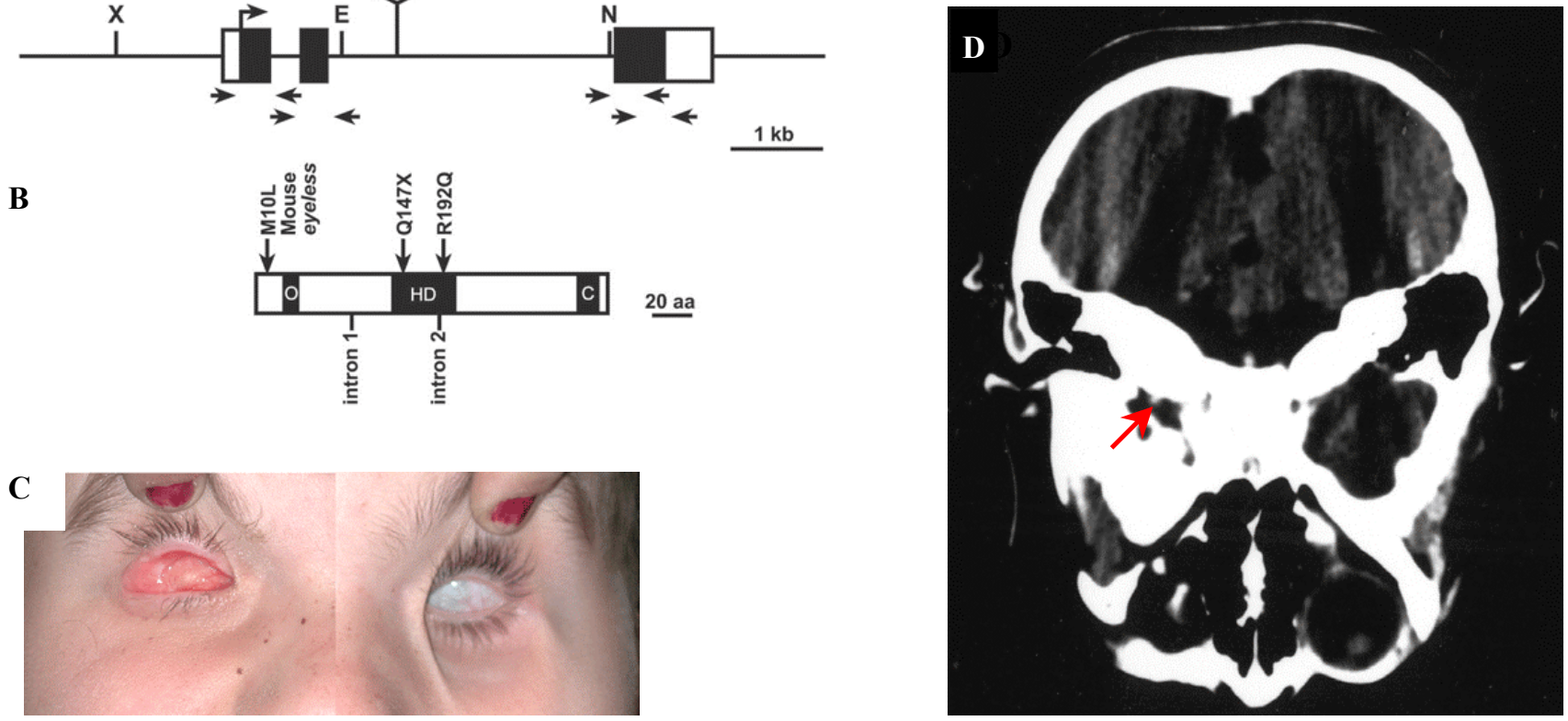

Fig.9 Position of RX locus mutations and ocular phenotype of proband

A. Schematic of the human RX locus containing three exons that code for the RX protein. The position of $\mathrm{a}>13 \mathrm{~kb}$ insertion in the $\mathrm{Rx} 3$ gene that is responsible for the medaka eyeless mutant (Loosli et al., 2001) is indicated in the homologous position of human RX intron 2. E=EcoRI, $\mathrm{N}=$ NotI, and $\mathrm{X}=\mathrm{XhoI}$.

B. Schematic of the RX protein with the position of the Q147X and R192Q mutations indicated, along with that of the M10L mutation that has been correlated with the mouse eyeless mutation in the ZRDCT strain (Tucker et al., 2001). Like other Rx/RX proteins, the human RX protein contains three highly conserved domains that are common in paired-like homeodomain proteinsthe octapeptide (O), the homeodomain (HD), and the C-terminal domain (C; also known as the OAR or paired-tail domain).

C. Orbits of proband, showing absence of ocular tissue OD (his right) and sclerocornea OS (his left). Note that the tissue seen in the right orbit is a dermal fat graft placed at two years of age.

D. CT scan of proband showing anophthalmic orbit (arrow). 
This nonsense mutation also destroys a Pvu II site, making this enzyme digestion a diagnostic screen for the mutation (Fig. 11B). This mutation eliminates helices 2 and 3 of the homeodomain, the nuclear localization signal, the Rx-domain and C-terminal domain from the truncated protein, and therefore, would be expected to eliminate RX function completely (see below). In addition, the premature termination codon makes the mRNA a potential target for degradation through the process of nonsense-mediated decay (Zhang et al., 1998). Genetic analysis of family members identified the father and paternal grandmother as heterozygous carriers of this allele (Fig. 10A, 11A and B). They both report normal ocular development and vision, suggesting that a single functional copy of the RX gene is sufficient to direct normal eye development, a finding consistent with our mouse Rx-mutation model (Mathers et al., 1997).

The proband was found to carry a second mutation within exon 3 on the other allele of the RX gene (Fig. 10B). The G>A missense mutation changes a highly conserved arginine at position 192 to glutamine (R192Q). Arginine 192 corresponds to amino acid 57 of the homeodomain, falling within DNA-recognition helix 3. A positively charged amino acid at this position is extremely well conserved, with $98 \%$ of homeodomain proteins carrying either arginine $(\mathrm{R})$ or lysine $(\mathrm{K})$. The crystal structure of the paired homeodomain reveals that R57 makes electrostatic contacts with the phosphate backbone of the DNA (Wilson et al., 1995), as does the analogous K57 of the Engrailed homeodomain (Kissinger et al., 1990). Genetic analysis revealed that the mother and maternal grandfather are heterozygous carriers of this allele (Fig. 10B, 11A and C). Both possess normal vision and ocular development, again suggesting that a single copy of the R192Q mutation over a normal RX allele is not sufficient to cause abnormal ocular development.

Based on the strong conservation of amino acid charge at amino acid 57 of the homeodomain and the interaction with the phosphate backbone and water molecules in the major groove of the DNA shown by crystal structure analysis, a change in the charge of this amino acid is postulated to reduce the DNA-binding affinity of the altered RX protein. Similar electrostatic changes at arginine 53 of the homeodomain in the CHX10 and HESX1 genes disrupt the DNA-binding activity of these proteins in microphthalmia and septo-optic dysplasia patients (Dattani et al., 1998; Ferda Percin et al., 
$\mathbf{A}$

Mother Patient Father Control

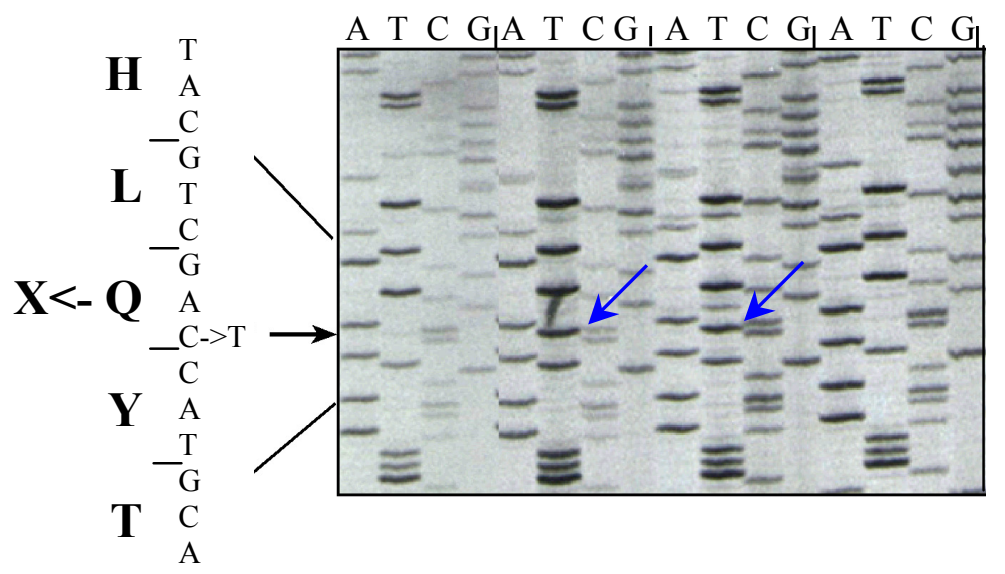

B

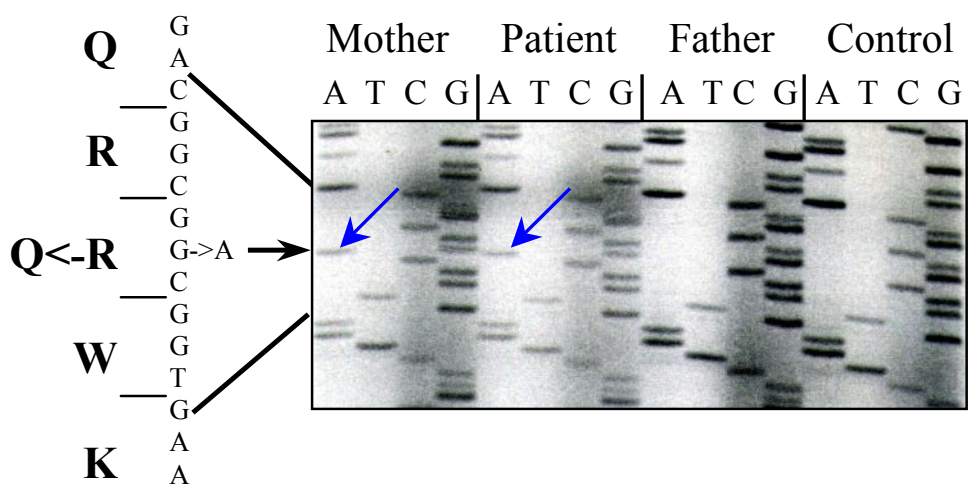

Fig.10 Sequencing analysis of proband and immediate family A. Mutation within exon 2 of Rx in the proband and his father B. Mutation within exon 3 of $\mathrm{Rx}$ in the proband and his mother 
A

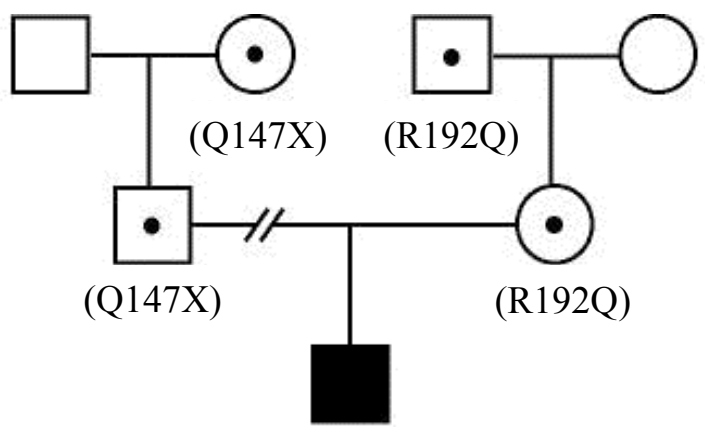

B

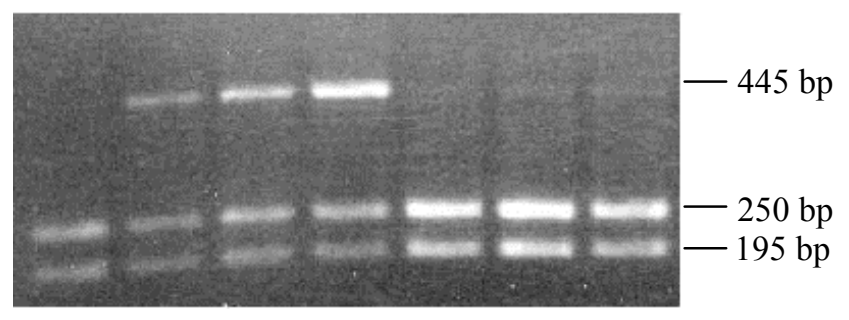

C

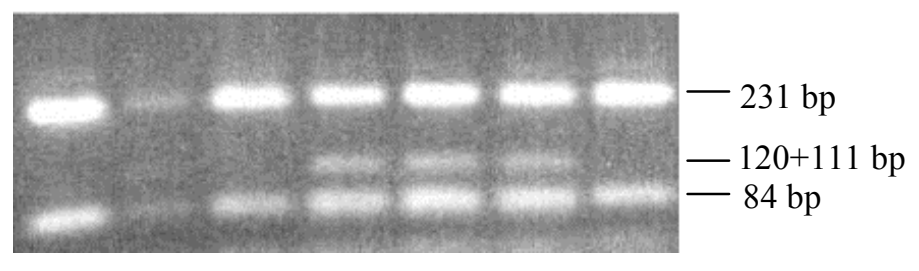

Fig.11 Pedigree and mutation detection in proband's family

A. Pedigree showing recessive inheritance pattern of Q147X (paternal lineage) and R192Q (maternal lineage) mutations. The proband is a compound heterozygote for the two mutations.

B. Pvu II-digestion of PCR-amplified exon 2 in the pedigree. The Q147X mutation causes the loss of the Pvu II site, (C>T)AGCTG. The uncut band is $445 \mathrm{bp}$, while Pvu II digestion cuts this band into 250 and $195 \mathrm{bp}$ bands. Note that each digestion sample is positioned under the appropriate individual in the pedigree shown in $a$.

C. MspA1 I-digestion of PCR-amplified exon 3 in the pedigree. The R192Q mutation introduces an MspA1 I site, $\mathrm{C}(\mathrm{C}>\mathrm{A}) \mathrm{GCGG}$. The normal pattern of MspA1 I digestion gives bands of 231 and $84 \mathrm{bp}$. The R192Q mutation causes the $231 \mathrm{bp}$ band to be cleaved into 111 and $120 \mathrm{bp}$ bands. 
al., 2000), and in a cataract-causing mutation of the bHLH protein, L-Maf (Lyon et al., 2003). In order to test the DNA-binding ability of the R192Q and Q147X mutations, wild-type and mutant RX proteins were synthesized in vitro and used in electrophoretic mobility shift assays (Fig. 12). As a probe for RX binding, we used radioactive oligonucleotides containing the photoreceptor conserved element as probe (PCE I or Ret1) (Kikuchi et al., 1993), which acts as a RX binding target (Kimura et al., 2000). Cold oligonucleotides (PCE I and the unrelated COUP-TF recognition site) were used to test the specificity of RX binding. We found that cold COUP-TF oligos failed to compete with RX protein for the PCE I probe while cold PCE I does compete with probe, showing that binding activity in RX-programmed lysates is specific for the PCE I binding site. When R192Q RX protein lysates are used in the binding assay, a ten-fold reduction in the amount of retarded probe is observed when compared to wild-type RX protein, suggesting that the R192Q mutation contributes to the phenotype of the proband by reducing the occupancy of RX binding sites (Fig. 12). As expected from the position of the truncation, Q147X RX protein fails to show any residual DNA-binding activity. 


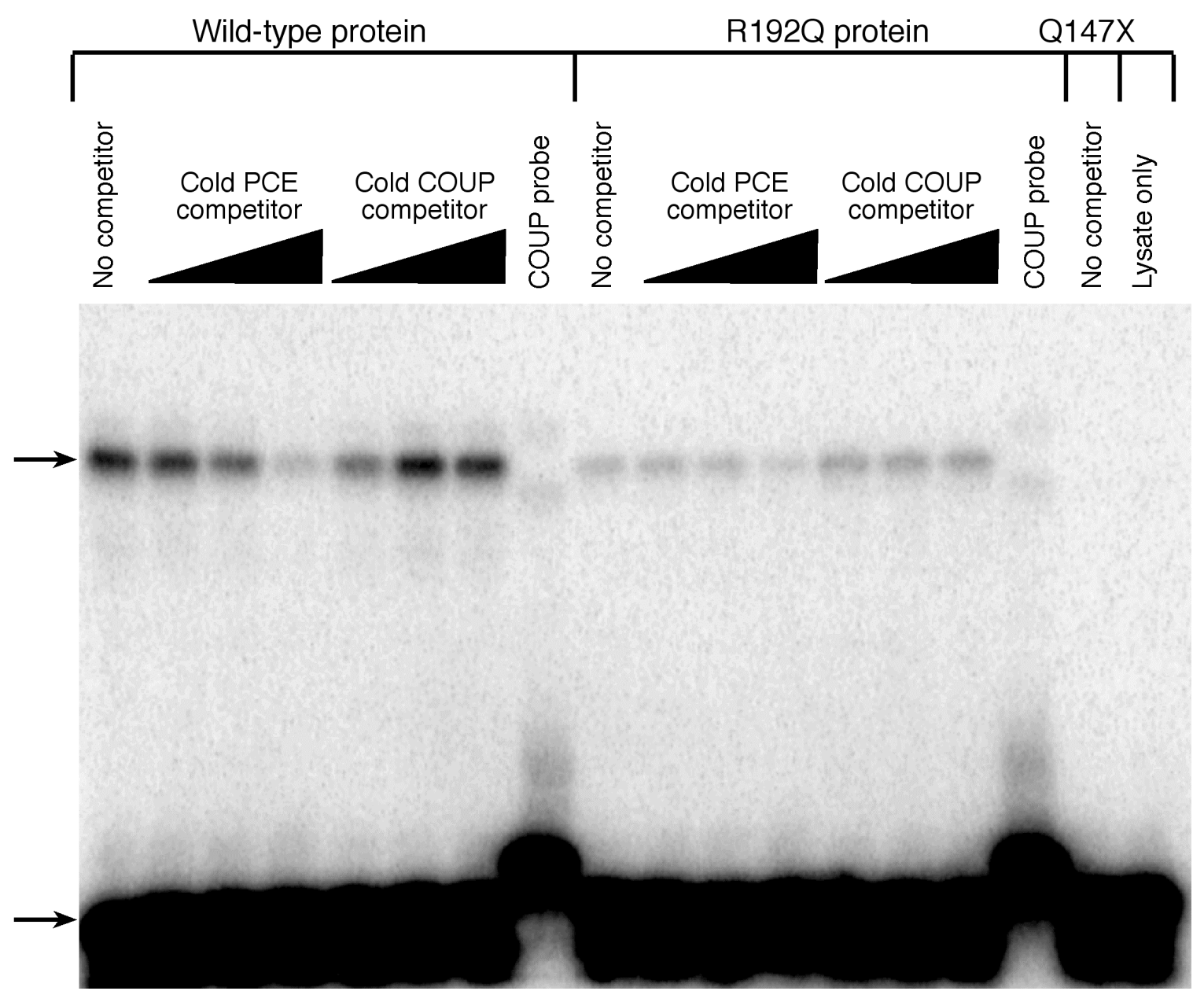

Fig.12 Electrophoretic mobility shift assay with normal and mutant RX proteins Lysates containing FLAG-tagged RX, R192Q RX and Q147X RX proteins were incubated with radioactively labeled oligonucleotides containing a RX-binding site (PCE I) or an unrelated binding site (COUP-TF). The specificity of RX binding was determined by competing the interaction with excess unlabeled oligonucleotides at 4-, 100-, and 1000-fold molar excess. Note that equal volume of lysate was loaded per lane, with equal concentrations of RX proteins confirmed by Western blot analysis using an anti-FLAG antibody (data not shown). The top arrow indicates probe retarded by protein binding and the bottom arrow indicates unbound probe. 


\section{Discussion}

Through our mutational screen of patients with anophthalmia and microphthalmia, we have identified RX gene mutations in the proband that were not found in the other 74 patients analyzed or in the 55 control samples. The proband is a compound heterozygote, with mutations in both alleles of the RX gene. This is consistent with the autosomal recessive inheritance seen in some familial cases of anophthalmia and microphthalmia (Sjogren, 1949; Warburg, 1981; Kohn et al., 1988). Given the similarity to the mouse Rx mutant phenotypes (Mathers et al., 1997; Tucker et al., 2001), we conclude that the net effect of these two mutations was sufficient to cause the anophthalmia/sclerocornea phenotype observed in the proband.

Multiple lines of evidence suggest that the $\mathrm{Rx} / \mathrm{Rax} / \mathrm{RX}$ genes function as transcriptional activators of retinal cell fate, and are able to bind the PCE I site, possibly in conjuction with Pax6 and other homeodomain proteins, to stimulate transcription (Mathers et al., 1997; Andreazzoli et al., 1999; Furukawa et al., 2000; Kimura et al., 2000; Chuang and Raymond, 2001; Mikkola et al., 2001). A complete loss of Rx function in mice blocks the earliest stages of ocular development, but also leads to organogenic defects in the ventral forebrain that presumably lead to the lethal phenotype of the null mice (Mathers et al., 1997; Zhang et al., 2000). Therefore, it is probable that the limited remaining DNA-binding activity of the R192Q RX protein is sufficient to allow for both the overall viability and partial ocular development observed in the proband.

The normal eye formation of the proband's family members and of mice heterozygous for RX gene mutations suggests that $50 \%$ of normal RX protein activity is sufficient to drive proper ocular development. The eyeless mutation in ZRDCT mice has been found to be caused in part by an M10L mutation in the Rx gene and that this mutation affects the overall level of Rx protein synthesis by disrupting a highly conserved, alternative start site for the Rx protein (Tucker et al., 2001). The defects associated with loss or reduction of Rx activity would suggest that a threshold limit of functional RX protein is necessary to stimulate and/or maintain ocular development. In the proband, the ten-fold reduction in DNA-binding activity from the R192Q RX protein, when coupled with the presumed loss-of-function Q147X allele, is apparently not 
sufficient to reach or maintain that threshold. Given that no gross morphological deficits are observed in the central nervous system of the proband compared to those seen in the development of ocular tissue, we conclude that the levels of RX protein are less crucial for initiation and proliferation of the ventral forebrain than for optic vesicle formation. This conclusion is consistent with our recent findings in the mouse Rx deletion model (E.A.K. and P.H.M., unpublished observations). Based on our current identification of RX gene mutations in a patient with anophthalmia and sclerocornea and published reports of Rx mutations leading to eyeless phenotypes in both mouse and medaka fish, we conclude that the RX/Rx gene family is crucial for the proper establishment of retinal cell fate and is required for optic vesicle formation in all vertebrates. 


\section{Chapter IV.}

\section{Conditional Inactivation of Rx Leads to Anophthalmia}

Vera A. Voronina, Serguei Kozlov, Catherine Wilson, Peter H. Mathers, and Mark Lewandoski 


\section{A. Introduction}

The initial events of eye formation occur within the early anterior neural plate, where a uniform field of stem cells is specified toward development of the future retina. As development proceeds, the retinal field is divided along the midline of the embryo, creating two independent retinal domains. The first morphologically visible stage of the retina development is a lateral protrusion of the telencephalon called the optic pit. The optic pits grow and become optic vesicles that contact the lens placodal ectoderm. This contact is critical for induction of lens differentiation and correct positioning of the eye (Grainger, 1992). Surface ectoderm thickens and forms a lens placode, which in turn evaginates to form the lens vesicle via closure of the external opening. This event is coupled with invagination of the optic vesicle that leads to formation of the optic cup around mouse embryonic day 10.5 (E10.5). The inner layer of the optic cup later develops into the neural retina, while the outer layer gives rise to the retinal pigmented epithelium (RPE). The "stem" connecting the optic cup to the brain narrows, elongates and becomes the optic stalk that provides the route for the projection of retinal ganglion cell (RGC) axons to the brain. The ventral parts of the optic cup and the optic stalk remain transiently open allowing axonal projection Afterwards the optic folds fuse and optic stalk cells differentiate into astrocytes that populate the body of the mature optic nerve. Finally, differentiation of retinal stem cells creates the individual cell types that comprise the pigment epithelium and the neural layers of the retina (Sidman, 1961; Adler and Hatlee, 1989; Adler, 1993).

Multiple anomalies in the establishment of eye architecture result in anophthalmia or microphthalmia - complete or partial loss of the ocular structures, respectively (Ashley et al., 1947), with combined prevalence rates for these conditions from 1.0 (Dolk et al., 1998) to 1.7-4.1 per 10,000 live births (Tucker et al., 1996). Anophthalmia and severe microphthalmia result in blindness or impaired vision and also require comprehensive medical care to prevent facial malformation in affected children. Incidences of anophthalmia/microphthalmia in vertebrates include Small eye (Sey) in mouse and rat (Matsuo et al., 1993; Hogan et al., 1986), and the mouse eyeless (Chase and Chase, 1941) and ocular retardation strains ( $o r$ and or $^{J}$ )(Theiler et al., 1976; Robb et al., 1978). 
Molecular analysis of Sey, eyeless, and $o r^{J}$ mutations corroborated by deciphering the developmental patterns of eye formation resulted in isolation of multiple genes regulating commitment, specification, differentiation and proliferation of retinal cells.

Among the genes that control proliferation are transcription factors, such as Six3 and Six6, that appear to function as transcriptional repressors that are required for eye formation. Fusion of zebrafish Six3.2 or Xenopus Six6 (Xoptx2) with a repressor domain of Drosophila Engrailed mimics Six3.2/Six6 overexpression data, which results in an increase of eye and brain territories (Kobayashi et al., 1998, 2001; Loosli et al., 1999; Zuber et al., 1999; Bernier et al., 2000). In contrast, Six3.2 or Six6 fusion with the activation domain of herpes simplex virus VP16 decreases the eye size (Zuber et al., 1999; Kobayashi et al., 2001). Six6 knockout mice are characterized by hypocellular retinas with all cell types present, reduced level of proliferation and upregulation of cyclin-dependent kinase (CDK) inhibitors in the retina. These data suggest a role of Six6 in regulation of the proliferation potential of retinal progenitor cells (Li et al., 2002).

Chx10 is another homeodomain factor that is involved in regulation of retinal cell proliferation. Chx 10 is expressed in the presumptive neural retina prior to the invagination of the optic vesicle into the optic cup (Liu et al., 1994). Mutations in human and mouse Chx10 are associated with microphthalmia, characterized by smaller that normal ocular structures (Burmeister et al., 1996; Ferda Percin et al., 2000). It is worth noticing that the hypocellular retinal phenotype of $\mathrm{Chx} 10$ mutant mice can be partially rescued by inactivation of $\mathrm{CDK}$ inhibitor Kip1/p27, providing a compensatory mechanism to restore the abnormally low cellularity of Chx10 deficient retinas (Green et al., 2003). In addition, misexpression of Chx 10 in retinal explants can increase the population of inner nuclear layer cells (Hatakeyama et al., 2001). These data strongly argue in favor of Chx10 implication in proliferation of the developing optic structures. Along with Six 3 and Six6, mitotic control imposed on retinal cells by Chx10 is particularly critical during the initial stages of eye formation when there is a rapid expansion of ocular structures.

Soon after its formation the optic vesicle acquires proximo-distal (P-D), dorso-ventral (D-V) and naso-temporal (N-T) polarity (for recent reviews see Chow and Lang, 2001; Peters, 2002). These polarities are critical for the topographic projections of the RGC to 
the superior colliculus in mammals or optic tectum in other vertebrates. Transplantation experiments reveal that spatially organized retinotectal projections are initially specified at the optic vesicle stage (Dutting and Meyer, 1995), and subsequently, the patterning fully determines the correct processing of visual input in the adult animal.

Specification of N-T polarity appears to happen prior to D-V patterning (Matsuno et al., 1992). Two winged-helix transcriptional factors Foxg1 and Foxg2 are restricted to the nasal and temporal retina and optic stalk respectively (Hatini et al., 1994). Misexpression of Foxg1 results in abnormal projection of temporal axons, whereas if Foxg2 is misexpressed nasal, but not temporal, axons make abnormal connections (Yuasa et al., 1996). In Foxg1 knockout mice ectopic expression of Foxg2 is found in the nasal retina, suggesting that Foxg1 normally downregulates Foxg2 in this region (Huh et al., 1999). These data indicate that Foxg1 and Foxg2 may determine N-T specificity of the retina and consequently specify the topographic projections of RGC axons.

The list of early markers of D-V patterning includes BMP4, Tbx5, Vax2 and Pax2. Tbx5 and BMP4 are critical for the development of the dorsal retina whereas Vax 2 and Pax2 determine ventral fate. Genetic evidence indicates extensive cross-regulation among these genes in the course of eye morphogenesis. Abrogation of Vax2 in mouse (Barbieri et al., 2002) and zebrafish (Take-Uchi et al., 2003) leads to a failure of optic fold fusion, known as coloboma, with no change in the expression pattern of Tbx5 and Pax2 (Barbieri et al., 2002; Take-Uchi et al., 2003). Additionally, Vax2 misexpression causes the ventralization of the retina and also abolishes the normal pattern of dorsal axon projection to the brain (Barbierri et al., 1999; Schulte et al., 1999). Overexpression of chicken Tbx5 leads to suppression of ventral markers (cVax and Pax2) and expansion of expression domains of late dorsal markers (Koshiba-Takeuchi et al., 2000), simultaneously affecting projection of ventral axons. BMP4 appears to activate Tbx5 and thus provides a dorsalizing activity (Koshiba-Takeuchi et al., 2000).

Pax2, Vax 1 and Pax6 are indispensable for P-D patterning of the eye and its partitioning to the optic cup and the optic stalk structures. Pax2 and Pax6 have complementary expression patterns in the developing eye with Pax 2 expressed in the optic stalk and proximal optic cup, and Pax6 expressed in the distal optic cup (Nornes et al., 1990; Grindley et al., 1995; Torres et al., 1996). Pax2 and Pax6 mutant mice 
demonstrate complementary phenotypes: Pax2 nulls form enlarged optic cups, lack glial cells that are originate from the optic stalk cells and also demonstrate expansion of the Pax6-positive retinal pigmented epithelium to the optic stalk region (Torres et al., 1996). In contrast, rudimentary visual organs of Pax6-deficient mice have the optic stalk morphology and show an expansion of the Pax 2 expression domain to optic cup (Schwarz et al., 2000). Demonstration of direct inhibition between Pax2 protein and the Pax6 enhancer and vice versa led to the proposal of a mechanism for segregation of the optic cup and the optic stalk based on reciprocal transcriptional repression of Pax 2 and Pax6 genes along the P-D axis (Schwarz et al., 2000). This repression appears to define the optic cup/optic stalk boundary as early as E9.5, before the development of the retinal pigmented epithelium (Schwarz et al., 2000). Vax 1 is another gene that has optic stalk specific expression (Ohsaki et al., 1999). Vax1 null mice form aberrant retinotectal projections, and similarly to Pax2 mutants develop optic nerve colobomas (Bertuzzi et al., 1999; Hallonet et al., 1999). Marker analysis of Vax1 mutant embryos indicates that Pax2 and Vax1 function independently (Hallonet et al., 1999), despite sharing a common upstream regulation by Six3 (Kobayashi et al., 1998; Carl et al., 2002).

$\mathrm{Rx}$ is one of the earliest genes essential for eye development, since Rx-null embryos do not form optic pits (Mathers et al., 1997). All newborns die within a few hours after birth and display anophthalmia as well as a variety of brain defects, that range from the complete absence of forebrain and severely affected midbrain to only mild neural defects (Mathers et al., 1997). In addition to its role at the optic pit stage, there is evidence that Rx plays a role later in eye development (Mathers et al., 1997; Jean et al., 1998; Andreazzoli et al., 1999). First, Rx is expressed throughout development of the optic tissue (Furukawa et al., 1997; Mathers et al., 1997) and later in the adult neural retina (Chuang and Raymond, 1997; Furukawa et al., 2000; Kimura et al., 2000) and forebrain (Deschet et al., 1999; Asbreuk et al., 2002), although the specific pattern of adult ocular expression of Rx is controversial (Chuang and Raymond, 1997; Furukawa et al., 2000; Kimura et al., 2000). Second, partial loss of the Rx function leads to viable anophthalmic/ microphthalmic phenotype in mouse (Tucker et al., 2001), eye formation is initiated normally in the eyeless mice, however, it arrests at the optic vesicle stage. Finally, Rx can upregulate expression of arrestin, interphotoreceptor binding protein (IRBP), Notch1 and 
Hes1 promoters (Furukawa et al., 2000; Kimura et al., 2000). Arrestin and IRBP are necessary for phototransduction, while Rx induced overexpression of Notch1 and Hes1 affects the composition of the postnatal retina, thus suggesting a role for Rx in eye maturation and the adult vision.

In the present study we show with a conditional gene targeting approach that Rx plays a role in eye development during the transition from the optic vesicle to the optic cup/optic stalk stage. Furthermore, we show that Rx is essential for the normal patterning of the optic cup and optic stalk in N-T, D-V and P-D directions. 


\section{B. Materials and Methods}

\section{Targeting of the Rx locus}

Genomic clones for the Rx locus were previously isolated (Mathers et al., 1997). The 5'-loxP site and neo ${ }^{\mathrm{R}}$ cassette flanked by FRT sites were inserted into a CelII restriction site located in intron 1 (Fig. 13A). The 3'-loxP site was introduced into a EcoRI restriction site in intron 2 . The 5'homology arm was $6.2 \mathrm{~kb}$ long and the 3 ' homology arm was $4.7 \mathrm{~kb}$ long. PGK-TK was inserted downstream of the 3' homology arm.

Electroporation and selection of W9.5 embryonic stem (ES) cells (strain 129SvJ, gift of Dr. Colin Stewart) were performed according to standard procedure. Homologous recombinants were identified at the 5' end by EcoRI digest of genomic DNA and Southern blotting. A $1 \mathrm{~kb}$ EcoRI/PstI genomic fragment upstream of the 5'homology arm was used as a probe (Fig. 13A, striped rectangle) to distinguish the wild-type (9.2 kb) from the targeted $\mathrm{Rx}^{\text {flneo }}(8 \mathrm{~kb}$ ) locus (Fig. 13B). To assay the 3' end of homologous recombinants genomic DNA was digested with BglII. A $1.05 \mathrm{~kb}$ EcoRI/BglII genomic fragment downstream of the 3' homology arm was used as a probe (Fig. 13A, dotted rectangle) to distinguish between the wild-type $(8.5 \mathrm{~kb})$ and the targeted $\mathrm{Rx}^{\text {flneo }}(7 \mathrm{~kb})$ locus (Fig. 13B). Genomic DNA of clones that showed correct targeting was analyzed by PCR to determine presence of the 3' loxP site using primers A (5'CGGAAAAACTCTCTTCCCTTG-3') and B (5'-ATCCCTACTGCCTGGAAATCC-3'; Fig. 13A). Positive clones were expanded for chromosome counting and blastocyst injections. Chimeras were crossed with C57/B16 albino mice.

\section{Breeding of mice to generate allelic series at the Rx locus}

Breeding of chimeras to $\mathrm{C} 57 / \mathrm{B} 16$ albino females generated $\mathrm{Rx}^{\text {flneo } /+}$ progeny that were used in multiple crosses:

1). $\mathrm{Rx}^{\text {flneo }} /+$ mice were intercrossed to produce $\mathrm{Rx}^{\text {flneo }} / \mathrm{Rx}^{\text {flneo }}$ offspring

2). $\mathrm{Rx}^{\text {flneo } /+}$ were mice crossed to $\mathrm{Rx}^{\Delta 1,2} /+$ to generate compound heterozygotes $\left(\mathrm{Rx}^{\text {flneo }} / \mathrm{Rx}^{\Delta 1,2}\right)$ 
3). $\mathrm{Rx}^{\text {flneo }} /+$ mice were crossed to $\beta$ actin-FLPe mice (Rodriguez et al., 2000) to remove neo $^{\mathrm{R}}$ cassette. This breeding generated $\mathrm{Rx}^{\text {flox }}$ progeny (Fig. 13A) that were crossed inter se to produce $\mathrm{Rx}^{\text {flox }}$ homozygotes.

4). $\mathrm{Rx}^{\text {flneo }} /+$ mice were crossed to $\beta$ actin-Cre mice (Lewandoski et al., 1997) to remove exon 2 of $\mathrm{Rx}$ generating the $\mathrm{Rx}^{\Delta 2}$ allele. $\mathrm{Rx}^{\Delta 2} /+$ offspring were interbred to generate $\mathrm{Rx}^{\Delta 2}$ homozygotes.

3. Mouse breeding to achieve conditional inactivation of $\mathrm{Rx}$

To inactivate $\mathrm{Rx}$ in the eye after formation of the optic pits we utilized Foxg1-Cre (Hebert and McConnell, 2000) and performed the following crosses:

ठFoxg1-Cre $\quad \mathrm{X} \bigodot_{\mathrm{Rx}^{\Delta 1,2} /+}$

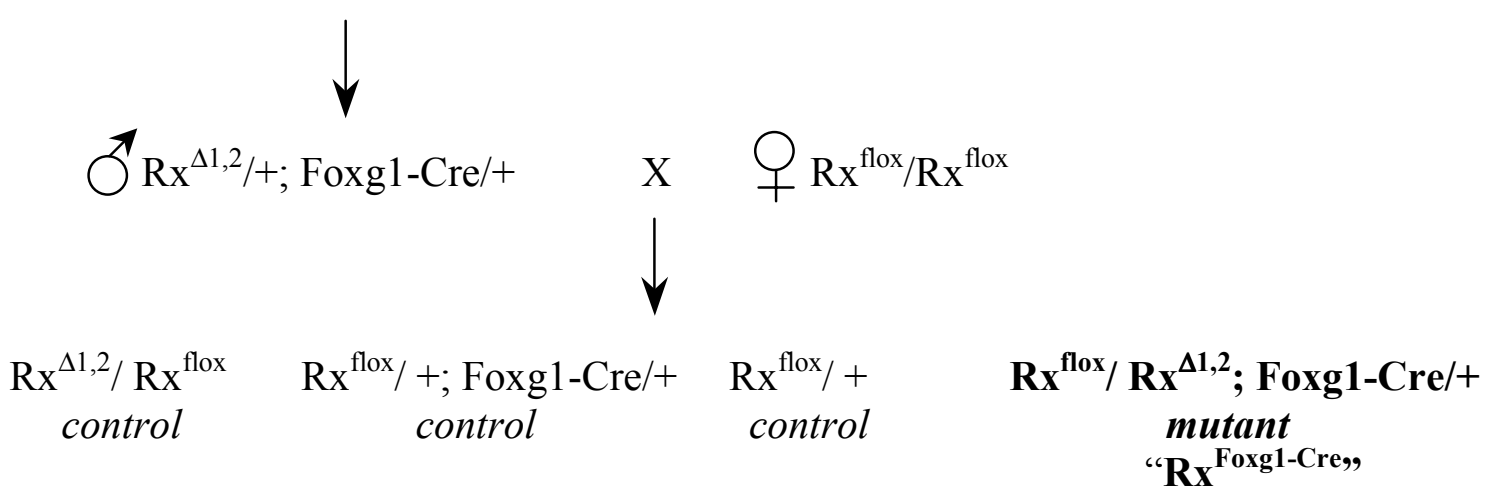

\section{Genotyping}

PCR genotyping for the targeted ( $\mathrm{Rx}^{\mathrm{flneo}}$ ) allele was performed with a 5' primer specific for neo ${ }^{\mathrm{R}}$ cassette, neo (5'-CAGCTCATTCCTCCCACTCATGATC-3'), and a 3' primer in exon 2, \#2 (5'-GGACGTGCTTCTCCTTGCTCCTTGG-3'), producing a 520 bp band. Genotyping of the conditional allele $\left(\mathrm{Rx}^{\text {flox }}\right)$ was carried out with the following Rx specific primers: \#1 (5'-AGGAGCTCCAGGAGCTCGAAAGAGC-3') and \#2 (5'GGACGTGCTTCTCCTTGCTCCTTGG-3'), that generate a 470 bp band for the Rx ${ }^{\text {flox }}$ allele and a $400 \mathrm{bp}$ band for the wild-type allele. The $\mathrm{Rx}$ null allele lacking exon $2\left(\mathrm{Rx}^{\Delta 2}\right)$ was detected by PCR with primers \#1 (5'-AGGAGCTCCAGGAGCTCGAAAGAGC-3') and \#3 (5'-CGAGTATCCCTACTGCCTGGAAATC-3'), producing a 265 bp band for the $\mathrm{Rx}^{\Delta 2}$ allele and a $1.3 \mathrm{~kb}$ band for the wild-type allele (detectable when $\mathrm{Rx}^{\Delta 2}$ allele is 
absent). Genotyping of the $\mathrm{Rx}$ null allele lacking both exon 1 and $2\left(\mathrm{Rx}^{\Delta 1,2}\right)$ was carried out with primers \#3 (5'-CGAGTATCCCTACTGCCTGGAAATC-3') and neo (5'CAGCTCATTCCTCCCACTCATGATC-3'), producing a $350 \mathrm{bp}$ band. Presence of Cre was detected by PCR with a generic Cre-specific primer pair, Crel (5'TGATGAGGTTCGCAAGAACC-3') and Cre2 (5'-CCATGAGTGAACGAACCTGG3') primers, resulting in a $400 \mathrm{bp}$ band. Transmission of the $\beta$ actin-FLPe transgene was analyzed with SD24 (5'- CTAATGTTGTGGGAAATTGGAGC-3') and SD25 (5'CTCGAGCATAACTTGTTTATTGC-3') primers, generating a 650 bp product. Conditional knock out mice were identified by the presence of Cre-specific, $\mathrm{Rx}^{\Delta 1,2}$ specific and $\mathrm{Rx}^{\text {flox }}$-specific PCR products. $\mathrm{Rx}^{\text {flneo }}$ homozygotes were identified by the presence of the $\mathrm{Rx}^{\text {flneo }}$-specific PCR product and absence of the wild-type product. Similar strategies were used to genotype $\mathrm{Rx}^{\Delta 2}$ and $\mathrm{Rx}^{\text {flox }}$ homozygotes, where the wild type allele was detected by the same PCR that determines presence of the $\mathrm{Rx}^{\text {flox }}$ allele.

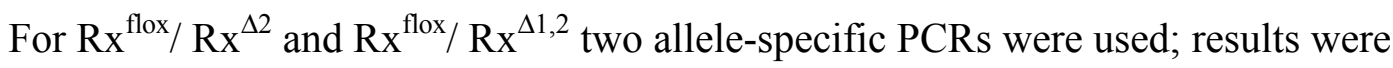
confirmed by PCR showing absence of the wild-type allele. In all embryos heart tissue was collected for genomic DNA isolation and genotyping. $1 \mathrm{~kb}$ Plus DNA ladder (Invitrogen, Ca, USA) was used for sizing DNA fragments.

\section{$\underline{\text { 5. Histologycal analysis }}$}

Newborn mice were decapitated, fixed for $24 \mathrm{hrs}$ in Bouin's fixative, transferred to $70 \%$ ethanol and used for paraffin sections. E9.5 and E10.5 embryos were processed as for in situ hybridization (4\% paraformaldehyde overnight at $+4^{\circ} \mathrm{C}$, followed by washes and dehydration), re-hydrated and used for embedding and sectioning. To study morphology of the eye, sections were stained with hematoxylin and eosin.

\section{In situ hybridization}

Whole mount in situ hybridizations were performed as previously described (Cygan et al., 1997) using digoxigenin labeled probes. For Rx-exon2 probe, a 320 bp DNA fragment containing the entire exon 2 was amplified from genomic DNA and cloned into pBluescript KS-vector. For 3'-Rx probe, a 3'-RACE clone that includes exon 3 and the 3' untranslated region was used (Mathers et al., 1997). 


\section{Results}

\section{Generation of an allelic series at the Rx locus}

Mice homozygous for a null allele of the Rx gene suffer from a variety of developmental defects of the anterior neural tube including the absence of optic pits (Mathers et al., 1997), which are normally evident at E8.75 as two ventrolateral evanginations of the prosencephalic neuroepithelium and are the earliest morphological indications of eye development. To analyze the role of $\mathrm{Rx}$ specifically in later stages of eye development we generated a mouse line carrying a conditional $\mathrm{Rx}$ allele $\left(\mathrm{Rx}^{\text {flneo }}\right)$ subject to Cre-mediated inactivation. Using conventional embryonic stem cell technology we flanked the second exon of Rx with loxP sites (Fig.13A). We anticipated that deletion of this exon would inactivate $\mathrm{Rx}$ as exon 2 includes the nuclear localization signal as well as the majority of the Rx homeobox. Moreover, as the number of nucleotides in exon 2 is not a multiple of three, Cre-mediated deletion of this exon results in a potential $\mathrm{Rx}$ transcript in which the coding region of exon 3 is frameshifted. The neomycin-resistance selection cassette $\left(\right.$ neo $^{\mathrm{R}}$ ) required for this targeting event was inserted into intron1 and flanked with FRT sites so that it could be deleted via FLPmediated recombination.

$\mathrm{Rx}^{\text {flneo }}$ homozygotes all died at birth, lacked eyes and displayed a range of brain and facial defects (Fig. 14A and data not shown). As these abnormalities resemble those displayed by mice homozygous for a $\mathrm{Rx}$ null allele which lacked exons 1 and $2\left(\mathrm{Rx}^{\Delta 1,2}\right.$, Mathers et al., 1997), we concluded that $\mathrm{Rx}^{\text {flneo }}$ allele was either a null or a severe hypomorph.

We hypothesized that the range of $\mathrm{Rx}^{\text {flneo }}$ homozygous phenotypes was due to the presence of neo ${ }^{\mathrm{R}}$, as is the case with similarly targeted loci (reviewed in Lewandoski, 2001), and that therefore its removal by FLP-mediated recombination would restore $\mathrm{Rx}$ activity to the targeted locus. Therefore we converted the $\mathrm{Rx}^{\text {flneo }}$ allele to the $\mathrm{Rx}^{\text {flox }}$ (Fig. $13 \mathrm{~A})$ allele in the offspring of $\mathrm{Rx}^{\text {flneo }}$ heterozygotes crossed to $\beta$ actin-FLPe mice (Rodriguez et al., 2000) and then generated $\mathrm{Rx}^{\text {flox }}$ homozygotes. $\mathrm{Rx}^{\text {flox }}$ homozygotes were apparently normal, fertile and had normal eyes (data not shown). To assess the activity of 


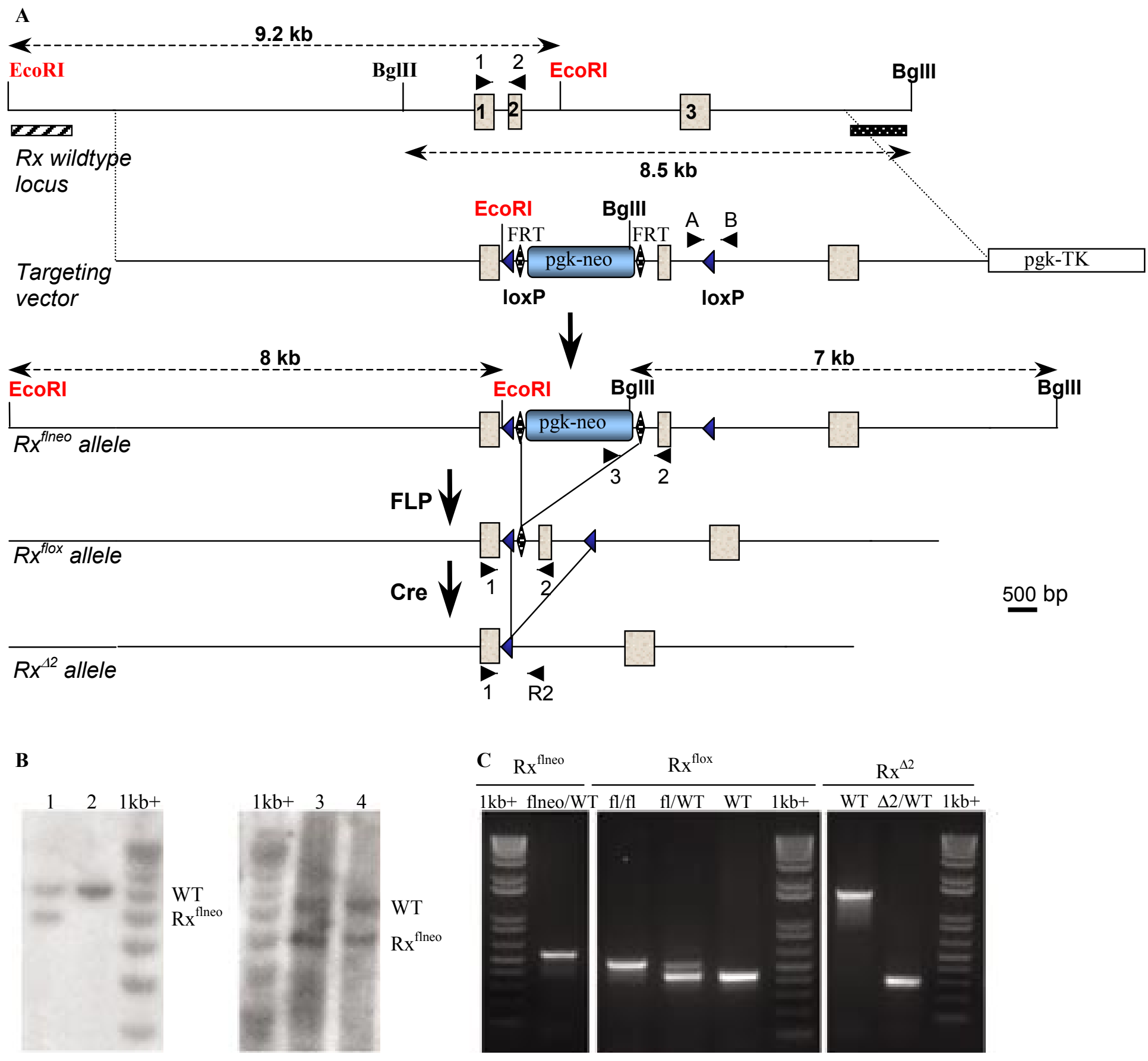

Fig. 13 Generation of allelic series at the Rx locus and recombination analysis

A. The wild-type locus, the targeting vector, the targeted allele of $\mathrm{Rx}\left(\mathrm{Rx}^{\text {flneo }}\right)$, targeted allele after FLPmediated recombination $\left(\mathrm{Rx}^{\text {flox }}\right)$, and targeted allele after Cre-mediated inactivation $\left(\mathrm{Rx}^{\Delta 2}\right)$. Grey boxes represent exons, blue triangles - loxP sites, diamonds - FRT sites. Arrowheads show primers used for genotyping as shown in panel C. Rectangles represent probes used for Southern blot analysis.

B. Southern analysis of genomic DNA isolated from ES cell lines. Left panel: EcoRI-digested ES cell DNA hybridized with the 5 ' probe. The $9.2 \mathrm{~kb}$ wild-type and $8 \mathrm{~kb}$ mutant bands are shown for Rx ${ }^{\text {fleeo }} / \mathrm{WT}$ (lane 1) and WT/WT (lane2). Right panel: BglII-digested ES cell DNA hybridized with the 3' probe produces $8.5 \mathrm{~kb}$ wild-type and $7 \mathrm{~kb}$ mutant bands for $\mathrm{Rx}{ }^{\text {flneo }} /$ WT samples (lanes 3 and 4 ).

C. PCRs used to genotype animals with modified Rx alleles. Left panel: $\mathrm{Rx}^{\text {flneo }}$ allele was amplified with primers 3 and 2, wild-type DNA does not produce a band. Middle panel: $\mathrm{Rx}^{\text {flox }}$ allele and wild-type $\mathrm{Rx}$ were detected with primers 1 and 2. Right panel: $\mathrm{Rx}^{\Delta 2}$ allele was amplified with primers 1 and $\mathrm{R} 2$, wildtype DNA produced $1.3 \mathrm{~kb}$ product when no $\mathrm{Rx}^{\Delta 2} \mathrm{DNA}$ was present. 
the $\mathrm{Rx}^{\text {flox }}$ allele in a high stringency test we crossed $\mathrm{Rx}^{\text {flox }}$ heterozygotes with $\mathrm{Rx}^{\Delta 1,2}$ heterozygotes (Mathers et al., 1997) to produce $\mathrm{Rx}^{\mathrm{flox}} / \mathrm{Rx}^{\Delta 1,2}$ compound heterozygotes in which all $\mathrm{Rx}$ activity is produced by the single $\mathrm{Rx}{ }^{\text {flox }}$ allele. These mice were also apparently normal and fertile and sections through the eye socket of newborn pups demonstrated that eye development proceeded normally (Fig. 14C). Thus, we concluded that FLP-mediated removal of neo ${ }^{\mathrm{R}}$ restored Rx activity to within normal levels.

We next determined if Cre-mediated recombination of exon 2 generated a null allele by crossing mice carrying the $\mathrm{Rx}^{\text {flox }}$ allele to $\beta$-actin-Cre animals (Lewandoski et al., 1997), thereby generating mice carrying the $\mathrm{Rx}^{\Delta 2}$ allele (Fig.13A). These mice were interbred to produce homozygotes, which died soon after birth, always lacked eyes and displayed the range of brain and facial defects (data not shown) that characterize Rx null mice (Mathers et al., 1997). Moreover, optic pits were absent in $\mathrm{Rx}^{\Delta 2}$ homozygotes although they were clearly evident at the normal embryonic stage in $\mathrm{Rx}^{\mathrm{flox}} / \mathrm{Rx}^{\Delta 1,2}$ compound heterozygotes (Fig. 15D and data not shown). Thus mice lacking Rx exon 2 display the same phenotype as previously reported for mice lacking Rx exons 1 and 2 and we conclude that Cre-mediated recombination of $\mathrm{Rx}^{\text {flox }}$ generates a null allele.

2. Foxg1-Cre mediated deletion of Rx arrests eye development prior to formation of the optic cup.

In Foxg1-Cre /+ mice, Cre-mediated recombination is reported to occur in the telencephalon, nasal neural retina and optic stalks due to the insertion of Cre coding sequences into the Foxg1 locus (Hebert and McConnell, 2000). To delete Rx after the optic pit stage of eye development in these Foxg1-expressing regions we developed a breeding scheme (see Materials and Methods) to generate Foxg1-Cre /+; $\mathrm{Rx}^{\mathrm{flox}} / \mathrm{Rx}^{\Delta 1,2}$

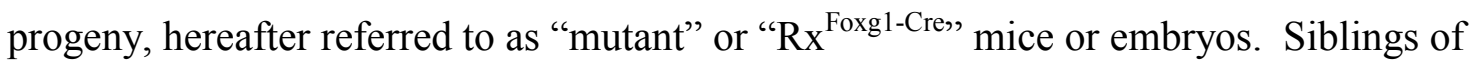
mutants in this genetic cross are of the $\mathrm{Rx}^{\text {flox }} / \mathrm{Rx}^{\Delta 1,2}$ or $\mathrm{Rx}^{\text {flox }} /+$ or Foxg1-Cre /+; $\mathrm{Rx}^{\text {flox }}$ I+ genotype (see Materials and Methods) and will be referred to as "control" embryos or mice.

The tissue specificity of Cre activity due to the Foxg1-Cre allele can vary with different genetic backgrounds (Hebert and McConnell, 2000). All Rx alleles are maintained on a mixed background of $129 \mathrm{SvJ} / \mathrm{C} 57 / \mathrm{B} 16$. Therefore we determined where 

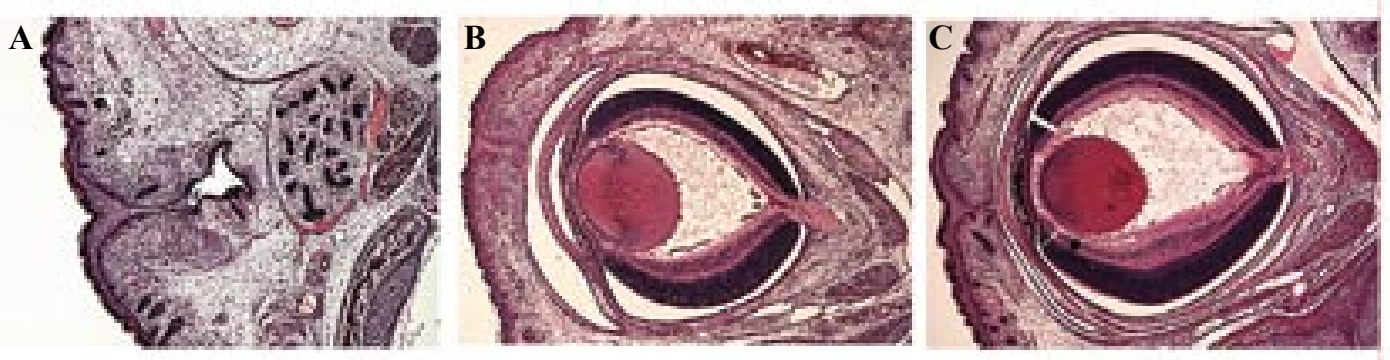

Fig. 14 Phenotype of mice carrying modified Rx alleles

Coronal sections through the heads of newborn pups stained with hematoxylin and eosin.
A. Eye socket of $\mathrm{Rx}^{\mathrm{flneo}} / \mathrm{R} \mathrm{x}^{\mathrm{flneo}}$ homozygous newborn.
B. Normal eye of the control littermate.
C. Normal eye of $\mathrm{Rx}^{\mathrm{flox}} /$ null newborn. 
deletion of Rx exon 2 occurred by whole mount in situ hybridization using a probe specific for Rx sequences deleted by Cre-mediated recombination (Rx-exon 2 probe). At $\mathrm{E} 8.5$, prior to embryonic turning, the normal pattern of $\mathrm{Rx}$ in the retinal field was slightly reduced in $\mathrm{Rx}^{\text {Foxgl-Cre }}$ embryos along the ventrolateral edges (Fig. 15A-B). Shortly after, at $\mathrm{E} 8.75$, the optic pits form in normal embryos (Fig. 15C) but not in $\mathrm{Rx}^{\Delta 2}$ homozygotes even as late as E9.0 (Fig. 15D). In Rx ${ }^{\text {Foxg1-Cre }}$ embryos optic pits form normally (Fig. $15 \mathrm{E})$, thus allowing eye development to proceed beyond the stage where it arrests in $\mathrm{Rx}$ null homozygotes. In situ hybridization with Rx-exon2 probe showed that Rx has been deleted along the anterior neuroepithelium of the optic pits where $\mathrm{Rx}$ is normally expressed (Fig. 15F-G), this region gives rise to the future nasal portion of the optic cup and the optic stalk.

By E9.5 continued outgrowth of the optic pit in normal development results in formation of the optic vesicle. Gross examination of mutant embryos as well as histological sectioning revealed that at this stage control and mutant embryos display very similar eye development (Fig. 15H-I). However, consistent with the pattern of Rx deletion during the optic pit stage, Rx-exon2-specific in situ hybridization demonstrated that Rx was deleted selectively in the nasal portion of the optic vesicle (Fig. 15J-K).

By E10.5 the distal portion of the optic vesicle has contacted the head surface ectoderm and induced lens placode formation and invagination of the distal optic vesicle (Fig. 15M), leading to a partition of the optic vesicle into two structures: the distal optic cup and the proximal optic stalk. At this stage two categories of mutants could be distinguished: the majority has an optic stalk and a "rudimentary" (not invaginated) optic cup (Fig. 15N) whereas a minority of mutants has degenerate optic vesicles with either hypoplastic or non-existing optic structures (data not shown). In both cases neither lens placode induction nor the concomitant invagination of the optic cup to form the pigmented and neural retina has occurred.

In control embryos by E10.5 Rx is expressed in the optic cup, particularly in the neural retina and is downregulated along the optic stalk (Fig. 15O). In E10.5 mutants that had a clear optic stalk and cup, no Rx-exon2-specific transcripts could be detected in the optic cup but are readily detected at abnormally high levels specifically in the temporal optic stalk. 


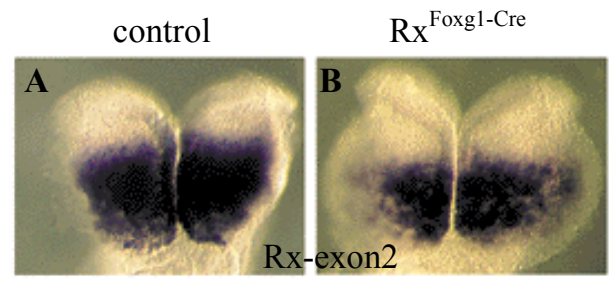

E8.75-

E9.0
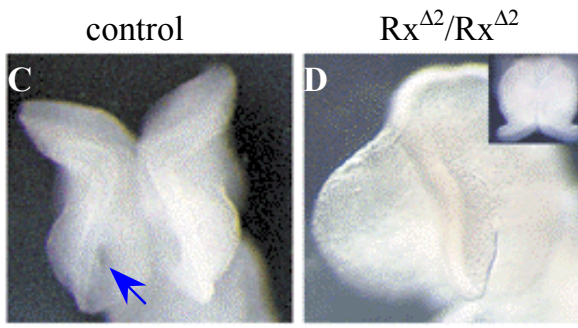

$\mathrm{Rx}^{\text {Foxg1-Cre }}$

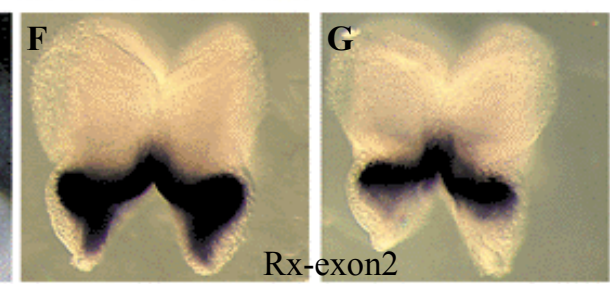

control

$\mathrm{Rx}^{\text {Foxg1-Cre }}$

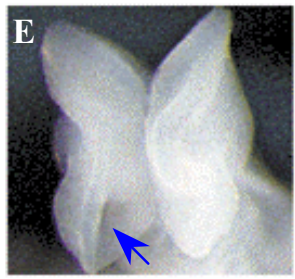

E9.5
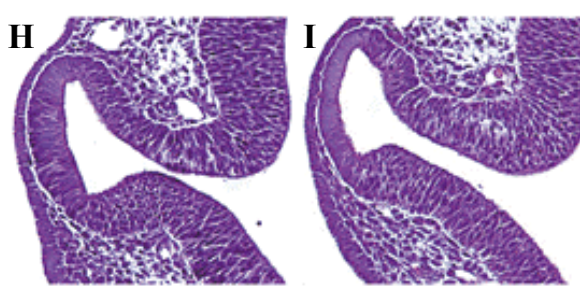

control

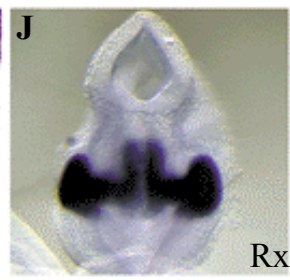

$\mathrm{Rx}^{\text {Foxg1-Cre }}$
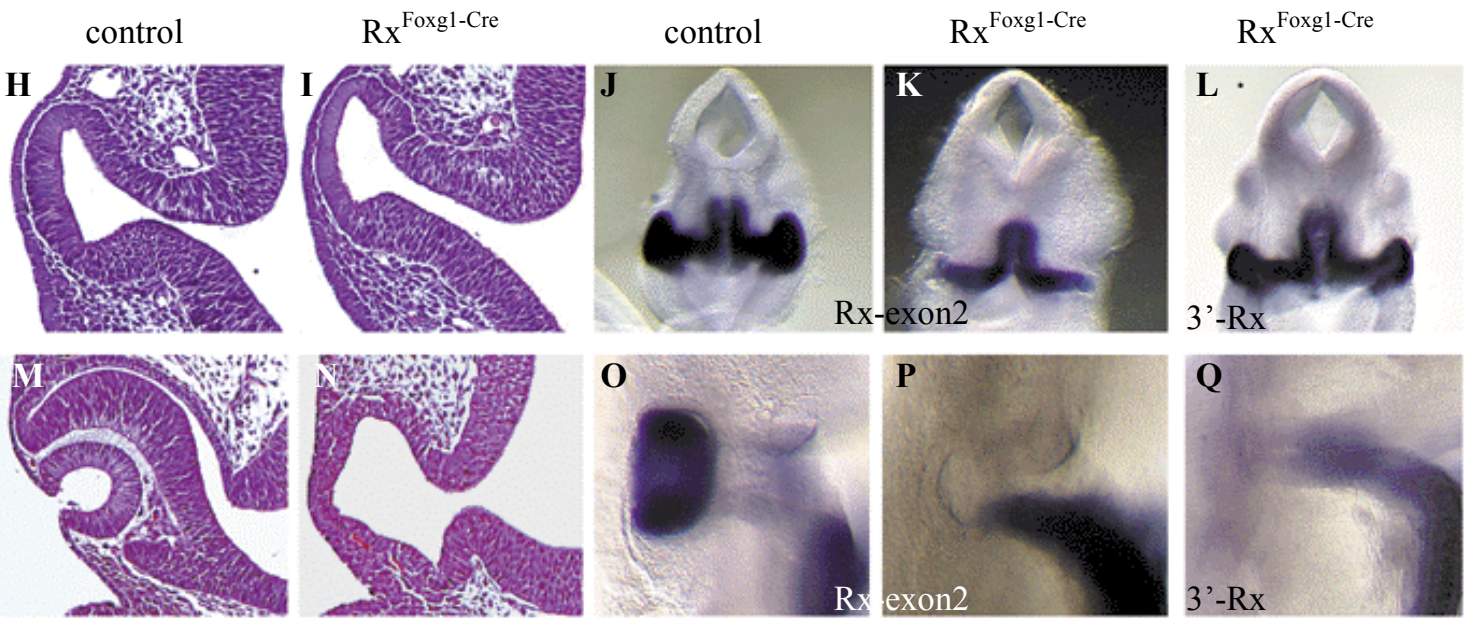

Fig.15 Eye development and dynamics of Cre-mediated excision in $\mathrm{Rx}^{\text {Foxgl-Cre }}$

Anterior view of E8.5 embryos (A,B) and frontal view of the E9.5 embryos (F,G) subjected to whole mount in situ hybridization with $\mathrm{Rx}$-exon 2 probe. $\mathrm{C}$ and $\mathrm{E}-$ frontal view of the control and $\mathrm{Rx}^{\text {Foxg1- }}$ Cre embryos show normal formation of optic pits (arrow), while $\mathrm{Rx}^{\Delta 2} / \mathrm{Rx}^{\Delta 2}$ do not develop optic pits even half a day later (D -frontal view, insert - view from the top). H-I and M-N show frontal sections of embryo heads stained with hematoxilin and eosin. J-L - dorsal view of E9.5 day embryos hybridized with indicated probes. O-Q - following whole mount in situ hybridization with indicated probes heads of E10.5 embryos were dissected to reveal the developing eyes and photographed with nasal side at the top. 
The absence of Rx-exon 2-containing transcripts at E10.5 could be due to Cremediated deletion of exon 2 or due to the lack of Rx transcription as a result of abnormal development of optic structure. To distinguish between these possibilities, we also performed in situ hybridization on mutants and control embryos using an Rx-3' probe outside the region deleted by Cre-mediated recombination (see Materials and Methods). 3'-specific Rx transcripts were detected in a normal pattern at E9.5 (Fig. 15L) but at E10.5 no Rx transcripts were detected in the mutant optic cup but were detected in both nasal and temporal portions of the optic stalk (Fig. 15Q).

From these data we conclude that in $\mathrm{Rx}^{\text {Foxgl-Cre }}$ embryos $\mathrm{Rx}$ is not expressed in the anterior or nasal portion of the mutant visual organ from E8.75 - 9.5 due to Cre-mediated recombination. However, by E10.5 Rx expression was unexpectedly absent from the mutant optic cup but upregulated throughout the optic stalk. The Rx transcripts present in the temporal portion of the optic stalk contain exon 2 and presumably generate a wild type Rx protein whereas those present in the nasal portion are nonfunctional due to Cremediated deletion of exon 2. Thus the expression of $\mathrm{Rx}$ in mutant embryos is a function of both Cre-mediated recombination and aberrant Rx transcription due to the mutant phenotype.

Histological examination of E11.5 embryos and morphological analysis of E13.5 embryos reveal that mutant visual organs are completely absent in nearly all mutants (data not shown). In the marker analysis described below we thus limited our analyses to E $9.5-$ E10.5 as it is during this stage that eye development is affected in $\mathrm{Rx}^{\text {Foxgl-Cre }}$ embryos and utilized only the majority of E10.5 mutants that contained obvious optic cups/stalks.

\section{Adult phenotype of Rx-mutants}

Because of the tissue-specific loss of Rx we hypothesized that the mutant phenotype would be restricted to optic structures and, unlike Rx null homozygotes, mutant mice would have normal neural development except for a possible lack of eyes (anophthalmia). This is indeed the case, as mutant mice were born at expected Mendelian frequencies but were found anophthalmic (Fig. 16A \& C). A gross examination of mutant brains indicated apparently normal neural development; however, as a consequence of 

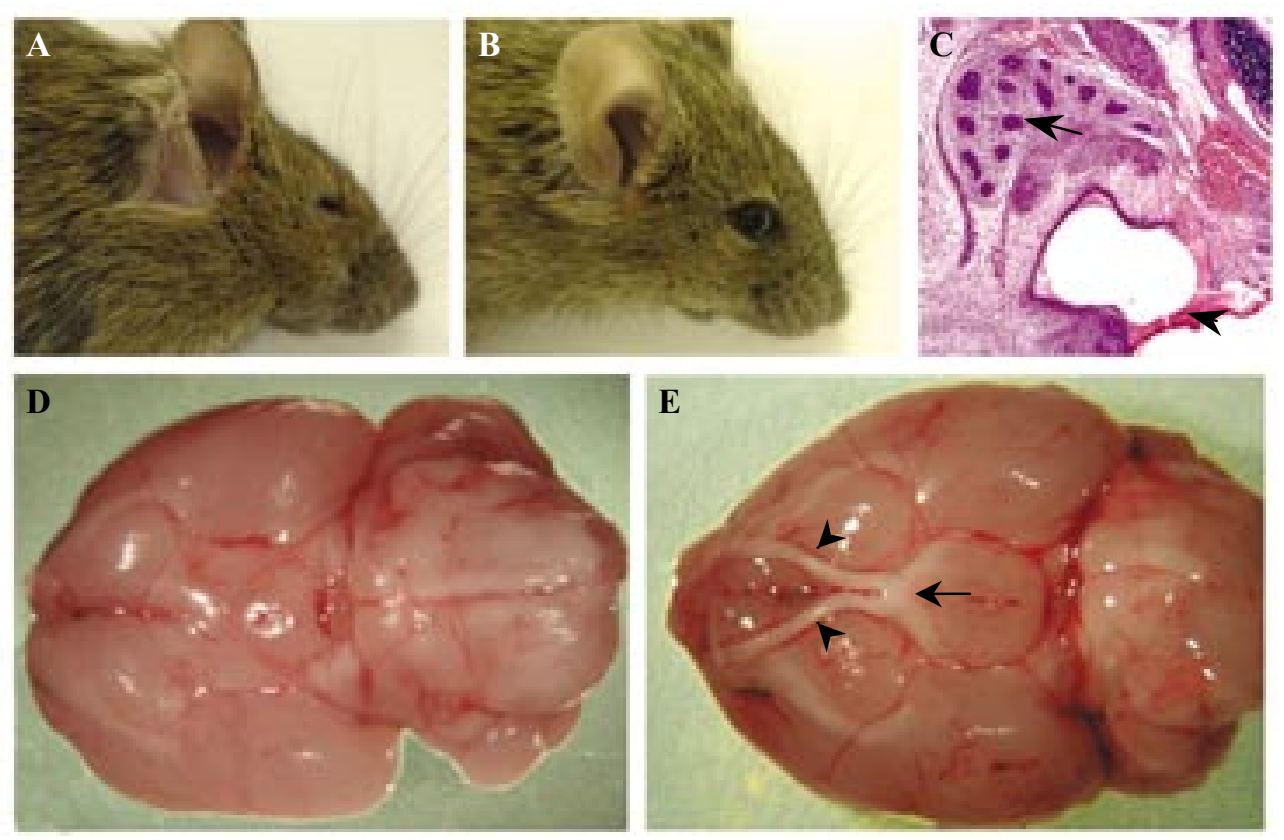

Fig. 16 Phenotype of the adult $\mathrm{Rx}{ }^{\text {Foxgl-Cre }}$ mice

A. Adult $\mathrm{Rx}^{\text {Foxg1-Cre }}$ mouse

B. Normal littermate

C. Frontal section of the eye socket of the newborn $\mathrm{Rx}^{\text {Foxg1-Cre }}$ mouse, section was stained with hematoxylin and eosin. Eye lids are indicated by an arrowhead, Harderian gland - by an arrow

D. Ventral view of the brain of the adult $\mathrm{Rx}^{\text {Foxg1-Cre }}$ mouse lacking optic nerves and the optic chiasm

E. Ventral view of the brain of a control littermate showing optic nerves (arrowheads) and the optic chiasm (arrow) 
absent ocular tissue, no optic nerves or optic chiasm were found on gross examination of the brain (Fig.16D).

\section{Proliferation of OV cells is affected in Rx-Foxg1 mutants.}

Progressive rapid loss of optic vesicle tissue can be explained by a decrease in proliferation. To test this possibility we examined the expression domains of Six3, Six6 and $\mathrm{Chx} 10$, genes that are known to affect proliferation in the eye. Chx10 has been implicated in proliferation because or ${ }^{\mathrm{J}}$ mouse phenotype was attributed to the mutation in Chx 10 (Burmeister et al., 1996). Moreover, Chx10 appears to indirectly repress transcription of the CDK inhibitor Kip1 (Green et al., 2003). In Rx ${ }^{\text {Foxg1-Cre }}$ embryos Chx10 expression was never initiated while normal littermates demonstrate its strong expression in the presumptive neural retina both at E9.5 and at E10.5 (Fig. 17A-D).

Two other genes, Six 3 and Six6, appear to function as transcriptional repressors regulating eye and forebrain formation (Kobayashi et al., 2001; Li et al., 2002). An interaction between Six3 protein and the co-repressor Groucho was shown in frog, mouse and medaka fish (Tessmar et al., 2002; Zhu et al., 2002), while several CDK inhibitors are upregulated in Six6 -/- embryos (Li et al., 2002). Six6 expression is downregulated in the optic stalks of mutant embryos compared to littermate control embryos at E10.5 (Fig. 17E-F) while no changes were found at E9.5 (data not shown). Six3 shows reduced expression in $\mathrm{Rx}^{\mathrm{Foxg} 1-\mathrm{Cre}}$ embryos at E10.5 when compared to control embryos with no visible effect at E9.5 (Fig. 17G-H \& data not shown). Based on downregulation of Six3, Six6 and Chx 10 and their roles in governing neural retinal proliferation we suggest that Rx-mutant phenotype results from a decrease in proliferation rate within the developing eye.

\section{Rx is required for $\mathrm{D}-\mathrm{V}$ and $\mathrm{N}-\mathrm{T}$ patterning of the optic vesicle.}

Normal patterning of the retina along the D-V and the N-T axes is critical for the correct topological projection of RGC to the visual cortex and the proper distribution of rod photoreceptors (reviewed in Peters 2002). Patterning along the N-T axis is thought to occur around the optic vesicle stage (Hatini et al., 1994) whereas patterning along the D- 

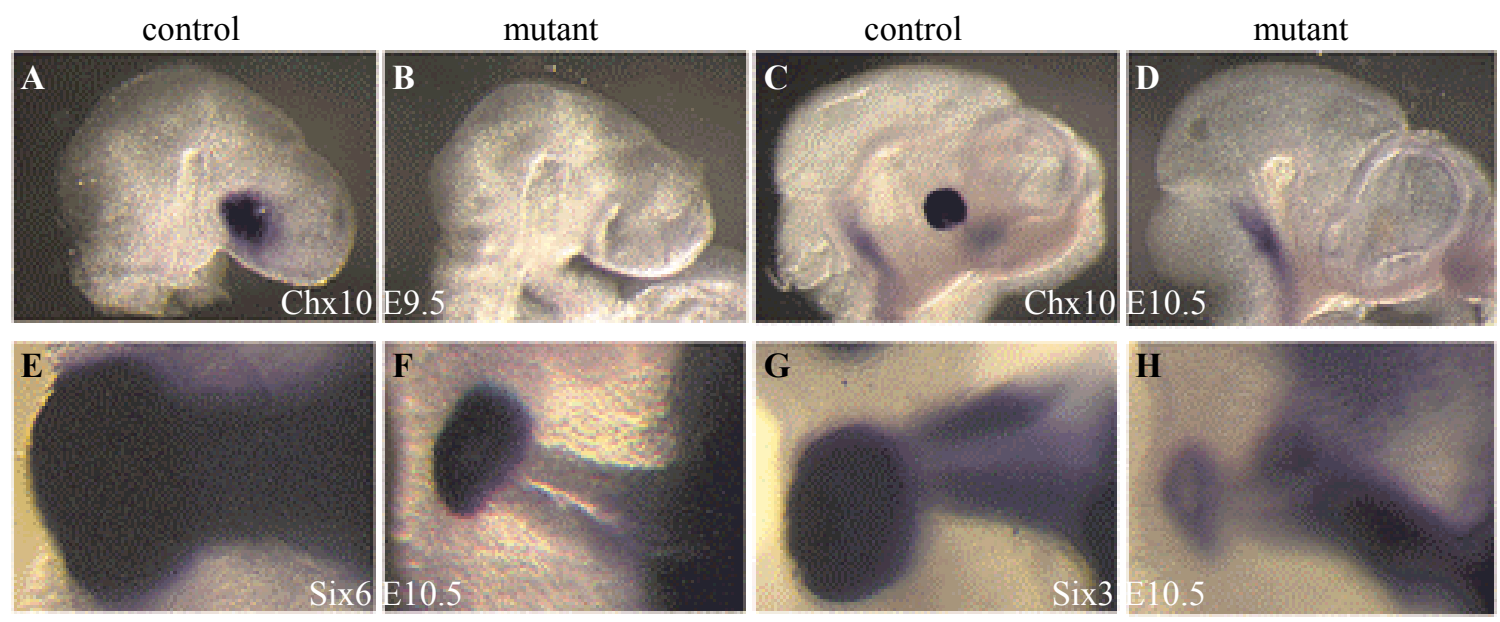

Fig.17 Expression of genes implicated in controlling retinal cell proliferation Panels A, C, E and G represent control embryos, panels B, D, F and H - mutant embryos. All mutants were collected at E10.5 with exception to A and B that were collected at $\mathrm{E} 9.5$. Embryos were hybridized with $\mathrm{Chx} 10$ antisense probe (A-D), Six6 probe (E-F) and Six 3 probe (G-H). Side view of embryos were taken to show Chx10 expression (A-D), otherwise heads were dissected open and photographed ventral side facing up (E-H). 
V axis occurs somewhat later but is largely established by the optic cup stage (Matsuno et al., 1992; Peters 2002). As development of the $\mathrm{Rx}^{\text {Foxg1-Cre }}$ eye is arrested just prior to the optic cup/stalk stage, we explored by marker analysis whether Rx plays a role in the establishment of these axes.

To analyze the D-V axis we examined expression of the homeobox gene, Vax2, and the T-box gene, Tbx5, (Chapman et al., 1996; Sowden et al., 2001), which are expressed in the ventral and dorsal optic cup, respectively. Misexpression studies of Vax2 (Barbieri et al., 1999; Schulte et al., 1999; Barbieri et al., 2002) or Tbx5 (Koshiba-Takeuchi et al., 2000) as well as analysis of eye development in mice lacking Vax2 (Barbieri et al., 2002) demonstrated that these genes are critical in determining the ventral and the dorsal retinal cell fates. We assayed both E9.5 and E10.5 day embryos and detected the expression of neither gene in $\mathrm{Rx}^{\text {Foxg1-Cre }}$ embryos although expression was readily detected in control embryos at these stages (Fig. 18A-H). Bmp4 is another marker for the dorsal optic cup and appears to regulate Tbx5 (Furuta and Hogan, 1998; Koshiba-Takeuchi et al., 2000).

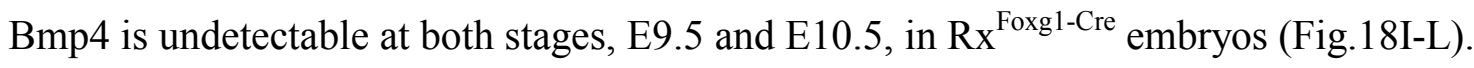

The two winged-helix transcriptional factors Foxg1 and Foxg2 are restricted to the nasal and temporal retina respectively (Hatini et al., 1994). Both misexpression and murine gene inactivation studies indicate that Foxg1 and Foxg2 may determine N-T specificity of the retina and consequently specify the topographic projections of retinal ganglion cell axons (Huh et al., 1999; Yuasa et al., 1996). In mutant embryos Foxg1 was normally expressed along the nasal neuroepithelium at E9.0 (data not shown). At E10.5 Foxg1 was normally detected in the mutant optic stalk but expression was absent in the optic vesicle (Fig. 18M-N). Foxg2 transcripts were detected normally along the temporal neuroepithelium of the optic vesicle in mutant embryos at E9.5 but were not detected in the optic stalk at E10.5 (Fig. 18O-P).

Together these data suggest that although $\mathrm{Rx}$ is required for normal patterning along both D-V and N-T axes of the optic vesicle and optic cup/stalk, there is no shift of either axes such that the visual organ acquires more dorsal (or ventral) or nasal (or temporal) character. Rather, these axes are generally disorganized with genes that play a role in their determination displaying aberrant expression patterns. 

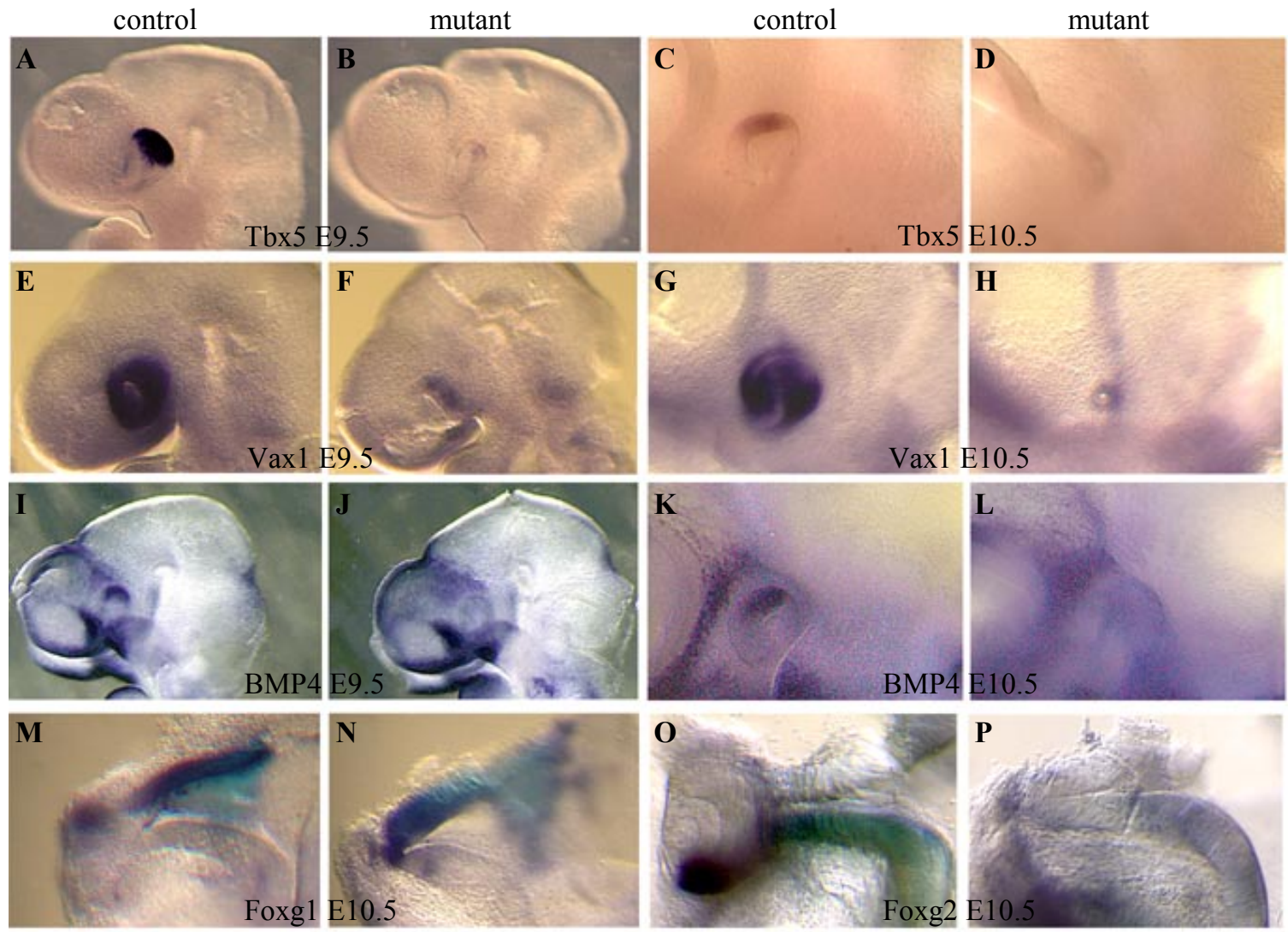

Fig.18 Markers analysis for D-V and N-T patterning of the eye in $\mathrm{Rx}^{\text {Foxg1-Cre }}$ Whole mount in situ hybridizations were performed on mutant embryos (B, D, F, H, J, L, N and P) and normal littermates (A, C, E, G, I, K, M and O) with stages and probes used as indicated. Side view pictures were taken for panels A-L, for panels M-P heads were dissected open to expose the developing eye and photographed with their ventral side facing up. 


\section{6. $\mathrm{Rx}$ is required for a normal optic cup/optic stalk boundary}

The major morphological landmark along the P-D axis of the optic vesicle is the formation of the optic cup/optic stalk boundary at E 10.0. Pax2 and Pax6 are expressed in the optic stalk and cup, respectively, with a region of overlap in the ventral optic cup (Nornes et al., 1990; Grindley et al., 1995; Torres et al., 1996). Gene inactivation studies in mice demonstrated that proper formation of the optic cup/stalk boundary relies on a mutual transcriptional repression between these Pax genes (Schwarz et al., 2000). Therefore to analyze P-D patterning in mutants we examined the distribution of Pax 2 and Pax6 transcripts.

In mutant embryos the Pax2 expression pattern was not altered at E9.5 (data not shown). However, at E10.5 Pax2 transcripts could not be detected in the optic stalk although expression remained in the proximal optic cup (Fig. 19A-B). At E9.5 Pax6 is localized to the distal optic vesicle that will develop into the optic cup. This localization is not observed in Rx mutant embryos where Pax6 is expressed throughout the entire optic vesicle (data not shown). At E10.5 Pax6 expression in mutants was significantly decreased in the optic cup while aberrantly increased in the distal optic stalk (Fig. 19CD). These altered domains of Pax $2 / 6$ expression indicated that the formation of the optic cup/stalk boundary might be impaired in $\mathrm{Rx}^{\mathrm{Foxgl}-\mathrm{Cre}}$ mutants. This interpretation is further supported by the observation that $\mathrm{Rx}$ itself, although normally restricted to the optic cup at E10.5, is upregulated along the optic stalk (Fig. 19E-F) as demonstrated by in situ hybridization using the Rx-3' probe described above.

To explore this phenotype further we also examined the expression of Otx2, which is expressed in the optic cup by E10.5 and predominately restricted to RPE (Bovolenta et al., 1997). Otx2 expression was similarly expressed throughout the optic vesicle in E9.5 mutant and control embryos. However, at E10.5, Otx2 transcript was detected in the distal optic stalk of mutants in addition to the normal expression in the optic cup (Fig. 19G-H), reinforcing the hypothesis that the optic cup/stalk boundary is impaired in $\mathrm{Rx}^{\mathrm{Foxg} 1-\mathrm{Cre}}$ mutants.

Vax1 is a homeobox gene expressed in the optic stalk that has been implicated in maintaining the P-D identity of the developing visual organ as both Rx and Pax6 expression domains are expanded proximally in mice lacking Vax1 activity (Hallonet et 
al., 1999). However, we found that Vax1 expression in E9.5 and E10.5 mutants was normal with transcripts present along the entire stalk up to the proximal optic cup (Fig. 19I-J and data not shown).

Two genes, Pax6 and Lhx2, are not only expressed in the developing optic cup but also both show arrest at the optic vesicle stage when mutated in mice. Pax6 is disrupted in the classical mouse mutation, Small eye (Sey). In the Sey phenotype enlarged optic vesicles make contact with the surface ectoderm but formation of the lens placode does not occur. Lhx2, like Pax6, is required for the normal progression of eye development beyond the optic vesicle stage (Porter et al., 1997). As eye development arrests after outgrowth of the optic vesicle in Sey mice, it is possible that the decrease in Pax6 expression that we observed in optic cups (Fig. 19C-D) could contribute to the failure of eye development in our mutants. We also investigated whether Lhx2 expression was affected in our mutants. Normal Lhx2 expression was found in mutants at E9.5 and at E10.5 throughout both the optic cup and stalk (Fig. 19K-L and data not shown), consistent with the model that Pax6 and Lhx2 are required in separate and parallel pathways during early eye development (Porter et al., 1997).

Taken together, our data demonstrate that gene expression is not uniformly decreased in mutant optic structures, as Lhx2 and Vax1 are normally expressed. Rx function is required for the normal patterning along the P-D axis, possibly through $\mathrm{Rx}$ regulation of both Pax6 and Pax2. 

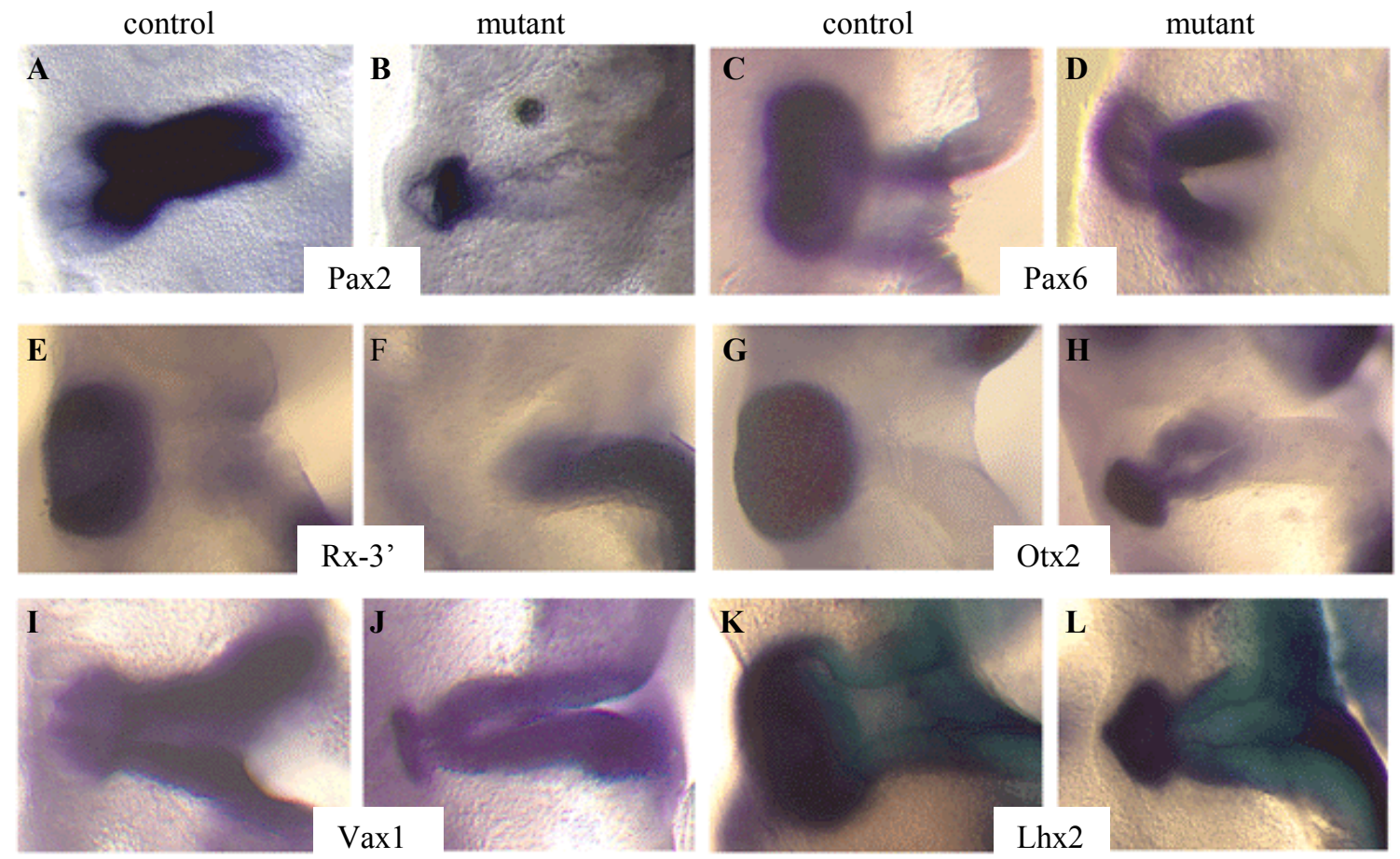

Fig.19 Markers of the P-D patterning in $\mathrm{Rx}^{\text {Foxg1-Cre }}$ embryos

Whole mount in situ hybridizations were performed on E10.5 Rx ${ }^{\text {Foxg1-Cre }}$ embryos (B, D, F, H, J and L) and their normal littermates (A, C, E, G, I and K). After hybridization embryonic heads were open to reveal developing eyes and photographed nasal part facing up. Antisense RNA probes used as indicated. 


\section{Discussion}

Several lines of evidence argue that Rx may play multiple roles such as maintaining eye development, maturation of the adult eye or proper regulation of visual stimulation in the adult. These arguments are based on persistent $\mathrm{Rx}$ expression in rat, human and mouse adult eye (Kimura et al., 2000; Voronina et al., in preparation), degeneration of optic vesicles in the partial loss of Rx function in the eyeless mouse (Tucker et al., 2001), and Rx-dependent activation of photoreceptor-specific genes and several components of the Notch signaling pathway. These putative latter roles of the mouse Rx gene in eye development could not be tested in loss of function experiments because of the extremely early phenotype in Rx-null homozygotes. To overcome this limitation we utilized a conditional gene inactivation strategy allowing us to inactivate $\mathrm{Rx}$ and study its role after initiation of eye development.

To study Rx function we have generated an allelic series at the Rx locus that includes a null allele $\left(\mathrm{Rx}^{\Delta 2}\right)$, a severe hypomorphic or null allele $\left(\mathrm{Rx}^{\text {flneo }}\right)$ and a conditional allele $\left(\mathrm{Rx}^{\mathrm{flox}}\right)$. The early postnatal lethality, lack of eyes and cleft face observed in both $\mathrm{Rx}^{\text {flneo }}$ and $\mathrm{Rx}^{\Delta 2}$ homozygotes are very similar to the phenotype observed in previously published $\mathrm{Rx}$ null $\left(\mathrm{Rx}^{\Delta 1,2}\right)$ homozygotes, which lack exons 1 and 2 (Mathers et al., 1997). $\mathrm{Rx}^{\text {flox }}$ homozygotes appear to be phenotypically normal, making the $\mathrm{Rx}^{\text {flox }}$ allele suitable for conditional inactivation.

To bypass the early phenotype of Rx-null homozygotes and extend analysis of the role for $\mathrm{Rx}$ in developmental stages beyond optic pit formation, we deleted $\mathrm{Rx}$ with Cre recombinase controlled by Foxg1 regulatory sequences. Foxg1-Cre is active in the region that will later give rise to nasal parts of the optic cup and the optic stalk. In contrast to the complete absence of optic pit development observed in Rx null homozygotes, the optic pits are formed normally in $\mathrm{Rx}^{\text {Foxg1-Cre }}$ embryos indicating that the approach to induce $\mathrm{Rx}$ inactivation after the initial steps of eye development was successful. The analysis of $\mathrm{Rx}^{\text {Foxg1-Cre }}$ embryos demonstrated that their eye development arrests prior to the optic cup/ optic stalk stage. Additionally, we found that retarded optic cups of Rx mutant embryos are characterized by complete disorganization of axial patterning along all three axes. 
$\underline{\mathrm{Rx} \text { activity is required for the transition to the optic cup/optic stalk stage }}$

Despite the normal start of eye formation adult $\mathrm{Rx}^{\mathrm{Foxg} 1-\mathrm{Cre}}$ mice are anophthalmic. We have shown that the first morphological defects are visible around E10.0 when mutant optic structures do not show signs of lens formation. At E10.5 when normal embryos have well formed lens vesicles, developing eyes of $\mathrm{Rx}^{\text {Foxg1-Cre }}$ do not invaginate maintaining the rudimentary optic cup structure. These rudimentary optic cups show aberrant expression patterns of neural retinal markers that does not appear to result from a delay in development, as evident by marker analysis. For example, at no time is Chx 10 gene expression present in $\mathrm{Rx}{ }^{\text {Foxg1-Cre }}$ embryos. Another group of retinal markers shows proper initiation of expression followed by abnormal downregulation. This group includes Pax6, Otx2, Foxg1 and others. The retarded optic cup in mutant embryos does not correspond to the presumptive neural retina, because some neural retina markers are absent (Chx10), some are downregulated ( $\mathrm{Rx}, \mathrm{Pax} 6)$ and others are expressed normally (Six6). This tissue will not develop into RPE either because it expresses markers specific for both, neural retina (Rx, Pax6, Six6) and RPE (Otx2).

Disruption of Lhx2 and Pax6 leads to arrest of eye development at a similar stage. Deletion of Lhx2 results in anophthalmia, among other defects (Porter et al., 1997). Optic vesicles are formed in these animals but their development arrests prior to contact with the surface ectoderm and lens placode formation does not occur (Porter et al., 1997). Lhx 2 does not seem to contribute to the Rx mutant phenotype because its expression is not affected in $\mathrm{Rx}^{\text {Foxg1-Cre }}$ embryos.

Loss-of-function mutations in Pax6 are semi-dominant and in the heterozygous state they lead to the Sey phenotype in mouse (Hogan et al., 1986; Hill et al., 1991) and rat (Matsuo et al., 1993). Homozygotes do not develop eyes or nasal epithelium and die soon after birth. At first, these mutants form enlarged optic vesicles that make contact with the surface ectoderm but lens placode thickening does not occur (Hogan et al., 1986; Matsuo et al., 1993; Grindley et al., 1995), later resulting in anophthalmia. Pax6 expression is initiated normally in $\mathrm{Rx}^{\text {Foxg1-Cre }}$ embryos, however, later it gets downregulated in the retarded optic cup and upregulated in the optic stalk, where it is not found in normal embryos. Involvement of Pax6 but not Lhx2 in the aberrant eye development of Rx 
mutants is consistent with independent function of these two factors (Porter et al., 1997). Abnormal expression of Pax6 may contribute to the eye phenotype of $\mathrm{Rx}{ }^{\text {Foxg1-Cre }}$ embryos. Alternatively, Pax6 misexpression may be a result of abnormal eye patterning.

The optic vesicle phenotype in our $\mathrm{Rx}^{\text {Foxg1-Cre }}$ embryos also resembles that present in embryos lacking the Bmp4 gene. Disruption of mouse Bmp4 (Bmp4 $\left.{ }^{\mathrm{tm} 1}\right)$ prevents lens placode thickening despite a close contact between the optic vesicle and the surface ectoderm (Furuta and Hogan, 1998). Exposure of Bmp4 ${ }^{\mathrm{tm} 1}$ cultured eye primordia to the BMP4 protein can partially rescue this phenotype and lead to formation of lens-like structures (Furuta and Hogan, 1998). When vesicles are cultured in BMP4-containing media an increased size of the lens vesicles as compared to untreated structures is observed (Trousse et al., 2001), reinforcing the concept of Bmp4's role as a lens inducing agent. Thus we hypothesize that absence of lens development in $\mathrm{Rx}^{\mathrm{Foxg} 1-\mathrm{Cre}}$ is at least partially due to a loss of Bmp4 and possibly Pax6 expression.

\section{$\underline{\mathrm{Rx} \text { plays a role in the establishment of the } \mathrm{D}-\mathrm{V} \text { and } \mathrm{N}-\mathrm{T} \text { axes }}$}

Multiple experiments including surgical manipulation in the chicken (Matsuno et al., 1992; Dutting and Meyer, 1995) suggest that the initial three-dimensional specification of the retina is indispensable for the establishment of correct retinotectal projections. Spatial patterning of the growing retina in mice becomes evident as early as E9.5 by an asymmetric distribution of transcripts of regulatory genes along each of the three axes. As previously shown, Rx expression is initiated prior to the outgrowth of optic pits and therefore occurs prior to establishment of visual organ polarity (Furukawa et al., 1997; Mathers et al., 1997).

The D-V axis specification is characterized by an exclusive distribution of Vax2 transcript in the developing ventral retina and Bmp4 and Tbx5 transcripts in the developing dorsal retina. Misexpression studies have proven that these factors are required for the proper D-V patterning of the eye. $\mathrm{Rx}^{\text {Foxg1-Cre }}$ embryos lack expression of all three of these genes, demonstrating that $\mathrm{D}-\mathrm{V}$ patterning does not occur in mutant embryos. As Bmp4 is the earliest of these genes to be expressed and it also regulates Tbx5 (Koshiba-Takeuchi et al., 2000), we hypothesize that aberrant D-V patterning in $\mathrm{Rx}^{\mathrm{Foxg} 1-\mathrm{Cre}}$ embryos is due to a loss of this secreted factor. 
Two transcription factors, Foxg1 and Foxg2, are essential for normal N-T patterning of retina. Foxg1 is expressed in the nasal retina whereas Foxg2 is localized to the temporal retina. Absence of functional Rx does not seem to affect the expression of Foxg1 at E9.5 whereas it is lost from the rudimentary optic cup but not optic stalk at E10.5 in mutant embryos . However, Foxg2 expression is absent in the optic stalk of mutant embryos. These results allow us to speculate that multiple parallel pathways are implicated in the patterning of the developing retina. An attractive possibility is that for each pair of genetic markers specifying the boundary along a particular axis, one member is regulated by a Rx-dependent pathway and the other by an alternative pathway. As a result, an alternative pathway will still be active in the developing eyes of $\mathrm{Rx}^{\text {Foxg1-Cre }}$ embryos leading to disorganization of retinal patterning rather than a unidirectional shift (such as dorzalization) in one or more axes as observed in knock out or misexpression experiments of downstream polarity determinants (Barbieri et al., 1999; Schulte et al., 1999; Koshiba-Takeuchi et al., 2000).

$\underline{\text { Rx plays a role in the establishment of the optic cup / optic stalk boundary }}$

Proper formation of the optic stalk/optic cup boundary is critical for RGC axon extension and guidance toward the brain. An abnormal optic stalk/optic cup boundary severely impairs visual system connectivity and is most probably incompatible with the proper procession of visual input. We discovered that the optic cup and the optic stalk partitioning depends on Rx expression. Marker analysis demonstrated that Rx and Pax6 genes that are normally expressed in the optic cup are downregulated in this structure in $\mathrm{Rx}^{\text {Foxg1-Cre }}$ embryos. At the same time Otx2, Rx and Pax6 markers are upregulated in the mutant optic stalk. Establishment of P-D patterning is regulated by reciprocal inhibition of Pax 2 and Pax6 genes (Schwarz et al., 2000), which are expressed in the optic stalk and the optic cup, respectively. Analysis of Pax2 and Pax6 transcripts demonstrated downregulation of Pax6 expression in the optic cup and a complete loss of Pax2 expression in the optic stalk but not in the proximal optic cup of mutant embryos.

The abnormal P-D patterning in $\mathrm{Rx}^{\text {Foxg1-Cre }}$ can be due to severe downregulation of Bmp4. Recent experiments demonstrated involvement of Bmp4 in P-D patterning, because overexpression of this gene results in almost complete suppression of optic stalk 
development (Ohkubo et al., 2002; Sasagawa et al., 2002). Thus the absence of BMP4 in our mutants could explain both the arrest of development at the optic cup/stalk stage and the loss of PD patterning of the eye.

In this paper we have demonstrated that inactivation of $\mathrm{Rx}$ after the initial stages of eye development results in mispatterning of the developing optic structures and prevents proper formation of the eye. Aberrant patterning of all three axes in eyes of Rx mutant embryos may suggest that their formation proceeds in an interdependent manner, where each following step occurs only if the previous step is initiated normally.

To get a deeper insight into its role, the conditional $\mathrm{Rx}$ allele described here may be inactivated at different developmental stages using an inducible, stage or tissue specific Cre transgene. Another way to study multiple roles of Rx during eye development is to perform "rescue" experiments using the $\mathrm{Rx}^{\text {flneo }}$ line that has been generated as part of the allelic series. $\mathrm{Rx}^{\text {flneo }}$ homozygotes do not form eyes and die perinatally as a result of the loss of RX activity due to the presence of the neomycin resistance cassette (neo ${ }^{\mathrm{R}}$ ) in intron 1. We have demonstrated that removal of neo ${ }^{\mathrm{R}}$ via Flp-mediated recombination results in the $\mathrm{Rx}^{\text {flox }}$ allele, which is functionally equivalent to a wild-type allele. Therefore, specific Flp transgene expression could result in "rescuing" Rx activity in those Flp expressing domains/stages. Inactivation (with Cre) and rescue experiments (with Flp) will determine the various roles of Rx at different developmental stages and marker analysis of these mutants will indicate its place in the genetic network at each particular stage. 


\section{Chapter V.}

\section{Summary and Future Directions}


Involvement of Rx in eye formation was demonstrated by germ line inactivation that showed that eye development is not initiated in Rx nulls as no optic pits are formed. This condition is known as true anophthalmia. A serious limitation of this conventional knock out approach is that it only reveals the earliest role of the inactivated gene. Normal formation of optic vesicles followed by their degeneration in the eyeless mouse and the fact that mouse and human Rx genes are expressed in the eye after birth, suggest that in addition to its role in specification of retinal fate $\mathrm{Rx}$ can participate in eye formation at developmental stages later than initial optic pit formation. Conditional inactivation of $\mathrm{Rx}$ after initiation of eye development, using eye- and forebrain-specific Cre-recombinase (Foxg1-Cre), showed that even if optic pits and optic vesicles are formed normally, Rx disruption still leads to a loss of visual structures. Aberrant expression of multiple transcription factors in the optic structures of $\mathrm{Rx}^{\text {Foxg1-Cre }}$ is indicative of direct or indirect regulation of these factors by $\mathrm{Rx}$. In addition, neither partitioning of the optic vesicle into the optic cup and the optic stalk nor patterning along D-V and N-T axes occurs properly in $\mathrm{Rx}^{\text {Foxg1-Cre }}$. These findings are consistent with a current view of eye development that is believed to be regulated by an interactive network of eye specification genes. The abnormal axial patterning of the developing eye may cause loss of the visual structures resulting in birth of viable anophthalmic mice.

To get a deeper insight into its role, the conditional $\mathrm{Rx}$ allele described here may be inactivated at different developmental stages using an inducible Cre transgene. One example is the $\mathrm{ER}^{\mathrm{TM}}$-Cre transgene in which the Cre-coding region is fused with a ligand-binding domain of the estrogen receptor. We have generated mice of the appropriate genotype $\left(\mathrm{Rx}^{\text {flox }} / \mathrm{Rx}^{\Delta 1,2} ; \mathrm{ER}^{\mathrm{TM}}-\mathrm{Cre}\right)$ for this analysis and we have performed the necessary control experiments. We have demonstrated that $\mathrm{ER}^{\mathrm{TM}}$-Cre transgene drives tamoxifen-induced recombination in the eye, suggesting that this strategy is suitable for conditional inactivation of Rx. Another way to study multiple roles of Rx during eye development is to perform "rescue" experiments using $\mathrm{Rx}$ flneo line that has been generated as a part of allelic series. $\mathrm{Rx}^{\text {flneo }}$ homozygotes do not form eye and die perinatally as a result of the presence of neomycin resistance cassette in intron 1 . We have demonstrated that removal of neo ${ }^{\mathrm{R}}$ via Flp-mediated recombination results in the 
$\mathrm{Rx}^{\text {flox }}$ allele, which is functionally equivalent to a wild type allele. An available array of FLP transgenes should allow rescuing Rx activity in the domains where specific FLP transgenes are expressed. Both, FLP-mediated rescue and Cre-mediated inactivation will determine roles of Rx at different developmental stages. Marker analysis of generated mutants will indicate Rx place in the genetic network at each particular stage.

The next step will be to show direct binding and regulation biochemically, in vitro or in cell cultures. A list of current candidates for Rx regulation includes the Otx2, Pax2, Pax6, BMP4 and Chx10 genes that show none or diminishing transcription in $\mathrm{Rx}^{\text {Foxg1-Cre }}$ embryos. Other potential targets include Notch1 and Hes1 that show upregulation upon co-transfection of Rx-expression plasmid. More detailed biochemical analysis would include identification of promoter regions that $\mathrm{Rx}$ binds to and accessory factors regulating and modulating transcription of the same genes. If such regulation is demonstrated it would have implications for how RX mutations found in a patient with anophthalmia might affect expression of $\mathrm{Rx}$ target genes.

In the adult eye Rx is expressed in the photoreceptor layer, the inner nuclear layer and the ciliary body. Rx expression in photoreceptors indicates that Rx may be involved in phototransduction that is supported by in vitro experiments where $\mathrm{Rx}$ is able to upregulate transcription of certain components of phototransduction cascade. Rx expression in the ciliary body and the inner nuclear layer indicates a potential role of $\mathrm{Rx}$ in maintenance of retinal stem cells. It was recently demonstrated that mammalian ciliary body contains retinal progenitor cells, while Müller glia (cell bodies are located in the inner nuclear layer) has an ability to de-differentiate and produce multiple retinal cell types. Thus, Rx expression in the ciliary body and Müller glia would be consistent with $\mathrm{Rx}$ role in maintenance of multipotent state of retinal progenitors and opens a possibility for stem cell therapy. 
Chapter VI.

References 
Acampora, D., Mazan, S., Lallemand, Y., Avantaggiato, V., Maury, M., Simeone, A., and Brulet, P. (1995). Forebrain and midbrain regions are deleted in Otx2-/- mutants due to a defective anterior neuroectoderm specification during gastrulation. Development 121, 3279-90.

Adler, R. (1993). Determination of cellular types in the retina. Invest Ophthalmol Vis Sci 34, 1677-82.

Adler, R., and Hatlee, M. (1989). Plasticity and differentiation of embryonic retinal cells after terminal mitosis. Science 243, 391-3.

Ahmad, I., Tang, L., and Pham, H. (2000). Identification of neural progenitors in the adult mammalian eye. Biochem Biophys Res Commun 270, 517-21.

Andreazzoli, M., Gestri, G., Angeloni, D., Menna, E., and Barsacchi, G. (1999). Role of Xrx1 in Xenopus eye and anterior brain development. Development 126, 2451-60.

Ang, S. L., Jin, O., Rhinn, M., Daigle, N., Stevenson, L., and Rossant, J. (1996). A targeted mouse Otx2 mutation leads to severe defects in gastrulation and formation of axial mesoderm and to deletion of rostral brain. Development 122, 243-52.

Asbreuk, C. H., van Schaick, H. S., Cox, J. J., Smidt, M. P., and Burbach, J. P. (2002). Survey for paired-like homeodomain gene expression in the hypothalamus: restricted expression patterns of Rx, Alx4 and goosecoid. Neuroscience 114, 8839 .

Ashery-Padan, R., and Gruss, P. (2001). Pax6 lights-up the way for eye development. Curr Opin Cell Biol 13, 706-14. 
Ashery-Padan, R., Marquardt, T., Zhou, X., and Gruss, P. (2000). Pax6 activity in the lens primordium is required for lens formation and for correct placement of a single retina in the eye. Genes Dev 14, 2701-11.

Ashley, L. M. (1947). Bilateral anophthalmos in a brother and sister. J Hered 38, 174-6.

Barabino, S. M., Spada, F., Cotelli, F., and Boncinelli, E. (1997). Inactivation of the zebrafish homologue of Chx10 by antisense oligonucleotides causes eye malformations similar to the ocular retardation phenotype. Mech Dev 63, 133-43.

Barbieri, A. M., Broccoli, V., Bovolenta, P., Alfano, G., Marchitiello, A., Mocchetti, C., Crippa, L., Bulfone, A., Marigo, V., Ballabio, A., and Banfi, S. (2002). Vax2 inactivation in mouse determines alteration of the eye dorsal-ventral axis, misrouting of the optic fibres and eye coloboma. Development 129, 805-13.

Barbieri, A. M., Lupo, G., Bulfone, A., Andreazzoli, M., Mariani, M., Fougerousse, F., Consalez, G. G., Borsani, G., Beckmann, J. S., Barsacchi, G., Ballabio, A., and Banfi, S. (1999). A homeobox gene, vax2, controls the patterning of the eye dorsoventral axis. Proc Natl Acad Sci U S A 96, 10729-34.

Baumer, N., Marquardt, T., Stoykova, A., Ashery-Padan, R., Chowdhury, K., and Gruss, P. (2002). Pax6 is required for establishing naso-temporal and dorsal characteristics of the optic vesicle. Development 129, 4535-45.

Beebe, D. C. (1994). Homeobox genes and vertebrate eye development. Invest Ophthalmol Vis Sci 35, 2897-900.

Belecky-Adams, T., Tomarev, S., Li, H. S., Ploder, L., McInnes, R. R., Sundin, O., and Adler, R. (1997). Pax-6, Prox 1, and Chx 10 homeobox gene expression correlates with phenotypic fate of retinal precursor cells. Invest Ophthalmol Vis Sci 38, 1293-303. 
Bernier, G., Panitz, F., Zhou, X., Hollemann, T., Gruss, P., and Pieler, T. (2000). Expanded retina territory by midbrain transformation upon overexpression of Six6 (Optx2) in Xenopus embryos. Mech Dev 93, 59-69.

Bernier, G., Vukovich, W., Neidhardt, L., Herrmann, B. G., and Gruss, P. (2001). Isolation and characterization of a downstream target of Pax6 in the mammalian retinal primordium. Development 128, 3987-94.

Bertuzzi, S., Hindges, R., Mui, S. H., O'Leary, D. D., and Lemke, G. (1999). The homeodomain protein vax1 is required for axon guidance and major tract formation in the developing forebrain. Genes Dev 13, 3092-105.

Bierich, J. R., Christie, M., Heinrich, J. J., and Martinez, A. S. (1991). New observations on midline defects: coincidence of anophthalmos, microphthalmos and cryptophthalmos with hypothalamic disorders. Eur J Pediatr 150, $246-9$.

Biggin, M. D., and McGinnis, W. (1997). Regulation of segmentation and segmental identity by Drosophila homeoproteins: the role of DNA binding in functional activity and specificity. Development 124, 4425-33.

Bird, A. C. (1995). Retinal photoreceptor dystrophies LI. Edward Jackson Memorial Lecture. Am J Ophthalmol 119, 543-62.

Boncinelli, E., and Morgan, R. (2001). Downstream of Otx2, or how to get a head. Trends Genet 17, 633-6.

Bone-Larson, C., Basu, S., Radel, J. D., Liang, M., Perozek, T., Kapousta-Bruneau, N., Green, D. G., Burmeister, M., and Hankin, M. H. (2000). Partial rescue of the ocular retardation phenotype by genetic modifiers. J Neurobiol 42, 232-47. 
Bonini, N. M., Bui, Q. T., Gray-Board, G. L., and Warrick, J. M. (1997). The Drosophila eyes absent gene directs ectopic eye formation in a pathway conserved between flies and vertebrates. Development 124, 4819-26.

Bonini, N. M., Leiserson, W. M., and Benzer, S. (1993). The eyes absent gene: genetic control of cell survival and differentiation in the developing Drosophila eye. Cell 72, 379-95.

Bovolenta, P., Mallamaci, A., Briata, P., Corte, G., and Boncinelli, E. (1997). Implication of OTX2 in pigment epithelium determination and neural retina differentiation. $J$ Neurosci 17, 4243-52.

Bovolenta, P., Mallamaci, A., Puelles, L., and Boncinelli, E. (1998). Expression pattern of cSix 3 , a member of the Six/sine oculis family of transcription factors. Mech Dev 70, 201-3.

Brodsky, M. C., and Frindik, J. P. (1996). Hypothalamic-hypophyseal dysgenesis as a neuroimaging correlate of pituitary hormone deficiency in anophthalmia. Am J Ophthalmol 122, 747-8.

Burglin, T. R. (1994). A comprehensive classification of homeobox genes. In "Guidebook to the homeobox genes" (D. Duboule, Ed.), pp. 27-71. Oxford University Press, New York.

Burmeister, M., Novak, J., Liang, M. Y., Basu, S., Ploder, L., Hawes, N. L., Vidgen, D., Hoover, F., Goldman, D., Kalnins, V. I., Roderick, T. H., Taylor, B. A., Hankin, M. H., and McInnes, R. R. (1996). Ocular retardation mouse caused by Chx 10 homeobox null allele: impaired retinal progenitor proliferation and bipolar cell differentiation. Nat Genet 12, 376-84. 
Callaerts, P., Halder, G., and Gehring, W. J. (1997). PAX-6 in development and evolution. Аппи Rev Neurosci 20, 483-532.

Campbell, H., Holmes, E., MacDonald, S., Morrison, D., and Jones, I. (2002). A capturerecapture model to estimate prevalence of children born in Scotland with developmental eye defects. J Cancer Epidemiol Prev 7, 21-8.

Carl, M., Loosli, F., and Wittbrodt, J. (2002). Six3 inactivation reveals its essential role for the formation and patterning of the vertebrate eye. Development 129, 4057-63.

Casarosa, S., Andreazzoli, M., Simeone, A., and Barsacchi, G. (1997). Xrx 1, a novel Xenopus homeobox gene expressed during eye and pineal gland development. Mech Dev 61, 187-98.

Catron, K. M., Iler, N., and Abate, C. (1993). Nucleotides flanking a conserved TAAT core dictate the DNA binding specificity of three murine homeodomain proteins. Mol Cell Biol 13, 2354-65.

Chapman, D. L., Garvey, N., Hancock, S., Alexiou, M., Agulnik, S. I., Gibson-Brown, J. J., Cebra-Thomas, J., Bollag, R. J., Silver, L. M., and Papaioannou, V. E. (1996). Expression of the T-box family genes, Tbx 1-Tbx5, during early mouse development. Dev Dyn 206, 379-90.

Chase, H. B. (1942). Studies on an anophthalmic strain of mice. III. Results of crosses with other strains. Genetics 27, 339-48.

Chase, H. B. (1944). Studies on an anophthalmic strain of mice. IV. A second major gene for anophthalmia. Genetics 29, 264-9.

Chase, H. B. (1945). Studies on anophthalmic strain of mice. V. Associated cranial nerves and brain centers. J Comp Neurol 83, 121-39. 
Chase, H. B., and Chase, E. B. (1941). Studies of an anophthalmic strain of mice. I. Embryology of the eye region. $J$ Morph 68, 279-301.

Chen, C. M., and Cepko, C. L. (2000). Expression of Chx 10 and Chx10-1 in the developing chicken retina. Mech Dev 90, 293-7.

Chen, C. M., and Cepko, C. L. (2002). The chicken RaxL gene plays a role in the initiation of photoreceptor differentiation. Development 129, 5363-75.

Chen, G., and Courey, A. J. (2000). Groucho/TLE family proteins and transcriptional repression. Gene 249, 1-16.

Chen, R., Amoui, M., Zhang, Z., and Mardon, G. (1997a). Dachshund and eyes absent proteins form a complex and function synergistically to induce ectopic eye development in Drosophila. Cell 91, 893-903.

Chen, S., Wang, Q. L., Nie, Z., Sun, H., Lennon, G., Copeland, N. G., Gilbert, D. J., Jenkins, N. A., and Zack, D. J. (1997b). Crx, a novel Otx-like pairedhomeodomain protein, binds to and transactivates photoreceptor cell-specific genes. Neuron 19, 1017-30.

Cheyette, B. N., Green, P. J., Martin, K., Garren, H., Hartenstein, V., and Zipursky, S. L. (1994). The Drosophila sine oculis locus encodes a homeodomain-containing protein required for the development of the entire visual system. Neuron 12, 97796.

Chow, R. L., Altmann, C. R., Lang, R. A., and Hemmati-Brivanlou, A. (1999). Pax6 induces ectopic eyes in a vertebrate. Development 126, 4213-22.

Chow, R. L., and Lang, R. A. (2001). Early eye development in vertebrates. Annu Rev Cell Dev Biol 17, 255-96. 
Chuang, J. C., Mathers, P. H., and Raymond, P. A. (1999). Expression of three Rx homeobox genes in embryonic and adult zebrafish. Mech Dev 84, 195-8.

Chuang, J. C., and Raymond, P. A. (2001). Zebrafish genes rx1 and rx2 help define the region of forebrain that gives rise to retina. Dev Biol 231, 13-30.

Conlon, R. A., and Rossant, J. (1992). Exogenous retinoic acid rapidly induces anterior ectopic expression of murine Hox-2 genes in vivo. Development 116, 357-68.

Crossland, W. J., Cowan, W. M., Rogers, L. A., and Kelly, J. P. (1974). The specification of the retino-tectal projection in the chick. J Comp Neurol 155, 127-64.

Cygan, J. A., Johnson, R. L., and McMahon, A. P. (1997). Novel regulatory interactions revealed by studies of murine limb pattern in Wnt-7a and En-1 mutants. Development 124, 5021-32.

Czerny, T., Halder, G., Kloter, U., Souabni, A., Gehring, W. J., and Busslinger, M. (1999). twin of eyeless, a second Pax-6 gene of Drosophila, acts upstream of eyeless in the control of eye development. Mol Cell 3, 297-307.

Dattani, M. T., Martinez-Barbera, J. P., Thomas, P. Q., Brickman, J. M., Gupta, R., Martensson, I. L., Toresson, H., Fox, M., Wales, J. K., Hindmarsh, P. C., Krauss, S., Beddington, R. S., and Robinson, I. C. (1998). Mutations in the homeobox gene HESX1/Hesx 1 associated with septo-optic dysplasia in human and mouse. Nat Genet 19, 125-33.

Deschet, K., Bourrat, F., Ristoratore, F., Chourrout, D., and Joly, J. S. (1999). Expression of the medaka (Oryzias latipes) Ol-Rx3 paired-like gene in two diencephalic derivatives, the eye and the hypothalamus. Mech Dev 83, 179-82. 
Desplan, C. (1997). Eye development: governed by a dictator or a junta? Cell 91, 861-4.

Dolk, H., Busby, A., Armstrong, B. G., and Walls, P. H. (1998). Geographical variation in anophthalmia and microphthalmia in England, 1988-94. Bmj 317, 905-9; discussion 910 .

Dressler, G. R., Deutsch, U., Chowdhury, K., Nornes, H. O., and Gruss, P. (1990). Pax2, a new murine paired-box-containing gene and its expression in the developing excretory system. Development 109, 787-95.

Duboule, D. (1994). "Guidebook to the homeobox genes." Oxford University Press, New York.

Dutting, D., and Meyer, S. U. (1995). Transplantations of the chick eye anlage reveal an early determination of nasotemporal polarity. Int J Dev Biol 39, 921-31.

Dyer, M. A., and Cepko, C. L. (2001). Regulating proliferation during retinal development. Nat Rev Neurosci 2, 333-42.

Eggert, T., Hauck, B., Hildebrandt, N., Gehring, W. J., and Walldorf, U. (1998). Isolation of a Drosophila homolog of the vertebrate homeobox gene $\mathrm{Rx}$ and its possible role in brain and eye development. Proc Natl Acad Sci U S A 95, 2343-8.

Ekker, S. C., Ungar, A. R., Greenstein, P., von Kessler, D. P., Porter, J. A., Moon, R. T., and Beachy, P. A. (1995). Patterning activities of vertebrate hedgehog proteins in the developing eye and brain. Curr Biol 5, 944-55.

Evans, K., Duvall-Young, J., Fitzke, F. W., Arden, G. B., Bhattacharya, S. S., and Bird, A. C. (1995). Chromosome 19q cone-rod retinal dystrophy. Ocular phenotype. Arch Ophthalmol 113, 195-201. 
Fantes, J., Ragge, N. K., Lynch, S. A., McGill, N. I., Collin, J. R., Howard-Peebles, P. N., Hayward, C., Vivian, A. J., Williamson, K., Van Heyningen, V., and FitzPatrick, D. R. (2003). Mutations in SOX2 cause anophthalmia. Nat Genet 33, 461-3.

Faradji-Prevautel, H., Cespuglio, R., and Jouvet, M. (1990). Circadian rest-activity rhythms in the anophthalmic, monocular and binocular ZRDCT/An mice. Retinal and serotoninergic (raphe) influences. Brain Res 526, 207-16.

Favor, J., Sandulache, R., Neuhauser-Klaus, A., Pretsch, W., Chatterjee, B., Senft, E., Wurst, W., Blanquet, V., Grimes, P., Sporle, R., and Schughart, K. (1996). The mouse Pax2(1Neu) mutation is identical to a human PAX2 mutation in a family with renal-coloboma syndrome and results in developmental defects of the brain, ear, eye, and kidney. Proc Natl Acad Sci US A 93, 13870-5.

Ferda Percin, E., Ploder, L. A., Yu, J. J., Arici, K., Horsford, D. J., Rutherford, A., Bapat, B., Cox, D. W., Duncan, A. M., Kalnins, V. I., Kocak-Altintas, A., Sowden, J. C., Traboulsi, E., Sarfarazi, M., and McInnes, R. R. (2000). Human microphthalmia associated with mutations in the retinal homeobox gene CHX10. Nat Genet 25, 397-401.

Fernald, R. D. (2000). Evolution of eyes. Curr Opin Neurobiol 10, 444-50.

Fischer, A. J., and Reh, T. A. (2001). Muller glia are a potential source of neural regeneration in the postnatal chicken retina. Nat Neurosci 4, 247-52.

Freund, C. L., Gregory-Evans, C. Y., Furukawa, T., Papaioannou, M., Looser, J., Ploder, L., Bellingham, J., Ng, D., Herbrick, J. A., Duncan, A., Scherer, S. W., Tsui, L. C., Loutradis-Anagnostou, A., Jacobson, S. G., Cepko, C. L., Bhattacharya, S. S., and McInnes, R. R. (1997). Cone-rod dystrophy due to mutations in a novel photoreceptor-specific homeobox gene (CRX) essential for maintenance of the photoreceptor. Cell 91, 543-53. 
Fryns, J. P., Legius, E., Moerman, P., Vandenberghe, K., and Van den Berghe, H. (1995). Apparently new "anophthalmia-plus" syndrome in sibs. Am J Med Genet 58, 1134.

Furukawa, T., Kozak, C. A., and Cepko, C. L. (1997). rax, a novel paired-type homeobox gene, shows expression in the anterior neural fold and developing retina. Proc Natl Acad Sci U S A 94, 3088-93.

Furukawa, T., Mukherjee, S., Bao, Z. Z., Morrow, E. M., and Cepko, C. L. (2000). rax, Hes1, and notch1 promote the formation of Muller glia by postnatal retinal progenitor cells. Neuron 26, 383-94.

Furuta, Y., and Hogan, B. L. (1998). BMP4 is essential for lens induction in the mouse embryo. Genes Dev 12, 3764-75.

Gallardo, M. E., Lopez-Rios, J., Fernaud-Espinosa, I., Granadino, B., Sanz, R., Ramos, C., Ayuso, C., Seller, M. J., Brunner, H. G., Bovolenta, P., and Rodriguez de Cordoba, S. (1999). Genomic cloning and characterization of the human homeobox gene SIX6 reveals a cluster of SIX genes in chromosome 14 and associates SIX6 hemizygosity with bilateral anophthalmia and pituitary anomalies. Genomics 61, 82-91.

Galliot, B., de Vargas, C., and Miller, D. (1999). Evolution of homeobox genes: Q50 Paired-like genes founded the Paired class. Dev Genes Evol 209, 186-97.

Gehring, W. J., and Ikeo, K. (1999). Pax 6: mastering eye morphogenesis and eye evolution. Trends Genet 15, 371-7.

Ghanbari, H., Seo, H. C., Fjose, A., and Brandli, A. W. (2001). Molecular cloning and embryonic expression of Xenopus Six homeobox genes. Mech Dev 101, 271-7. 
Glaser, T., Jepeal, L., Edwards, J. G., Young, S. R., Favor, J., and Maas, R. L. (1994). PAX6 gene dosage effect in a family with congenital cataracts, aniridia, anophthalmia and central nervous system defects. Nat Genet 7, 463-71.

Glaser, T., Walton, D. S., and Maas, R. L. (1992). Genomic structure, evolutionary conservation and aniridia mutations in the human PAX6 gene. Nat Genet 2, 2329.

Goldberg, J. L., Klassen, M. P., Hua, Y., and Barres, B. A. (2002). Amacrine-signaled loss of intrinsic axon growth ability by retinal ganglion cells. Science 296, 18604.

Goldberg, M. F. (1997). Persistent fetal vasculature (PFV): an integrated interpretation of signs and symptoms associated with persistent hyperplastic primary vitreous (PHPV). LIV Edward Jackson Memorial Lecture. Am J Ophthalmol 124, 587626.

Gould, A., Morrison, A., Sproat, G., White, R. A., and Krumlauf, R. (1997). Positive cross-regulation and enhancer sharing: two mechanisms for specifying overlapping Hox expression patterns. Genes Dev 11, 900-13.

Grainger, R. M. (1992). Embryonic lens induction: shedding light on vertebrate tissue determination. Trends Genet 8, 349-55.

Granadino, B., Gallardo, M. E., Lopez-Rios, J., Sanz, R., Ramos, C., Ayuso, C., Bovolenta, P., and Rodriguez de Cordoba, S. (1999). Genomic cloning, structure, expression pattern, and chromosomal location of the human SIX3 gene. Genomics $55,100-5$. 
Green, E. S., Stubbs, J. L., and Levine, E. M. (2003). Genetic rescue of cell number in a mouse model of microphthalmia: interactions between $\mathrm{Chx} 10$ and G1-phase cell cycle regulators. Development 130, 539-52.

Grindley, J. C., Davidson, D. R., and Hill, R. E. (1995). The role of Pax-6 in eye and nasal development. Development 121, 1433-42.

Halder, G., Callaerts, P., Flister, S., Walldorf, U., Kloter, U., and Gehring, W. J. (1998). Eyeless initiates the expression of both sine oculis and eyes absent during Drosophila compound eye development. Development 125, 2181-91.

Halder, G., Callaerts, P., and Gehring, W. J. (1995a). Induction of ectopic eyes by targeted expression of the eyeless gene in Drosophila. Science 267, 1788-92.

Halder, G., Callaerts, P., and Gehring, W. J. (1995b). New perspectives on eye evolution. Curr Opin Genet Dev 5, 602-9.

Hallonet, M., Hollemann, T., Pieler, T., and Gruss, P. (1999). Vax1, a novel homeoboxcontaining gene, directs development of the basal forebrain and visual system. Genes Dev 13, 3106-14.

Hallonet, M., Hollemann, T., Wehr, R., Jenkins, N. A., Copeland, N. G., Pieler, T., and Gruss, P. (1998). Vax1 is a novel homeobox-containing gene expressed in the developing anterior ventral forebrain. Development 125, 2599-610.

Harch, C., Chase, H. B., and Gonsalves, N. I. (1978). Studies on an anophthalmic strain of mice. VI. Lens and cup interaction. Dev Biol 63, 352-7.

Hatakeyama, J., Tomita, K., Inoue, T., and Kageyama, R. (2001). Roles of homeobox and bHLH genes in specification of a retinal cell type. Development 128, 1313-22. 
Hatini, V., Tao, W., and Lai, E. (1994). Expression of winged helix genes, BF-1 and BF2, define adjacent domains within the developing forebrain and retina. $J$ Neurobiol 25, 1293-309.

Hebert, J. M., and McConnell, S. K. (2000). Targeting of cre to the Foxg1 (BF-1) locus mediates loxP recombination in the telencephalon and other developing head structures. Dev Biol 222, 296-306.

Hill, R. E., Favor, J., Hogan, B. L., Ton, C. C., Saunders, G. F., Hanson, I. M., Prosser, J., Jordan, T., Hastie, N. D., and van Heyningen, V. (1991). Mouse small eye results from mutations in a paired-like homeobox-containing gene. Nature 354, 522-5.

Hirsch, N., and Harris, W. A. (1997). Xenopus Pax-6 and retinal development. $J$ Neurobiol 32, 45-61.

Hitchcock, P. F., Macdonald, R. E., VanDeRyt, J. T., and Wilson, S. W. (1996). Antibodies against Pax6 immunostain amacrine and ganglion cells and neuronal progenitors, but not rod precursors, in the normal and regenerating retina of the goldfish. J Neurobiol 29, 399-413.

Hodgson, S. V., and Saunders, K. E. (1980). A probable case of the homozygous condition of the aniridia gene. $J$ Med Genet 17, 478-80.

Hogan, B. L., Horsburgh, G., Cohen, J., Hetherington, C. M., Fisher, G., and Lyon, M. F. (1986). Small eyes (Sey): a homozygous lethal mutation on chromosome 2 which affects the differentiation of both lens and nasal placodes in the mouse. $J$ Embryol Exp Morphol 97, 95-110.

Hsieh, Y. W., Zhang, X. M., Lin, E., Oliver, G., and Yang, X. J. (2002). The homeobox gene $\operatorname{Six} 3$ is a potential regulator of anterior segment formation in the chick eye. Dev Biol 248, 265-80. 
Hudson, R., Taniguchi-Sidle, A., Boras, K., Wiggan, O., and Hamel, P. A. (1998). Alx-4, a transcriptional activator whose expression is restricted to sites of epithelialmesenchymal interactions. Dev Dyn 213, 159-69.

Huh, S., Hatini, V., Marcus, R. C., Li, S. C., and Lai, E. (1999). Dorsal-ventral patterning defects in the eye of BF-1-deficient mice associated with a restricted loss of shh expression. Dev Biol 211, 53-63.

Ishikawa, Y., Yoshimoto, M., Yamamoto, N., Ito, H., Yasuda, T., Tokunaga, F., Iigo, M., Wakamatsu, Y., and Ozato, K. (2001). Brain structures of a medaka mutant, el (eyeless), in which eye vesicles do not evaginate. Brain Behav Evol 58, 173-84.

Jean, D., Bernier, G., and Gruss, P. (1999). Six6 (Optx2) is a novel murine Six3-related homeobox gene that demarcates the presumptive pituitary/hypothalamic axis and the ventral optic stalk. Mech Dev 84, 31-40.

Jean, D., Ewan, K., and Gruss, P. (1998). Molecular regulators involved in vertebrate eye development. Mech Dev 76, 3-18.

Jordan, T., Hanson, I., Zaletayev, D., Hodgson, S., Prosser, J., Seawright, A., Hastie, N., and van Heyningen, V. (1992). The human PAX6 gene is mutated in two patients with aniridia. Nat Genet 1, 328-32.

Joseph, R. (1957). A pedigree of anophthalmos. Brit J Ophthal 41, 541-3.

Keller, S. A., Jones, J. M., Boyle, A., Barrow, L. L., Killen, P. D., Green, D. G., Kapousta, N. V., Hitchcock, P. F., Swank, R. T., and Meisler, M. H. (1994). Kidney and retinal defects (Krd), a transgene-induced mutation with a deletion of mouse chromosome 19 that includes the Pax2 locus. Genomics 23, 309-20. 
Kikuchi, T., Raju, K., Breitman, M. L., and Shinohara, T. (1993). The proximal promoter of the mouse arrestin gene directs gene expression in photoreceptor cells and contains an evolutionarily conserved retinal factor-binding site. Mol Cell Biol 13, 4400-8.

Kimura, A., Singh, D., Wawrousek, E. F., Kikuchi, M., Nakamura, M., and Shinohara, T. (2000). Both PCE-1/RX and OTX/CRX interactions are necessary for photoreceptor-specific gene expression. J Biol Chem 275, 1152-60.

Kissinger, C. R., Liu, B. S., Martin-Blanco, E., Kornberg, T. B., and Pabo, C. O. (1990). Crystal structure of an engrailed homeodomain-DNA complex at $2.8 \mathrm{~A}$ resolution: a framework for understanding homeodomain-DNA interactions. Cell 63, 579-90.

Kobayashi, M., Nishikawa, K., Suzuki, T., and Yamamoto, M. (2001). The homeobox protein Six 3 interacts with the Groucho corepressor and acts as a transcriptional repressor in eye and forebrain formation. Dev Biol 232, 315-26.

Kobayashi, M., Toyama, R., Takeda, H., Dawid, I. B., and Kawakami, K. (1998). Overexpression of the forebrain-specific homeobox gene six 3 induces rostral forebrain enlargement in zebrafish. Development 125, 2973-82.

Kohn, G., el Shawwa, R., and el Rayyes, E. (1988). Isolated "clinical anophthalmia" in an extensively affected Arab kindred. Clin Genet 33, 321-4.

Koroma, B. M., Yang, J. M., and Sundin, O. H. (1997). The Pax-6 homeobox gene is expressed throughout the corneal and conjunctival epithelia. Invest Ophthalmol Vis Sci 38, 108-20. 
Koshiba-Takeuchi, K., Takeuchi, J. K., Matsumoto, K., Momose, T., Uno, K., Hoepker, V., Ogura, K., Takahashi, N., Nakamura, H., Yasuda, K., and Ogura, T. (2000). Tbx5 and the retinotectum projection. Science 287, 134-7.

Kronhamn, J., Frei, E., Daube, M., Jiao, R., Shi, Y., Noll, M., and Rasmuson-Lestander, A. (2002). Headless flies produced by mutations in the paralogous Pax6 genes eyeless and twin of eyeless. Development 129, 1015-26.

Kylstra, J. A., and Aylsworth, A. S. (1993). Cone-rod retinal dystrophy in a patient with neurofibromatosis type 1. Can J Ophthalmol 28, 79-80.

Laemle, L. K., Fugaro, C., and Bentley, T. (1993). The geniculohypothalamic pathway in a congenitally anophthalmic mouse. Brain Res 618, 352-7.

Laemle, L. K., and Ottenweller, J. E. (1998). Daily patterns of running wheel activity in male anophthalmic mice. Physiol Behav 64, 165-71.

Laemle, L. K., Ottenweller, J. E., and Fugaro, C. (1995). Diurnal variations in vasoactive intestinal polypeptide-like immunoreactivity in the suprachiasmatic nucleus of congenitally anophthalmic mice. Brain Res 688, 203-8.

Laemle, L. K., and Rusa, R. (1992). VIP-like immunoreactivity in the suprachiasmatic nuclei of a mutant anophthalmic mouse. Brain Res 589, 124-8.

Lagutin, O., Zhu, C. C., Furuta, Y., Rowitch, D. H., McMahon, A. P., and Oliver, G. (2001). Six3 promotes the formation of ectopic optic vesicle-like structures in mouse embryos. Dev Dyn 221, 342-9.

Leichtman, L. G., Wood, B., and Rohn, R. (1994). Anophthalmia, cleft lip/palate, facial anomalies, and CNS anomalies and hypothalamic disorder in a newborn: a midline developmental field defect. Am J Med Genet 50, 39-41. 
Lewandoski, M. (2001). Conditional control of gene expression in the mouse. Nat Rev Genet 2, 743-55.

Lewandoski, M., Meyers, E. N., and Martin, G. R. (1997). Analysis of Fgf8 gene function in vertebrate development. Cold Spring Harb Symp Quant Biol 62, 15968.

Li, H., Tierney, C., Wen, L., Wu, J. Y., and Rao, Y. (1997). A single morphogenetic field gives rise to two retina primordia under the influence of the prechordal plate. Development 124, 603-15.

Li, X., Perissi, V., Liu, F., Rose, D. W., and Rosenfeld, M. G. (2002). Tissue-specific regulation of retinal and pituitary precursor cell proliferation. Science 297, 11803.

Liu, I. S., Chen, J. D., Ploder, L., Vidgen, D., van der Kooy, D., Kalnins, V. I., and McInnes, R. R. (1994). Developmental expression of a novel murine homeobox gene (Chx10): evidence for roles in determination of the neuroretina and inner nuclear layer. Neuron 13, 377-93.

Lolley, R. N., Rong, H., and Craft, C. M. (1994). Linkage of photoreceptor degeneration by apoptosis with inherited defect in phototransduction. Invest Ophthalmol Vis Sci 35, 358-62.

Loosli, F., Koster, R. W., Carl, M., Krone, A., and Wittbrodt, J. (1998). Six3, a medaka homologue of the Drosophila homeobox gene sine oculis is expressed in the anterior embryonic shield and the developing eye. Mech Dev 74, 159-64.

Loosli, F., Winkler, S., Burgtorf, C., Wurmbach, E., Ansorge, W., Henrich, T., Grabher, C., Arendt, D., Carl, M., Krone, A., Grzebisz, E., and Wittbrodt, J. (2001). 
Medaka eyeless is the key factor linking retinal determination and eye growth. Development 128, 4035-44.

Loosli, F., Winkler, S., and Wittbrodt, J. (1999). Six3 overexpression initiates the formation of ectopic retina. Genes Dev 13, 649-54.

Lopez-Rios, J., Gallardo, M. E., Rodriguez de Cordoba, S., and Bovolenta, P. (1999). Six9 (Optx2), a new member of the six gene family of transcription factors, is expressed at early stages of vertebrate ocular and pituitary development. Mech Dev 83, 155-9.

Lopez-Rios, J., Tessmar, K., Loosli, F., Wittbrodt, J., and Bovolenta, P. (2003). Six3 and Six6 activity is modulated by members of the groucho family. Development 130, 185-95.

Lupo, G., Andreazzoli, M., Gestri, G., Liu, Y., He, R. Q., and Barsacchi, G. (2000). Homeobox genes in the genetic control of eye development. Int J Dev Biol 44, 627-36.

Lyon, M. F., Jamieson, R. V., Perveen, R., Glenister, P. H., Griffiths, R., Boyd, Y., Glimcher, L. H., Favor, J., Munier, F. L., and Black, G. C. (2003). A dominant mutation within the DNA-binding domain of the bZIP transcription factor Maf causes murine cataract and results in selective alteration in DNA binding. Hum Mol Genet 12, 585-94.

Macdonald, R., Barth, K. A., Xu, Q., Holder, N., Mikkola, I., and Wilson, S. W. (1995). Midline signalling is required for Pax gene regulation and patterning of the eyes. Development 121, 3267-78. 
Mailhos, C., Andre, S., Mollereau, B., Goriely, A., Hemmati-Brivanlou, A., and Desplan, C. (1998). Drosophila Goosecoid requires a conserved heptapeptide for repression of paired-class homeoprotein activators. Development 125, 937-47.

Manak, J. R., Mathies, L. D., and Scott, M. P. (1994). Regulation of a decapentaplegic midgut enhancer by homeotic proteins. Development 120, 3605-19.

Mardon, G., Solomon, N. M., and Rubin, G. M. (1994). dachshund encodes a nuclear protein required for normal eye and leg development in Drosophila. Development 120, 3473-86.

Mariman, E. C. (1998). Clustering of anophthalmia and microphthalmia. No clustering has been found-but a link seems to exist with population density. Bmj 317, 895-6.

Marquardt, T., Ashery-Padan, R., Andrejewski, N., Scardigli, R., Guillemot, F., and Gruss, P. (2001). Pax6 is required for the multipotent state of retinal progenitor cells. Cell 105, 43-55.

Martinez-Morales, J. R., Signore, M., Acampora, D., Simeone, A., and Bovolenta, P. (2001). Otx genes are required for tissue specification in the developing eye. Development 128, 2019-30.

Mathers, P. H., Grinberg, A., Mahon, K. A., and Jamrich, M. (1997). The Rx homeobox gene is essential for vertebrate eye development. Nature 387, 603-7.

Mathers, P. H., and Jamrich, M. (2000). Regulation of eye formation by the Rx and pax6 homeobox genes. Cell Mol Life Sci 57, 186-94.

Matsuno, T., Itasaki, N., Ichijo, H., and Nakamura, H. (1992). Retinotectal projection after partial ablation of chick optic vesicles. Neurosci Res 15, 96-101. 
Matsuo, I., Kuratani, S., Kimura, C., Takeda, N., and Aizawa, S. (1995). Mouse Otx2 functions in the formation and patterning of rostral head. Genes Dev 9, 2646-58.

Matsuo, T., Osumi-Yamashita, N., Noji, S., Ohuchi, H., Koyama, E., Myokai, F., Matsuo, N., Taniguchi, S., Doi, H., Iseki, S., and et al. (1993). A mutation in the Pax-6 gene in rat small eye is associated with impaired migration of midbrain crest cells. Nat Genet 3, 299-304.

McGinnis, W. (1994). A century of homeosis, a decade of homeoboxes. Genetics 137, 607-11.

Mikkola, I., Bruun, J. A., Holm, T., and Johansen, T. (2001). Superactivation of Pax6mediated transactivation from paired domain-binding sites by dna-independent recruitment of different homeodomain proteins. J Biol Chem 276, 4109-18.

Moritz, O. L., Peck, A., and Tam, B. M. (2002). Xenopus laevis red cone opsin and Prph2 promoters allow transgene expression in amphibian cones, or both rods and cones. Gene 298, 173-82.

Morrison, D., FitzPatrick, D., Hanson, I., Williamson, K., van Heyningen, V., Fleck, B., Jones, I., Chalmers, J., and Campbell, H. (2002). National study of microphthalmia, anophthalmia, and coloboma (MAC) in Scotland: investigation of genetic aetiology. J Med Genet 39, 16-22.

Mui, S. H., Hindges, R., O'Leary, D. D., Lemke, G., and Bertuzzi, S. (2002). The homeodomain protein Vax2 patterns the dorsoventral and nasotemporal axes of the eye. Development 129, 797-804.

Nguyen, M., and Arnheiter, H. (2000). Signaling and transcriptional regulation in early mammalian eye development: a link between FGF and MITF. Development 127, $3581-91$. 
Noll, M. (1993). Evolution and role of Pax genes. Curr Opin Genet Dev 3, 595-605.

Nornes, H. O., Dressler, G. R., Knapik, E. W., Deutsch, U., and Gruss, P. (1990). Spatially and temporally restricted expression of Pax2 during murine neurogenesis. Development 109, 797-809.

Ohkubo, Y., Chiang, C., and Rubenstein, J. L. (2002). Coordinate regulation and synergistic actions of BMP4, SHH and FGF8 in the rostral prosencephalon regulate morphogenesis of the telencephalic and optic vesicles. Neuroscience 111, $1-17$.

Ohsaki, K., Morimitsu, T., Ishida, Y., Kominami, R., and Takahashi, N. (1999). Expression of the Vax family homeobox genes suggests multiple roles in eye development. Genes Cells 4, 267-76.

Ohuchi, H., Tomonari, S., Itoh, H., Mikawa, T., and Noji, S. (1999). Identification of chick rax/rx genes with overlapping patterns of expression during early eye and brain development. Mech Dev 85, 193-5.

Olavarria, J., and van Sluyters, R. C. (1984). Callosal connections of the posterior neocortex in normal-eyed, congenitally anophthalmic, and neonatally enucleated mice. J Comp Neurol 230, 249-68.

Oliver, G., and Gruss, P. (1997). Current views on eye development. Trends Neurosci 20, 415-21.

Oliver, G., Loosli, F., Koster, R., Wittbrodt, J., and Gruss, P. (1996). Ectopic lens induction in fish in response to the murine homeobox gene Six3. Mech Dev 60, 233-9. 
Oliver, G., Mailhos, A., Wehr, R., Copeland, N. G., Jenkins, N. A., and Gruss, P. (1995). Six3, a murine homologue of the sine oculis gene, demarcates the most anterior border of the developing neural plate and is expressed during eye development. Development 121, 4045-55.

Pan, D., and Rubin, G. M. (1998). Targeted expression of teashirt induces ectopic eyes in Drosophila. Proc Natl Acad Sci U S A 95, 15508-12.

Peters, M. A., and Cepko, C. L. (2002). The dorsal-ventral axis of the neural retina is divided into multiple domains of restricted gene expression which exhibit features of lineage compartments. Dev Biol 251, 59-73.

Pichaud, F., Treisman, J., and Desplan, C. (2001). Reinventing a common strategy for patterning the eye. Cell 105, 9-12.

Pignoni, F., Hu, B., Zavitz, K. H., Xiao, J., Garrity, P. A., and Zipursky, S. L. (1997). The eye-specification proteins So and Eya form a complex and regulate multiple steps in Drosophila eye development. Cell 91, 881-91.

Porter, F. D., Drago, J., Xu, Y., Cheema, S. S., Wassif, C., Huang, S. P., Lee, E., Grinberg, A., Massalas, J. S., Bodine, D., Alt, F., and Westphal, H. (1997). Lhx2, a LIM homeobox gene, is required for eye, forebrain, and definitive erythrocyte development. Development 124, 2935-44.

Quiring, R., Walldorf, U., Kloter, U., and Gehring, W. J. (1994). Homology of the eyeless gene of Drosophila to the Small eye gene in mice and Aniridia in humans. Science 265, 785-9.

Robb, R. M., Silver, J., and Sullivan, R. T. (1978). Ocular retardation (or) in the mouse. Invest Ophthalmol Vis Sci 17, 468-73. 
Rodriguez, C. I., Buchholz, F., Galloway, J., Sequerra, R., Kasper, J., Ayala, R., Stewart, A. F., and Dymecki, S. M. (2000). High-efficiency deleter mice show that FLPe is an alternative to Cre-loxP. Nat Genet 25, 139-40.

Sanyanusin, P., Schimmenti, L. A., McNoe, L. A., Ward, T. A., Pierpont, M. E., Sullivan, M. J., Dobyns, W. B., and Eccles, M. R. (1995). Mutation of the PAX2 gene in a family with optic nerve colobomas, renal anomalies and vesicoureteral reflux. Nat Genet 9, 358-64.

Sasagawa, S., Takabatake, T., Takabatake, Y., Muramatsu, T., and Takeshima, K. (2002). Axes establishment during eye morphogenesis in Xenopus by coordinate and antagonistic actions of BMP4, Shh, and RA. Genesis 33, 86-96.

Schimmenti, L. A., De La Cruz, J., Lewis, R. A., Karkera, J. D., Manligas, G. S., Roessler, E., and Muenke, M. (2003). Novel mutation in sonic hedgehog in nonsyndromic colobomatous microphthalmia. Am J Med Genet 116, 215-21.

Schimmenti, L. A., Pierpont, M. E., Carpenter, B. L., Kashtan, C. E., Johnson, M. R., and Dobyns, W. B. (1995). Autosomal dominant optic nerve colobomas, vesicoureteral reflux, and renal anomalies. Am J Med Genet 59, 204-8.

Schulte, D., Furukawa, T., Peters, M. A., Kozak, C. A., and Cepko, C. L. (1999). Misexpression of the Emx-related homeobox genes cVax and mVax2 ventralizes the retina and perturbs the retinotectal map. Neuron 24, 541-53.

Schwarz, M., Cecconi, F., Bernier, G., Andrejewski, N., Kammandel, B., Wagner, M., and Gruss, P. (2000). Spatial specification of mammalian eye territories by reciprocal transcriptional repression of Pax2 and Pax6. Development 127, 432534. 
Seimiya, M., and Gehring, W. J. (2000). The Drosophila homeobox gene optix is capable of inducing ectopic eyes by an eyeless-independent mechanism. Development 127, 1879-86.

Shen, W., and Mardon, G. (1997). Ectopic eye development in Drosophila induced by directed dachshund expression. Development 124, 45-52.

Sidman, R. L. (1961). Histogenesis of the mouse eye studied with thymidine-H3. In "Structure of the eye" (G. K. Smesler, Ed.), pp. 487-506. Academic Press, New York.

Silver, J., and Hughes, A. F. (1974). The relationship between morphogenetic cell death and the development of congenital anophthalmia. J Comp Neurol 157, 281-301.

Silver, J., Puck, S. M., and Albert, D. M. (1984). Development and aging of the eye in mice with inherited optic nerve aplasia: histopathological studies. Exp Eye Res 38, 257-66.

Simeone, A., Acampora, D., Gulisano, M., Stornaiuolo, A., and Boncinelli, E. (1992). Nested expression domains of four homeobox genes in developing rostral brain. Nature 358, 687-90.

Simeone, A., Acampora, D., Mallamaci, A., Stornaiuolo, A., D'Apice, M. R., Nigro, V., and Boncinelli, E. (1993). A vertebrate gene related to orthodenticle contains a homeodomain of the bicoid class and demarcates anterior neuroectoderm in the gastrulating mouse embryo. Embo $J$ 12, 2735-47.

Simeone, A., D'Apice, M. R., Nigro, V., Casanova, J., Graziani, F., Acampora, D., and Avantaggiato, V. (1994). Orthopedia, a novel homeobox-containing gene expressed in the developing CNS of both mouse and Drosophila. Neuron 13, 83101. 
Sjogren, T. T. L. (1949). Microphthalmos and anophthalmos with or without coincident oligophrenia. Acta Psychiatr Neurol Scand 56 (suppl), 1-103.

Smith, S. T., and Jaynes, J. B. (1996). A conserved region of engrailed, shared among all en-, gsc-, Nk1-, Nk2- and msh-class homeoproteins, mediates active transcriptional repression in vivo. Development 122, 3141-50.

Sorsby, A. (1934). Anophthalmos: An unpublished manuscript by James Briggs giving the first account of the familial occurrence of the condition. Brit J Ophthal 18, 469-72.

Sowden, J. C., Holt, J. K., Meins, M., Smith, H. K., and Bhattacharya, S. S. (2001). Expression of Drosophila omb-related T-box genes in the developing human and mouse neural retina. Invest Ophthalmol Vis Sci 42, 3095-102.

Spemann, H. (1988). "Embryonic development and induction." Garland Publishing Inc. Reprint. Originally published: New Haven: Yale University Press, 1938, New York and London.

Stenkamp, D. L., Frey, R. A., Mallory, D. E., and Shupe, E. E. (2002). Embryonic retinal gene expression in sonic-you mutant zebrafish. Dev Dyn 225, 344-50.

Strickler, A. G., Famuditimi, K., and Jeffery, W. R. (2002). Retinal homeobox genes and the role of cell proliferation in cavefish eye degeneration. Int J Dev Biol 46, 285 94.

Szlyk, J. P., Fishman, G. A., Alexander, K. R., Peachey, N. S., and Derlacki, D. J. (1993). Clinical subtypes of cone-rod dystrophy. Arch Ophthalmol 111, 781-8. 
Take-uchi, M., Clarke, J. D., and Wilson, S. W. (2003). Hedgehog signalling maintains the optic stalk-retinal interface through the regulation of Vax gene activity. Development 130, 955-68.

Tessmar, K., Loosli, F., and Wittbrodt, J. (2002). A screen for co-factors of Six3. Mech Dev 117, 103-13.

Theiler, K., Varnum, D. S., Nadeau, J. H., Stevens, L. C., and Cagianut, B. (1976). A new allele of ocular retardation: early development and morphogenetic cell death. Anat Embryol (Berl) 150, 85-97.

Thomas, P. Q., Dattani, M. T., Brickman, J. M., McNay, D., Warne, G., Zacharin, M., Cameron, F., Hurst, J., Woods, K., Dunger, D., Stanhope, R., Forrest, S., Robinson, I. C., and Beddington, R. S. (2001). Heterozygous HESX1 mutations associated with isolated congenital pituitary hypoplasia and septo-optic dysplasia. Hum Mol Genet 10, 39-45.

Ton, C. C., Hirvonen, H., Miwa, H., Weil, M. M., Monaghan, P., Jordan, T., van Heyningen, V., Hastie, N. D., Meijers-Heijboer, H., Drechsler, M., and et al. (1991). Positional cloning and characterization of a paired box- and homeoboxcontaining gene from the aniridia region. Cell 67, 1059-74.

Torres, M., Gomez-Pardo, E., and Gruss, P. (1996). Pax2 contributes to inner ear patterning and optic nerve trajectory. Development 122, 3381-91.

Toy, J., and Sundin, O. H. (1999). Expression of the optx2 homeobox gene during mouse development. Mech Dev 83, 183-6.

Toy, J., Yang, J. M., Leppert, G. S., and Sundin, O. H. (1998). The optx2 homeobox gene is expressed in early precursors of the eye and activates retina-specific genes. Proc Natl Acad Sci US A 95, 10643-8. 
Treisman, J., Harris, E., and Desplan, C. (1991). The paired box encodes a second DNAbinding domain in the paired homeo domain protein. Genes Dev 5, 594-604.

Treisman, J., and Lang, R. (2002). Development and evolution of the eye: Fondation des Treilles, September, 2001. Mech Dev 112, 3-8.

Treisman, J. E. (1999). A conserved blueprint for the eye? Bioessays 21, 843-50.

Tropepe, V., Coles, B. L., Chiasson, B. J., Horsford, D. J., Elia, A. J., McInnes, R. R., and van der Kooy, D. (2000). Retinal stem cells in the adult mammalian eye. Science 287, 2032-6.

Trousse, F., Esteve, P., and Bovolenta, P. (2001). Bmp4 mediates apoptotic cell death in the developing chick eye. J Neurosci 21, 1292-301.

Tso, M. O., Zhang, C., Abler, A. S., Chang, C. J., Wong, F., Chang, G. Q., and Lam, T. T. (1994). Apoptosis leads to photoreceptor degeneration in inherited retinal dystrophy of RCS rats. Invest Ophthalmol Vis Sci 35, 2693-9.

Tucker, P., Laemle, L., Munson, A., Kanekar, S., Oliver, E. R., Brown, N., Schlecht, H., Vetter, M., and Glaser, T. (2001). The eyeless mouse mutation (ey1) removes an alternative start codon from the Rx/rax homeobox gene. Genesis 31, 43-53.

Tucker, S., Jones, B., and Collin, R. (1996). Systemic anomalies in 77 patients with congenital anophthalmos or microphthalmos. Eye 10 ( Pt 3), 310-4.

van Heyningen, V., and Williamson, K. A. (2002). PAX6 in sensory development. Hum Mol Genet 11, 1161-7. 
Veraksa, A., Del Campo, M., and McGinnis, W. (2000). Developmental patterning genes and their conserved functions: from model organisms to humans. Mol Genet Metab 69, 85-100.

Wallis, D. E., Roessler, E., Hehr, U., Nanni, L., Wiltshire, T., Richieri-Costa, A., Gillessen-Kaesbach, G., Zackai, E. H., Rommens, J., and Muenke, M. (1999). Mutations in the homeodomain of the human SIX3 gene cause holoprosencephaly. Nat Genet 22, 196-8.

Warburg, M. (1981). Genetics of microphthalmos. Int Ophthalmol 4, 45-65.

Warburg, M., Sjo, O., Tranebjaerg, L., and Fledelius, H. C. (1991). Deletion mapping of a retinal cone-rod dystrophy: assignment to 18q211. Am J Med Genet 39, 288-93.

Webster, E. H., Jr., Silver, A. F., and Gonsalves, N. I. (1984). The extracellular matrix between the optic vesicle and presumptive lens during lens morphogenesis in an anophthalmic strain of mice. Dev Biol 103, 142-50.

Wilson, D. S., Guenther, B., Desplan, C., and Kuriyan, J. (1995). High resolution crystal structure of a paired (Pax) class cooperative homeodomain dimer on DNA. Cell 82, 709-19.

Winkler, S., Loosli, F., Henrich, T., Wakamatsu, Y., and Wittbrodt, J. (2000). The conditional medaka mutation eyeless uncouples patterning and morphogenesis of the eye. Development 127, 1911-9.

Xu, Y., Baldassare, M., Fisher, P., Rathbun, G., Oltz, E. M., Yancopoulos, G. D., Jessell, T. M., and Alt, F. W. (1993). LH-2: a LIM/homeodomain gene expressed in developing lymphocytes and neural cells. Proc Natl Acad Sci U S A 90, 227-31. 
Yuasa, J., Hirano, S., Yamagata, M., and Noda, M. (1996). Visual projection map specified by topographic expression of transcription factors in the retina. Nature 382, 632-5.

Zhang, J., Sun, X., Qian, Y., and Maquat, L. E. (1998). Intron function in the nonsensemediated decay of beta-globin mRNA: indications that pre-mRNA splicing in the nucleus can influence mRNA translation in the cytoplasm. Rna 4, 801-15.

Zhang, L., Mathers, P. H., and Jamrich, M. (2000). Function of Rx, but not Pax6, is essential for the formation of retinal progenitor cells in mice. Genesis $\mathbf{2 8}$, 135-42.

Zhu, C. C., Dyer, M. A., Uchikawa, M., Kondoh, H., Lagutin, O. V., and Oliver, G. (2002). Six3-mediated auto repression and eye development requires its interaction with members of the Groucho-related family of co-repressors. Development 129, 2835-49.

Zuber, M. E., Perron, M., Philpott, A., Bang, A., and Harris, W. A. (1999). Giant eyes in Xenopus laevis by overexpression of XOptx2. Cell 98, 341-52.

Zwaan, J., and Silver, J. (1983). Crystallin synthesis in the lens rudiment of a strain of mice with congenital anophthalmia. Exp Eye Res 36, 551-7. 